\title{
III. Zweiter Beratungsgegenstand: Die Reform des Wahlrechtes.
}

\author{
I. Bericht von Professor Dr. Heinrich Pohl t.
}

I. Das Reichswahlgesetz und die Entwicklung der Wahlrechtsreform ......................................... 132

II. Kritik am geltenden Wahlrecht und am Wirthschen Entwurf.

1. Das Frauenstimmrecht erscheint in keiner Weise bedroht.... 135

2. Die Herabsetzung des Wahlrechts von 25 auf 20 Jahre war ein Fehler .................................... 136

3. $\$ 2$ des Wirthschen Entwurfs ist unzweckmaßig ......... 138

4. Das Wahlrecht der Auslanddeutschen ................ 138 Allgemeine Entwicklung dieser Frage - Der Entwurf von 1930 - Eigener Vorschlag: Wahlmånner für Auslanddeutsche.

5. Das Wahlrecht der Osterreicher, die im Reich leben, wăre eine Tat für den AnschluB ......................... 142

6. Die Einführung der Wahlpflicht ist unnötig $\ldots \ldots \ldots \ldots \ldots 143$

7. Die Abgrenzung der Wahlkreise .................. 144 Der Entwarf 1930 und die Wahlkreisgeometrie - Das Wahlrecht muß wieder wirkliches Wahltecht werden - Die Unzulanglichkeit der langen Parteiliste - Ausschaltung der Wahlkreise? - Jeder Wahlkreiseinteilung haftet Willkür an - Doch ist der Wahlkreisgedanke im Interesse des Staatsganzen grundsatzlich zu billigen.

8. Die Reichsliste ............................. 147

Kollision der Wahlrechtsprinzipien - Eigener Vorschlag einer upersonell gebundenen Reichsliste - Niemand sollte mit Reichsreststimmen gewahlt werden kónnen, der nicht in einem Wahlkreise die Verteilungszahl erreicht - Wiedereinsetzung der Personnlichkeit in das Wahlgetriebe - Wahrung des Gleichheitsprinzips - Einwand des Bonzentums - 4 oder 6 Bewerber auf einem Stimmzettel.

9. Die Durchführung des Proporzes .................. 163 Kritik der Rechtsprechung des Staatsgerichtshofes - Mindestprozentsatz aller im Reich abgegebenen Stimmen.

10. Die Verteilungszahl ist heraufzusetzen $\ldots \ldots \ldots \ldots \ldots \ldots \ldots 165$ Anderung der Reichstagsausschüsse.

III. Schlu日bemerkungen........................ 166

Meinem Kollegen Lei b h ol $z$ und mir ist der Auftrag geworden, über die Wahlrechtsreform zu berichten, ein Thema, über das unendlich viel Kluges und Dummes gesagt und geschrieben worden ist. Wenn unser erhabener Duce Sartorius einen solchen Auf- 
trag gibt, dann gibt es nur Eins: parieren. So wird denn Herr Le i b h ol z versuchen, trotz der großen Schwierigkeiten noch etwas Kluges zur Sache zu bringen, während ich mich glücklich schätze, wenigstens nichts Dummes zu sagen.

Nach dieser zart andeutenden captatio benevolentiae lassen Sie mich gleich in medias res gehen - auf deutsch: gleich hinein in die MittelmäBigkeiten.

I.

Seitdem die Weimarer Verfassung mit den Worten "Die Staatsgewalt geht vom Volke aus" den Fundamentalsatz aller Demokratie, das Prinzip der Volkssouveränität, als geltendes Recht verkündet hat, ist die Gestaltung des Wahlrechts eines der wichtigsten und aktuellsten Probleme unseres politischen Lebens geblieben.

Schon vor dem Inkrafttreten der Verfassung wurden gegen das neue Wahlrecht sehr heftige Angriffe gerichtet. Die scharfe Kritik, die es erfuhr, hätte möglicherweise bereits die Nationalversammlung veranlaßt, einer grundlegenden Änderung des Wahlrechts näher zu treten, wenn nicht infolge des Kapp-Putsches und der danach notwendigen schleunigen Ausschreibung der Reichstagswahlen eine schnelle Verabschiedung des Reichswahlgesetzes geboten gewesen wäre. Dieses Gesetz vom 27. April 1920 ist bis heute in allen wesentlichen Punkten unverändert in Kraft. Dies gilt für das Wahlsystem als solches und auch für die Wahlkreiseinteilung. Die drei Novellen aus den Jahren 1922-1924 brachten - abgesehen von der Einführung des amtlichen Stimmzettels - lediglich eine Neuregelung einiger wahltechnischer Fragen von untergeordneter Bedeutung. Die Dringlichkeit einer durchgreifenden Wahlreform war nahezu unbestritten. Die Reichsregierung war bereit, den Reformwünschen zu Beginn des Jahres 1924 durch eine einschneidende Novelle zum Reichswahlgesetz Rechnung zu tragen. Doch hielten es die Reichstagsfraktionen mit Rücksicht auf die nahe bevorstehenden Neuwahlen nicht mehr für möglich, die Wahlvorbereitungen in der kurzen noch zur Verfügung stehenden Zeit auf eine neue Wahlkreiseinteilung umzustellen. So wurde erst im August 1924 dem neuen Reichstag ein Reformentwurf vorgelegt. Er kam indessen nicht zur Verhandlung, weil der Reichstag Ende Oktober 1924 aufgelöst wurde. Dieser Reformentwurf stellte sich die Aufgabe, der Einerwahl im Rahmen der Verhältniswahl möglichst nahe zu kommen. Er suchte das Verhältniswahlsystem so umzubauen, daB die bisherige Mechanisierung und Entpersönlichung mit ihren Nachteilen für das öffentliche Wohl abgemildert würde. Er bildete statt der 35 großen 156 kleine Wahlkreise, ließ in jedem Wahlkreise 
nur einen, höchstens zwei Bewerber zu, faßte die Wahlkreise zu den bisherigen 16 großen Wahlverbänden zusammen, sah die Addierung der innerhalb des Verbandes für eine Partei aufgebrachten Stimmen und die Verteilung der auf den Verband entfallenden Abgeordnetensitze unter die Bewerber in den einzelnen Wahlkreisen nach Maßgabe ihres Wahlerfolges vor. Nicht der Platz auf der Liste, sondern der Wahlerfolg sollte entscheidend werden. Der Entwurf wollte eine feste Zahl von 399 Abgeordneten und eine feste Verteilungszahl von 75000 Stimmen. Die Reichsliste sollte beibehalten werden. Die Reichsregierung versprach sich, wie sie in der Begründung ausführte, von dieser Lösung eine Reihe von Vorteilen: "Die Wählerschaft wird an der Aufstelluñ der Bewerber unmittelbar beteiligt, sie hat eine Reihe von Persönlichkeiten nicht mitzuwählen, die ihr nicht passen oder ihr unbekannt sind; die Bewerber und die Abgeordneten sind in der Lage, ihren Wahlkreis wirklich kennenzulernen, die Wähler wissen, th wen sie sich zu wenden haben; im Falle des Ausscheidens von Abgeordneten rücken als neue Abgeordnete solche Persönlichkeiten nach, die den ganzen Wahlkampf vorher persönlich geführt haben *.

Sehr erhebliche Änderungen am geltenden Wahlrecht faßte Reichsinnenminister Dr. Külz mit seinem Entwurf von 1926 ins Auge. Interessante Einzelheiten dieses amtlich nicht veröffentlichten Entwurfs sind - insbesondere durch Erdmannsdörffer und Schauff - bekannt geworden. Külz will die Reform gegenüber der Vorlage von 1924 dadurch wesentlich verstärken, daß nur ein Bewerber auf jedem örtlichen Wahlvorschlag zugelassen wird, da $B$ also auch der Rest der Liste, wie er in der Novelle von 1924 noch beibehalten wird, verschwindet, sodann dadurch, da $B$ die bestehenden Wahlkreise in 227 Stimmkreise zerlegt werden. Auf einen Wahlkreis entfallen durchschnittlich sechs Stimmkreise, auf jeden Stimmkreis kommen 275000 Einwohner. Derselbe Bewerber kann in mehreren Stimmkreisen desselben Wahlkreises aufgestellt werden. Nach Addition der Ziffern für die einzelnen Parteien im Wahlkreis wird die Zahl der einzelnen Mandate festgestellt. Die Anzahl der auf einen Wahlkreis entfallenden Mandate ergibt sich durch Teilung der abgegebenen Stimmen durch 70 000. Der Külz'sche Entwurf ist auf dem automatischen System aufgebaut. Die Aufrechterhaltung des automatischen Systems rechtfertigt die Begründung des Entwurfs mit dem kurzen Satze: "Die feste Verteilungszahl hat sich als ein so günstiges wahltechnisches Moment erwiesen, daB von ihr nicht ohne Not abgegangen werden darf w. Der Kandidat, der im Stimmkreis oder in seinen Stimmkreisen 70000 Stimmen erhalten hat, sowie die Kandidaten, die die höchsten Stimmprozentsätze im Stimmkreis oder in den Stimmkreisen erreicht haben, erhalten ein Mandat. 
Die Reststimmen werden an den Reichswahlausschuß weitergegeben. Von einer Reichsliste wird vollständig abgesehen. Die Reststimmen gehen in die Wahlkreise bzw. Stimmkreise mit höchsten Prozentsätzen. Hat aber eine Partei in keinem der Wahlkreise 70000 Stimmen erreicht, so kann sie bei der dritten Zuteilung keine Mandate bekommen.

Seitdem hat sich jede Reichsregierung veranlaßt gesehen, zu der Frage der Wahlreform irgendwie Stellung zu nehmen. Es dauerte aber volle sechs Jahre, bis dem Reformversuch von 1924 ein neuer der Offentlichkeit unterbreiteter Regierungsentwurf eines Reichswahlgesetzes folgte. Inzwischen hatte das dritte Kabinett Marx und die Regierung Hermann Müller sich zu der Notwendigkeit einer Wahlreform bekannt. In einer Erklärung vom 3. Juli 1928 hatte Müller anerkannt, daß das geltende Wahlrecht Mängel aufweise, die zu einer Entfremdung des Gewählten von den Wählern und zu einer Zersplitterung des Parteiwesens führten; es werde Aufgabe der Reform sein, das verfassungsmäßig festgelegte System der Verhältniswahl aufrechtzuerhalten, aber zugleich eine engere Beziehung des Abgeordneten zu den Wählern sicherzustellen.

Am 20. August 1930 legte der Reichsminister des Innerr. Dr. Wirth dem Reichsrat den Entwurf eines Reichswahlgesetzes nebst Begründung vor. Er sucht der Einerwahl, soweit dies im Rahmen der Verhältniswahl überhaupt erreichbar ist, möglichst nahezukommen und die politische Gesamtpersönlichkeit des $\mathrm{Be}$ werbers mehr als bisher in den Vordergrund treten zu lassen. Als Ziel der Reform wird die Beseitigung der langen Listen und der großen Wahlkreise bezeichnet. Gleichzeitig müsse - so heißt es in der Begründung - angestrebt werden, klare Mehrheitsverhältnisse im Parlament zu schaffen. Aufgabe des Parlaments im Staate mit parlamentarischer Verfassung sei es, dem Staate die Führung zu geben. Diese Aufgabe könne das Parlament nicht erfüllen, wenn die Zersplitterung der Parteien überhand nehme.

Dem Entwurf eines Reichswahlgesetzes ließ der Reichsinnenminister am 26. August 1930 eine umfassende Denkschrift "Vorschläge zur Wahlreform" folgen. Die Denkschrift befaßt sich mit den wenigen positiven Besserungsvorschlägen, die für eine andere Gestaltung der Verhältniswahl im Laufe der Jahre gemacht worden sind. Sie gibt sechs der wichtigsten Wahlreformvorschläge wieder, nämlich die Vorschläge von Jellinek, Heile, Heymann, Thoma, Klöcker, vom Demokratischen ArbeitsausschuB; kürzer werden Vorschläge von Campes und aus Kreisen des Jungdeutschen Ordens sowie einige weitere Anregungen, darunter die von Pfister, gewürdigt. Die erstgenannten sechs Wahlreformvorschläge sind vom Reichswahlleiter eingehend durchgeprüft worden; diese gutachtliche Stellungnahme des 
Reichswahlleiters ist im zweiten Teil der Denkschrift zum Abdruck gebracht.

Man kann wohl sagen, daß der Wirthsche Entwurf keine schlechte Presse gefunden hat. Und auch im Reichsrat ist er ohne wesentliche Korrekturen mit überraschend großer Mehrheit angenommen worden. Der Entwurf sah eine Heraufsetzung der Verteilungszahl von 60000 auf 70000 vor. Auf Antrag Preußens wurde die Zahl im Reichsrat auf 75000 erhöht; die Annahme des preußischen Antrags erfolgte mit 34 gegen 29 Stimmen bei 3 Stimmenthaltungen. Dann wurde die Vorlage des Reichsinnenministers im ganzen mit 56 gegen 10 Stimmen angenommen. Die Gegenstimmen wurden von den Ländern Thüringen, MecklenburgSchwerin und Sachsen abgegeben.

Die in dem Wirthschen Entwurf enthaltenen Neuerungen lassen sich kurz, wie folgt, zusammenfassen:

Abschaffung der langen Listen; die Stimmzettel können nur bis drei Bewerber enthalten.

Im Zusammenhang mit der Abschaffung der langen Listen ist eine erhebliche Verkleinerung, also Vermehrung, der Wahlkreise vorgesehen (162 gegen bisher 35).

Die Reichsliste verschwindet; die Stimmen werden in Wahlkreisverbänden und äußerstenfalls die hierbei verbleibenden Verbandsreststimmen in Ländergruppen zusammengezählt.

Der amtliche Stimmzettel wird abgeschafft.

Das bisherige Wahlvorschlagsverfahren fällt weg. Ein vereinfachtes Anmeldeverfahren für die Stimmzettel, dessen Ausgestaltung der Reichsstimmordnung vorbehalten ist, tritt an seine Stelle.

\section{II.}

1. In der Kritik am geltenden Wahlrecht und am Wirthschen Entwurf spielt die Abgrenzung des Wählerkreises eine relativ geringe Rolle. Daher sei vorab zu diesem Fragenkomplex kurz Stellung genommen.

Uber das Frauenstimmrecht wird heute in Deutschland nicht ernstlich debattiert, obwohl es sich anders ausgewirkt hat, als mancher bei seiner Einführung gedacht haben mag. Es zeigte sich bei den Wahlen seit 1919 im ganzen eine deutliche Hinneigung der Frauen zu den konfessionell betonten Parteien und eine starke Abneigung gegen jeden Radikalismus. Die grundsätzliche Gleichberechtigung von Männern und Frauen in Ansehung der staatsbürgerlichen Rechte und Pflichten ist eine Selbstverständlichkeit geworden. Die unverkennbar ablehnende Haltung der politisch führenden Frauen gegenüber Änderungen am bestehenden Wahlrecht ist nicht von Sorge vor einer Beseitigung 
oder Beeinträchtigung des Frauenstimmrechts diktiert, sondern von der Besorgnis um die Aussichten von Frauenkandidaturen für den Fall, da $\mathrm{B}$ am Wahlverfahren wesentliche Änderungen vorgenommen werden. Das Frauenstimmrecht, so wie es jetzt ist, erscheint in keiner Weise bedroht; es wird auf legalem Wege schwerlich wieder zu beseitigen sein.

2. Liegen die Dinge anders bei der Frage des Wahlrechts der Zwanzigjährigen?

Seine Einführung durch die Revolutionsregierung von 1918 entsprach einer alten sozialistischen Forderung des Erfurter Programms. Weite Kreise des Bürgertums fanden sich damit ab und billigten diese Neuerung im Hinblick auf die aus dem Felde zurückgekehrten Zwanzigjährigen - ein Gesichtspunkt, der heute nicht mehr in Betracht kommt.

In der Nationalversammlung setzten die sozialistischen Parteien es durch, daB ein Wahlalter von 20 Jahren in der Verfassung festgelegt, also seine Bestimmung nicht dem künftigen Reichswahlgesetz überlassen wurde. Sie schmiedeten das Eisen, solange es heiß war.

Vergebens widersprach Hugo PreuB: ebensogut könne man das ganze Wahlgesetz in die Verfassung aufnehmen, die Altersgrenze für aktives und passives Wahlrecht, die näheren Modalitäten der Wahl, wie die näheren Bestimmungen über die Methode des Proportionalwahlrechts. All diese Bestimmungen solle man nicht den Erschwerungen einer Verfassungsänderung aussetzen; es könnte sich immerhin im Laufe der Zeit eine Abänderung als nötig erweisen. Es sei mindestens ein Herausgreifen einer Einzelbestimmung des Wahlgesetzes, das Wahlalter in das Grundgesetz hineinzubringen.

Diese Ausführungen machten auf die Sozialisten keinen Eindruck. Für sie war die Festlegung des Wahlalters in der Verfassung von ebenso fundamentaler Bedeutung wie die Vorschrift, $\mathrm{da} B$ die Wahl allgemein, gleich und geheim sei. Sie erklärten mit großer Entschiedenheit, die Ablehnung des einmal gestellten Antrages würde gefährlich sein. Das klang wie eine Drohung. Ein Verzicht auf die Fixierung des Wahlalters in der Verfassung müßte den Verdacht aufkommen lassen, $\mathrm{da} B$ in diesem Punkte Änderungen beabsichtigt seien; gerade hier aber sei an eine Änderung nicht $\mathrm{zu}$ denken. In das Reichswahlgesetz würden die Sozialdemokraten das Wahlalter von 20 Jahren unter allen Umständen hineinschreiben. Man komme um die 20 Jahre nicht herum; es sei daher klüger, sie gleich in die Verfassung aufzunehmen.

Der von den bürgerlichen Parteien geleistete Widerstand war von vornherein aussichtslos und daher wenig energisch. Bezeichnend war eine Äußerung des Abgeordneten Dr. Spahn im 
VerfassungsausschuB: "Das Wahlalter von 20 Jahren kann, nachdem es einmal eingeführt, nicht mehr rückgängig gemacht werden. Es ist aber nicht zweckmäßig, es in der Verfassung festzulegen, schon mit Rücksicht auf die Rückwirkung, die die Bestimmung auf das Mündigkeitsalter notwendigerweise haben muB. Auch dieses", so meinte Dr. Spahn, "wird auf 20 Jahre herabgesetzt werden müssen. "

Die Herabsetzung des Wahlalters von 25 auf 20 Jahre war ein Fehler. Es ist unsinnig, ja widersinnig, da $B$ Unmündige wählen dürfen. Das Mindeste, was mit allem Nachdruck zu fordern wäre, ist die Heraufsetzung auf 21 Jahre; hier liegt auch in Frankreich und in den beiden angelsächsischen Großstaaten das Wahlalter. Der Wahlgesetzentwurf vom August 1930 sieht davon ab, das Wahlalter zu erhöhen, wahrscheinlich nur aus dem Grunde, weil selbst für eine so maBvolle Erhöhung die erforderliche Zweidrittelmehrheit nicht zu erreichen ist. Man hält eine Festsetzung des Wahlalters auf 24 Jahre, die sich, in verschiedenen Anträgen gefordert, im Reichstag nicht durchsetzen konnte, auf absehbare Zeiten für völlig aussichtslos. Selbst für 21 Jahre stehen die Chancen heute noch ungünstiger als im August 1930. Die extremen Parteien sind nicht dafür zu haben. Entscheidend ist für sie, daß sie aus den Reihen der Unmündigen starken $\mathrm{Zu}$ laufs sicher sind. Und auch die Sozialdemokraten, für die es sich hier im Grunde auch um eine Prestige-Frage handeln dürfte, werden von den 20 Jahren nicht abgehen wollen. Darlegungen, die der Reichstagspräsident Paul Löbe unlängst auf eine Rundfrage des Berliner Tageblatts (am 22. Februar 1931) gemacht hat, möchte ick im Wortlaut wiedergeben:

"Es ist nicht zu bestreiten, daB die unangenehmen Vorkommnisse im Parlament von auBerhalb desselben Zweifel an der Wahlfähigkeit und Wahlreife der jungen Wähler zwischen zwanzig und vierundzwanzig Jahren auch bei solchen Mitbürgern hervorgerufen haben, die dem Wahlrecht der Jugendlichen stets freundlich gegenüberstanden. Sowohl die Unreife mancher Abgeordneten, die ihre Wahl (vermutlich) dieser Jugend verdanken, wie die Krawalle und Bluttaten Halbwüchsiger auf der Straße haben diese Zweifel verstärkt. Trotzdem würde ich keiner Änderung des Wahlalters das Wort reden. Zwar trifft der ursprüngliche Grund für die Herabsetzung des Wahlalters im Jahre 1918, nämlich die Teilnahme der Jugend an der Verteidigung des Vaterlandes, heute nicht mehr zu. Die Jugend, die das Vaterland verteidigt hat, ist inzwischen sehr viel älter geworden. Aber man kann nicht zugleich rufen: Wer die Jugend hat, hat die Zukunft! - und diese Jugend entrechten. Man darf auch nicht übersehen, daß der größte Teil dieser Jugend schon vor dem zwanzigsten Lebensjahr wirtschaftlich selbständig wird und 
sich mit eigener Kraft durchs Leben schlagen muß, also an den Gesetzen des Landes ein besonderes Interesse hat. Man muß sich auch überlegen, daß die Entziehung dieses Rechtes in politisch aufgeregter Zeit den Trotz und die Opposition der so Entrechteten nur noch stärkt. Die heute $Z$ wanzig- und Einundzwanzigjährigen aber können bei den nächsten Wahlen schon vierundzwanzig und fünfundzwanzig Jahre alt sein und werden ihre Wahlentrechtung dann doppelt sicher mit extremen Stimmzetteln beantworten. Schließlich darf die unabänderliche Tatsache nicht außer Acht gelassen werden, da $B$ die Zahl der Jugendlichen sowieso vom Jahre 1935 an wegen der 1915 beginnenden Geburtenabnahme ganz erheblich zurückgeht, so daB der Anteil der Jungwählerstimmen am ganzen Wahlkörper sich stark vermindert und ein Ausgleich zwischen Alten und Jungen herbeigeführt wird. Es sprechen also so viele Gründe gegen die Heraufsetzung des Wahlalters, da $B$ die Anhänger dieser Idee den Vorsto $B$ ruhig unterlassen können, der bei den gesetzlichen Schwierigkeiten ohnehin keinen Erfolg verspricht. Die Änderung müßte mit verfassungsmäBiger Mehrheit, also mit zwei Dritteln aller $\mathrm{Ab}$ geordnetenstimmen, angenommen werden, und diese Mehrheit ist, wie bekannt, nicht zu haben."

3. In seinem $\S 2$ bringt der Entwurf bei den Wahlausschließungs- und Behinderungsgründen eine Änderung, über deren $Z$ weckmäßigkeit man wohl geteilter Meinung sein wird. Vom Stimmrecht soll nämlich künftig auch ausgeschlossen sein, wer wegen Geisteskrankheit oder Geistesschwäche dauernd in einer Heil- oder Pflegeanstalt untergebracht ist. Dagegen soll, wer aus dem gleichen Grunde nur vorübergehend in dieser Weise untergebracht ist, in der Ausübung des Stimmrechts behindert sein. Bisher wurde eine solche Unterscheidung zwischen dauernder und vorübergehender Unterbringung nicht gemacht, sondern in beiden Fällen eine Behinderung festgestellt. Die Bedeutung der Änderung liegt hauptsächlich darin, daß für die dauernd Untergebrachten mit dem Wahlrecht auch die Wählbarkeit ausgeschlossen werden soll; auch ist sie von Belang für die Feststellung der Zahl der Stimmberechtigten bei Volksbegehren und Volksentscheiden. Die neue Regelung kann für die Praxis zu Schwierigkeiten führen, die in keinem rechten Verhältnis zu der dem ärztlichen Personal der Anstalten erwachsenden Arbeit stehen und die man darum vermeiden sollte.

Es wäre wohl richtiger, unterschiedslos für beide Fälle einen Wahlausschließungsgrund festzulegen. In aller Regel wird die Allgemeinheit ohne Schaden auf eine Reichstagskandidatur von vorïbergehend in einer Heilanstalt Untergebrachten verzichten können.

4. Ungleich wichtiger ist eine andere Reformfrage zur Ab- 
grenzung des Wählerkreises: das Wahlrecht der Auslanddeutschen.

Der im März 1920 vom Reichsminister des Innern Koch der Nationalversammlung vorgelegte Entwurf eines Reichswahlgesetzes wollte den Auslanddeutschen das Recht zur Teilnahme an den Reichstagswahlen gewähren. Der Entwurf von 1920 sprach Wahlrecht und Wählbarkeit auch den Reichsangehörigen zu, dit sich im Auslande ständig aufhalten (Auslanddeutschen), sowie solchen Reichsangehörigen, die es vorübergehend tun und einen Wahlschein besitzen. Er verlegte die Auslandwahlgeschäfte soweit irgend möglich in das Inland. "Denn \&, so hieB es in der Begründung, "eigentliche Wahlhandlungen im Ausland, wie Einrichtung von Wahlbüros, Stimmabgabe vor Wahlvorständen, Stimmzählung durch Wahlausschüsse usw. müssen aus völkerund staatsrechtlichen Rücksichten auf das Ausland unterbleiben. Das Ausland würde in der Ausübung des heimatlichen Wahlrechts auf fremdem Boden einen Eingriff in seine Staatssouveränität erblicken. Nach dem Vorbild des norwegischen Wahlrechts wird daher den Auslanddeutschen nur gestattet, ihren Stimmzettel nach dem Inland einzusenden ", und zwar einen Stimmzettel, der einen Namen enthält. Das Wahlverfahren ist in dem Entwurf von 1920 hier möglichst einfach gestaltet. Es kennt keine Einreichung von Wahlvorschlägen durch Auslanddeutsche. Das gesamte Ausland bildet einen Wahlkreis, für den der Reichswahlleiter zugleich Kreiswahlleiter ist. Bei ihm wird die Sammlung der Stimmen zentralisiert. Auslanddeutsche übergeben ihren Stimmzettel zur Einsendung an den Reichswahlleiter dem zuständigen Konsul. Für die Stimmabgabe sind weite Fristen gesetzt, weil viele Auslanddeutsche erst geraume Zeit nach der Ausschreibung einer Reichstagswahl von dieser Tatsache Kenntnis erhalten. Auf die auslanddeutschen Stimmen entfallen so viel Abgeordnetensitze, wia oft die Summe der von ihnen abgegebenen Stimmen durch 60000 teilbar ist. Gewählt sind die Personen, welche die meisten Stimmen haben.

Die Bestimmungen des Entwurfs vom März 1920 über das Wahlrecht der Auslanddeutschen wurden bei der Ausschußberatung gestrichen. Das Gesetz vom 27. April 1920, auf dem im wesentlichen das heutige Reichstagswahlrecht beruht, wurde nach dem Kapp-Putsche von der Nationalversammlung in großer Eile zustandegebracht. Damals war schnelle Arbeit geboten. Wie der Abgeordnete Katzenstein als Berichterstatter bei der zweiten Lesung des Entwurfs erklärte, hatte sich der Ausschuß zu seinem großen Bedauern nicht in der Lage gesehen, angesichts der drängenden Zeit und auch mit Rücksicht auf gewisse Schwierigkeiten, die sich gerade damals noch für die Reichsangehörigen im Auslande hätten ergeben können, zur Zeit ein Wahlrecht 
für die Auslanddeutschen zu schaffen. Der Ausschuß hatte aber beschlossen, dem Plenum vorzuschlagen, die Regierung, sobald die Durchführung möglich wäre, um die Ausgestaltung eines entsprechenden Wahlrechtes zu ersuchen.

Die Wahlreformvorlage des Reichsinnenministers Dr. Jarres vom 21. August 1924, die infolge Auflösung des Reichstags nicht zur parlamentarischen Beratung kam, überging die Frage des Wahlrechts der Auslanddeutschen mit Stillschweigen. So ist es im geltenden Reichstagswahlrecht bei wenigen, den Kern der Frage nicht treffenden Vorschriften geblieben. Danach erhält einen Wahlschein auf Antrag ein Wähler, der in eine Wählerliste oder Wahlkartei nicht eingetragen oder darin gestrichen ist, wenn er Auslanddeutscher war und seinen Wohnort nach Ablauf der Einspruchsfrist in das Inland verlegt hat (\$12). Außerdem enthält das Reichswahlgesetz eine Bestimmung, wonach wahlberechtigte Staatsbeamte, Arbeiter in Staatsbetrieben, die ihren Wohnsitz im Ausland nahe der Reichsgrenze haben, und wahlberechtigte Angehörige des Hausstandes auf Antrag in die Wählerliste oder Wahlkartei einer benachbarten deutschen Gemeinde eingetragen werden.

Der Entwurf vom August 1930 sieht vor, daB auf Antrag einen Stimmschein der nicht in eine Stimmkartei (Stimmliste) eingetragene oder der darin gestrichene Stimmberechtigte erhält, 1. wenn er Auslanddeutscher ist und sich am Wahltag im Inlande aufhält, 2. wenn er Auslanddeutscher war und seinen Wohnort nach Ablauf der Einspruchsfrist in das Inland verlegt hat. Als Auslanddeutsche im Sinne der Ziffer 1 gelten auch Reichsangehörige, die im Ausland als Beamte, Angestellte oder Arbeiter des Reichs, eines deutschen Landes oder der Deutschen Reichsbahn-Gesellschaft angestellt sind oder als ihre Familienangehörigen und Hausangestellten in ihrem Haushalt leben.

Neu ist also im Entwurf insbesondere, da $B$ der Auslanddeutsche, der sich am Wahltage im Inlande aufhält, einen Stimmschein erhalten kann - immerhin ein Fortschritt, den manche Auslanddeutsche sich zunutze machen werden. Es ist lediglich durch geeignete Ausführungsvorschriften dafür Sorge zu tragen, daB eine mehrfache Ausübung des Stimmrechts verhindert wird. Aber für die große Masse der Auslanddeutschen, für viele Millionen Reichsangehörige, besteht nach dem Entwurf keine Möglichkeit, sich an der Wahl zu beteiligen. Der Entwurf eröffnet nicht eine Möglichkeit von der Art, wie sie der Regierungsentwurf von 1920 geben wollte; er läßt keinen Auslanddeutschen zur Wahl zu, der sich am Wahltage nicht im Inlande aufhält.

Uber die Motive, von denen sich die Reichsregierung bei dieser Stellungnahme leiten ließ, sagt die Begründung des Entwurts kein Wort. Sie sind wohl mit einiger Sicherheit der Ein- 
leitung $\mathrm{zu}$ entnehmen, die der zuständige Sachbearbeiter im Reichsministerium des Innern, Ministerialrat Dr. Kaisenberg seinem im August 1930 erschienenen Führer für die Reichstagswahlen ("Die Wahl zum Reichstag (, 4. Auflage) vorausgeschickt hat: "Der Gedanke, den Auslanddeutschen ein Wahlrecht zum inländischen Reichsparlament einzuräumen, hat auch im neueren Verfassungsrecht anderer Kulturstaaten keinen Vorgang. Man geht $u$. a. insbesondere davon aus, da $\beta$ durch die Stimmabgabe im Auslande die notwendige Einheitlichkeit des Auslanddeutschtums in Frage gestellt wird. Auch stehen bei der großen Zahl der über die ganze Welt verteilten Auslanddeutschen technische Bedenken und Einwände mangelhafter Unterrichtung entgegen."

Der Gesichtspunkt, daß die Durchführung der Auslandwahl die notwendige Einheitlichkeit des Auslanddeutschtums in Frage stellen könnte, ist gewiß sehr ernst zu nehmen. Schon Hermann Willms hat in seiner Preisschrift über "Das Wahlrecht der Auslanddeutschen " (Stuttgart 1920) sehr eindringlich auf die Gefahr hingewiesen, die darin liegt, da $B$ die politischen Parteien im Reiche sich der Aufstellung der Reichstagskandidaten des Auslanddeutschtums bemächtigen, damit aber naturgemäB auch den leidigen Wahlkampf ins Ausland tragen, mit der unseligen Parteizersplitterung auch noch unsere Auslanddeutschen mehr und mehr beglücken könnten. Der Wahlkampf, wie er üblich geworden ist, »die Entwicklung ins Groteske, Uferlose und geradezu Wüste, welche die Wahlvorbereitungen in den Kulturstaaten häufig angenommen haben ", kann überhaupt "einer der größten Feinde der Durchführung der Auslandwahl " genannt werden. Die Ubertragung des unerquicklichen deutschen Parteistreits ins Ausland muB unbedingt vermieden werden und sie wird im wesentlichen vermieden, wenn man sich einen von mir bereits im Dezember 1918 gemachten Vorschlag zu eigen macht: Die Wahlbefugnis sollte in allen Fällen durch einen in Deutschland ansässigen Reichstagswähler kraft Auftrags geschehen. Vielleicht empfiehlt es sich, den Kreis solcher "Wahlmänner" - wenn man diese Bezeichnung in Erinnerung an das alte preußische Wahlverfahren annehmen will - auf Auslanddeutsche, die sich gerade im Inlande aufhalten, und auf ehemalige Auslanddeutsche zu beschrănken. Der Auslandwähler hätte also nur den Namen des Wahlmannes zur Matrikel des Konsulates anzugeben, und es wäre Sache des Auswärtigen Amtes, davon der zuständigen Stelle Mitteilung zu machen. Die Vertretungsbefugnis des Wahlmannes wäre in der Wahlkartei (Wählerliste) neben seinem Namen zu vermerken. Ein solches Verfahren würde schwerlich zu irgendwelchen internationalen Komplikationen führen können. $\mathrm{DaB}$ dabei der Grundsatz der Unmittelbarkeit der Wahl durchbrochen wäre, müßte in Kauf genommen werden; eine Verfassungs- 
änderung wäre unerläßlich, doch vielleicht erreichbar, da es sich hier um eine ausgesprochen gesamtdeutsche, nicht eine Parteifrage handelt. Auch wäre der Einwand nicht allzu schwer zu nehmen, $\mathrm{daB}$ so in verkappter Form einem Pluralwahlrecht die Bahn freigegeben und damit auch das Prinzip der Wahlrechtsgleichheit durchlöchert würde. Das Bedenken könnte übrigens dadurch wenigstens teilweise ausgeräumt werden, daß man eine Höchstzahl der von einem Wahlmann Vertretenen festsetzte. Das Verfahren ist jedenfalls höchst einfach und kann ohne erhebliche Schwierigkeiten zur Durchführung gelangen. Eine übermäßige Belastung einzelner Wahlkreise - abgesehen von den Grenzbezirken an der Schweiz - würde schwerlich eintreten; denn die Wahlmänner der Auslanddiaspora würden im großen und ganzen ziemlich gleichmäBig über das Reich verteilt sein. Hindernisse technischer Art stellen sich jedenfalls der Durchführung des Wahlmänner-Gedankens nicht entgegen.

5. Ernster Erwägung wert ist auch ein weiterer, auf die Vergrößerung des Kreises der Wahlberechtigten zielender Gedanke: Soll den im Reich lebenden Osterreichern das Wahlrecht zum Reichstag gewährt werden? Dies könnte natürlich nur geschehen, wenn auch den Reichsangehörigen in Osterreich das Wahlrecht zum Nationalrat gegeben wird. Dahin geht bekanntlich eine von der großdeutschen Partei erhobene Forderung, zu deren Erfüllung durch das österreichische Bundesverfassungsgesetz vom 7. Dezember 1929 die Möglichkeit eröffnet ist. Entsprechende Anträge sind auch im deutschen Reichstag eingebracht worden. Ich erinnere vor allem an den Antrag Dr. Ha as (Baden) und Genossen vom 19. November 1928, „der Reichstag wolle beschließen: die Reichsregierung $\mathbf{z u}$ ersuchen, in Ergänzung des Reichswahlgesetzes einen Gesetzentwurf vorzulegen, durch den den im Reiche ansässigen Männern und Frauen österreichischer Staatsangehörigkeit das Wahlrecht verliehen wird. Bei der Ausarbeitung des Gesetzentwurfs wären die entsprechenden Bestimmungen slawischer Staaten heranzuziehen, die den Staatsangehörigen anderer slawischer Staaten das Wahlrecht gewähren." Undurchführbares verlangte der Antrag Dr. Frick, Stöhr und Genossen vom 16. November 1928. Danach sollte die Reichsregierung um Vorlegung eines Gesetzentwurfs ersucht werden, "durch den die in geschlossenen deutschen Siedlungsgebieten im Ausland lebenden Volksgenossen deutschen Stammes, jedoch fremder Staatsangehörigkeit, insbesondere in Osterreich, in der Tschechoslowakei und in den durch das Versailler Diktat gewaltsam von uns getrennten Gebieten eine Vertretung im deutschen Reichstag erhalten."

Ernstlich kann nur in Betracht gezogen werden, den im Reich ansässigen nichtreichsangehörigen Deutschen die Wahl- 
berechtigung zu geben. Die Zuerkennung des Wahlrechts an sie würde eine Verfassungsänderung bedeuten. Vielleicht wäre mit außenpolitischen Schwierigkeiten $\mathrm{zu}$ rechnen, wenngleich aus dem Versailler Friedensdiktat ein völkerrechtlich begründeter Einspruch gegen diese Neuerung nicht hergeleitet werden könnte. Die Anschlußbewegung käme durch die Verleihung unseres Wahlrechts an die im Reich lebenden Osterreicher einen Schritt vorwärts. Es wird sehr viel vom AnschluB gesprochen. Hier könnte eine Tat geschehen.

6. Der Entwurf vom August 1930 und seine Begründung sehen davon ab, die Frage der WahIpflicht aufzuwerfen.

Was regelmäBig sittliche Pflicht ist, soll nach einer aus verschiedenen Parteilagern erhobenen Forderung zu einer Rechtspflicht gestempelt werden. Andere betonen dagegen, schon heute habe der Wahlberechtigte nicht lediglich ein formales Stimmrecht, sondern materiellrechtlich die Pflicht, seine Stimme im Sinne aktiver Mitarbeit am Staate abzugeben. Man findet, daß die Rechtslage hier die gleiche sei, wie beim Reichstagsmitglied; es habe die Pflicht, an den Arbeiten des Reichstags teilzunehmen, ein Rechtssatz, der nicht deshalb bestritten werden könne, weil er nicht in der Verfassung ausgesprochen sei. Es möge hier auch die reine Begriffskonstruktion registriert werden, derzufolge eine Wahlpflicht aus der rechtlichen Natur des Wählers und der Wahlhandlung hergeleitet werden soll. Wem die Abstimmung bei der Parlamentswahl Staatshandlung, der Wähler als solcher Staatsorgan ist, der operiert mit einem völlig unbrauchbaren Organbegriff und verkennt - wie Trie pel in seiner Besprechung des Buches von Spira feststellte - daß es sich gerade darum handelt, ob der Bürger verpflichtet sei, als solches Staatsorgan aufzutreten, was ganz sicher nicht schon daraus gefolgert werden kann, da $\beta$ er zum Staatsorgan wird, wenn er es tut.

Wenn die Wahlpflicht schon heute als Rechtspflicht angesprochen werden kann, dann fehlt es ganz unzweifelhaft an einer Sanktionierung der bestehenden Wahlpflicht. Und um Einführung oder Nichteinführung einer solchen Sanktionierung dreht sich die Meinungsverschiedenheit.

Der Ruf nach ihrer Einführung pflegt vor und nach jeder Wahl aus Angst oder zur Entschuldigung eines Mißerfolges in Presse und Versammlungen von Parteien erhoben zu werden, die ohne eine solche vom Staate zu leistende Zutreiberhilfe an ihrer Zukunft zu verzweifeln geneigt sind. Die Kreuzzeitung, welche die Wahlreformvorlage vom August 1930 eine "große Enttäuschung " nannte, vermiBte darin vor allem die Einführung der Wahlpflicht. Vielleicht böte die Einführung der Wahlpflicht wenig lebensfrischen Parteien zunächst einige Vorteile. Aber politisches Pflicht- und Verantwortungsbewußtsein für Volk 
und Staat lassen sich so nicht wecken. Und das ist das Entscheidende. Die letzten und tiefsten Lebensbedingungen eines Staatsvolkes sind durch keinen noch so scharfen Wahlpflichtparagraphen sicherzustellen. Hier hilft keine Strafe, sondern nur politische Volkserziehung. Doch gibt es nicht wenige Politiker, die fürchten, es möchte gar zu lange dauern, bis diese Volkserziehung auch nur einigermaßen durchgeführt ist; sie geben der Besorgnis Ausdruck, es könnte gerade die nächste Wahl, im Gegensatz zur letzten, bei Enttäuschung größerer Wählermassen, die heute gefühlsmäßig rechts stehen, einen Wahlerfolg der radikalen Linken oder ähnliche UUberraschungserscheinungen zeitigen, denen gegenüber mehr als je Vorkehrung durch Wahlpflicht erforderlich sei. Sie richten deshalb an die Reichsregierung die Forderung, die Wahlpflicht in die Reform hineinzuarbeiten selbst auf die Gefahr hin, die ohnehin zweifelhaften parlamentarischen Aussichten der Reform noch ein wenig zu verschlechtern. Diese Auffassung wurde z. B. in der Deutschen Allgemeinen Zeitung vom 19. Februar 1931 vertreten. Sie hat kaum Aussicht, sich durchzusetzen.

7. Bei der Wahlrechtsreform im Reich, die jetzt zur Entscheidung steht, geht es in der Hauptsache nicht um die Fragen der Wahlberechtigung und erst recht nicht um die Einführung der Wahlpflicht, sondern - wie auch in den meisten anderen Staaten - um die Wahltechnik. Die Frage der Abgrenzung des Wählerkreises interessiert heute weit weniger als die Abgrenzung der Wahlkreise.

Wer den Entwurf vom August 1930 in die Hand nimmt und nur flüchtig darin blättert, dem fällt sofort in die Augen, daß eine sehr wesentliche Änderung der Wahlkreiseinteilung geplant ist. Ein heikles Unternehmen! Nach den Erfahrungen, die so alt sind wie die Wahlkreiseinteilung selbst, horchen alle Interessenten auf, wo dieses Thema zur Debatte gestellt wird. "Wahlkreisgeometrie" ist ein bekannter Vorwurf und Schreckruf. Parlamentarier und parteipolitisch eingeschworene Wahlrechtstheoretiker erheben ihn mißtrauisch und vorsorglich gegen jede von einer nicht genehmen Regierung vorgelegte Wahlreform mit Änderung der Wahlkreiseinteilung. Wer wollte dieses Mißtrauen dem modernen Berufsparlamentarier verdenken? Er hat ja Weib und Kind zu Haus, die ohne ihn verderben.

Ohne Not sollte man die bestehende Wahlkreiseinteilung nicht antasten, zumal wenn sich in den einzelnen Wahlkreisen bereits eine gewisse Tradition gebildet hat. Das Gefühl der $\mathrm{Zu}$ sammengehörigkeit, das sich da entwickelt hat, ist staatspolitisch nicht wertlos; es darf nicht ohne zwingende Gründe wieder vernichtet werden.

Eine Änderung der Wahlkreiseinteilung läßt sich nicht um- 
gehen, wenn dem Wähler wieder stärkerer Einfluß auf die Auswahl der Kandidaten gegeben werden soll. Dies aber muß Ziel jeder Reform sein und wird auch durch die Regierungsvorlage vom August 1930 angestrebt. Das Wahlrecht muB wieder zu einem wirklichen Wahlrecht werden. Mit vollem Recht hat Carl Schrnitt die Frage aufgeworfen, ob das, was sich heute bei einer Reichstags- oder Landtagswahl abspielt, überhaupt noch mit dem Worte "Wahl " bezeichnet werden könne. Und er gibt darauf die zutreffende Antwort: "Die Wahl selbst ist nicht mehr die Bestimmung von Abgeordneten durch wahlberechtigte Staatsbürger, sondern eine statistische Gruppierung der Wählermassen und ihre Aufteilung unter eine Reihe von Parteigebilden, wobei der einzelne Wähler nicht etwa seinen oder seine Abgeordnete wählt, sondern sich entweder als aktiver Soldat einer Parteiarmee betätigt, oder aber als nichtorganisiertes "Treibholz" zu einer der verschiedenen Armeen hinzustöBt. So verbindet sich hier ein Appell der stehenden Parteiheere mit dem Vorgang, daß ein dunkles und schwer berechenbares (den festen, den pluralistischen Staat bildenden Organisationen daher höchst widerwärtiges) plebiszitäres Element zwischen den Parteiorganisationen fluktuiert und dadurch den Ausschlag gibt. Man nennt das immer noch "Wahl" und verursacht mit diesem Wort die irreführende Vorstellung, irgendeiner unserer 577 Volksvertreter sei "gewählt*, wie etwa Windthorst oder Eugen Richter gewählt worden sind."

In der Begründung zu der Vorlage vom August 1930 wird der Mangel des Einflusses der Wähler auf die Auswahl der Kandidaten dem System der langen gebundenen Listen zur Last gelegt, die ihren Grund in den übergroßen Wahlkreisen haben. Darüber, daß die Wahlkreisvorschläge eine allzu lange Reihe von Bewerbern enthalten und daß der Kampf um den Platz auf den Listen zu ganz üblen Erscheinungen geführt hat, ist man sich in weitesten Kreisen ohne Unterschied der Parteizugehörigkeit einig. Wenn 1928 in den Wahlvorschlägen insgesamt mehr als 6200 Kandidaten aufgeführt werden, von denen nur 491 in das Parlament einziehen . konnten, so beleuchtet diese Feststellung zur Genüge die Unhaltbarkeit des jetzt geltenden Systems. Will man aber von der langen Liste loskommen, so geht das nicht anders als durch starke Verkleinerung, also durch erhebliche Vermehrung der Wahlkreise. Diese Konsequenz wird denn auch in dem Entwurf vom August 1930 gezogen, und zwar dahin, daB er einen Durchschnittswahlkreis von 385000 Einwohnern zugrunde legt und demgemä $B$ das Reichsgebiet in 162 Wahlkreise einteilen will. Die Reformvorlage von 1924 sah 156 Wahlkreise vor.

Einwendungen gegen die Umschreibung der neuen Wahlkreise werden nicht ausbleiben. Jede einzelne Partei schätzt 
ab, wie sie dabei voraussichtlich abschneidet, und danach entscheidet sie sich.

$\mathrm{Da}$ kann es auch nicht ausbleiben, $\mathrm{da} \beta$ sich bei dieser Gelegenheit die grundsätzlichen Gegner des Wahlkreisgedankens zu Worte melden und manch williges Ohr finden, wenn sie die Mängel, die schließlich doch jeder noch so unparteiisch sein wollenden Wahlkreiseinteilung anhaften, kräftig unterstreichen.

Es besteht deutlich erkennbar bei nicht wenigen Praktikern wie Theoretikern der Politik eine starke allgemeine Antipathie gegen die Einteilung des Reichs in Wahlkreise, und viele sind geneigt, einem Reformvorschlag schon aus dem Grunde Beifall zu zollen, weil er - wie der Pappenheim-Kelsensche - die Wahlkreise entbehrlich oder bedeutungslos macht. Gerade weil unter der Herrschaft des Proportionalwahlrechts die Wahlkreise ausgeschaltet werden können, geben sie ihm den Vorrang vor anderen Systemen.

Wenn unser geltendes Wahlrecht an dieser Zwischenbildung zwischen den einzelnen Wählern und der Gesamtheit der Wahlberechtigten, an den Wahlkreisen, festhält, so vermag darin keinen Nachteil zu erblicken, wer radikalem Zentralismus in allen seinen Formen abhold ist. Als Historiker wird er mit Hugo Preu B darauf hinweisen können, da $B$ die Idee einer Vertretung der Wahlkreise in der parlamentarischen Entwicklungsgeschichte älteren Datums ist als der einer Vertretung des ganzen Volkes, vor allem sehr viel älter als der Gedanke einer rechtlich organisierten Repräsentation der öffentlichen Meinung durch das Parlament; ferner darauf, daß im Gegensatz zu England die parlamentarische Entwicklung des Kontinents schon gleich zu Beginn vor dem Problem der Wahlkreise als eines zweckbewußt zu schaffenden künstlichen Hilfsmittels für die rechtliche Organisation der Vertretung des Gesamtvolkes und seiner öffentlichen Meinung gestanden hat. Als die französische Konstituante die rechtliche Organisierung der "volonté générale de la nation unie et indivisible " in Angriff nahm, da schuf sie Wahlkreise; sie zerlegte also zunächst die als unteilbar proklamierte Nation in Bezirke. Den darin liegenden Selbstwiderspruch empfindend dekretierte sie zugleich: Der Abgeordnete ist nicht Vertreter seines Wahlkreises, sondern des ganzen Volkes. Sie erklärte also kraft Rechtssatzes die Auseinanderlegung in Teile als nicht vorhanden.

Jeder Wahlkreiseinteilung haftet von Haus aus eine mehr oder minder große Willkür an. Sie bricht die Gruppierung nach den Elementen einer lokal nicht gebundenen vielgestaltigen öffentlichen Meinung, sie läßt die verschiedenen Richtungen der öffentlichen Meinung im Reich nicht unmittelbar zur Geltung kommen, sondern modifiziert und abgelenkt durch örtliche Einflüsse der künstlich abgezirkelten Wahlkreise. 
Auch darin hat Hugo PreuB richtig gesehen: "In dem $\mathrm{Maße}$, wie die Organisation von Zwischenbildungen zwischen einzelnen und Gesamtheit durch Rechtssatz zurücktritt, schwillt die Bedeutung der Selbstorganisation in Parteien und damit die entscheidende Macht der Parteiorganisationen an."

$\mathrm{DaB}$ der Entwurf vom August 1930 an dem Wahlkreisgedanken festhält und auch sonst nach geeigneten Maßnahmen Ausschau hält, dem allzu starken Einfluß der zentralen Parteiorgane gewisse Schranken zu setzen, ist im Interesse des Staatsganzen grundsätzlich zu billigen.

In dieser Richtung würde auch die geplante Beseitigung der Reichsliste wirken.

8. Die Reichsliste im heutigen Wahlrecht ist von Anfang an Gegenstand zahlreicher, zum Teil sehr heftiger Angriffe gewesen; sie erfolgten aus verschiedenen Parteilagern, aber im großen und ganzen stets von den gleichen Gesichtspunkten aus: -Die Wahl auf der Reichsliste ist eine glatte Ernennung durch Parteiinstanzen *. "Das Erfordernis der Unmittelbarkeit der Wahl verlangt das Verschwinden der Reichsliste, auf der Personen, die der Wähler nicht kennt, von den Parteiinstanzen ,benannt", sicher nicht von den Wählern ,gewählt' werden.« Es wird als unerträglich empfunden, da $\beta$ die den Parteien aus den Reichsreststimmen zustehenden Mandate an eine in Berlin zurechtgemachte Liste von "Parteibonzen " und "Kapitalisten " ausgeteilt werden, die nicht gesäet haben und doch ernten wollen. Und in der Begründung zum Entwurf vom August 1930 heißt es darüber: -Nach der Reichsverfassung sind die Abgeordneten, unmittelbar' zu wählen. Bei dem heutigen System der Reichsliste kann zweifelhaft sein, ob es sich noch um eine ,unmittelbare Wahl im Sinne der Verfassung handelt, wenn der Bewerber lediglich auf Grund der Benennung in einer zentral aufgestellten Liste in das Parlament einzieht. Bei den Fraktionen des Reichstags ist der Hundertsatz der Reichslistensitze recht erheblich und steigt bis zu 50 v. H. aller Sitze. Die Wahlreform geht von der völligen Abschaffung der Reichsliste aus, weil nur dadurch der Verfassungsgrundsatz der Unmittelbarkeit der Wahl restlos gewahrt und der Forderung der persönlichen Verbindung von Abgeordneten und Wählern Rechnung getragen wird."

Wenn auch jede Wahlreform auf möglichste Wahrung des Verfassungsgrundsatzes der Unmittelbarkeit bedacht sein muB, so darf man doch seine Kollision mit dem Gleichheitsgrundsatz, der sich gerade in der Reichsliste eine Position erobert hat, nicht ohne zwingende Gründe einfach zu Gunsten des Grundsatzes der Unmittelbarkeit beseitigen wollen. Die beiden Grundsätze stehen nun einmal in der Verfassung nebeneinander, jeder beansprucht Geltung. Es ist dem Reichsgesetzgeber überlassen, im 
einzelnen zu entscheiden, wie weit er jedem der beiden Grundsätze Rechnung tragen will. Eine vollständige Durchführuns, beider ist ein Ding der Unmöglichkeit.

$\mathrm{DaB}$ eine starre Durchführung der verschiedenen Wahlrechts grundsätze bis in die letzten Konsequenzen in der Praxis nich möglich ist und von der Verfassung auch nicht gewollt ist, weil sie dann miteinander und mit sonstigen das Staatsleben beherrschenden Rechtsgrundsätzen in Widerstreit geraten würden, hat Max Wenzel im Handbuch des Deutschen Staatsrechts (I S. 609, 610) klar ausgesprochen: Die Wahlrechtsprinzipien müßten sich in ihrer Ausführung gewisse Einschränkungen gefallen lassen, "wie sie ja vom Verfassungsgeber auch nur als Grundsätze gemeint sind, von denen die Reichsverfassung in Art. 22 Abs. 2 sagt, daß ,das Wahlgesetz das Nähere bestimme" ". Bei der Ausgestaltung des Wahlrechts soll der Reichsgesetzgeber nicht aus dem Auge verlieren, da $B$ auch das parlamentarische Regime funktionieren kann. Die parlamentarische Regierungsweise ist eine fundamentale Vorschrift der Reichsverfassung.

Die Forderung an den Gesetzgeber, daß er das Gleichheitsprinzip dem Proporzgedanken weitgehend zu opfern habe, ist ebenso berechtigt oder unberechtigt wie die Zumutung, dem Gleichheitsprinzip zuliebe den Proporzgedanken in die zweite Linie zurücktreten zu lassen.

Es ist schon oft von den verschiedensten Seiten darauf hingewiesen worden, daB mehrere Parteien Wert darauf legen, ihre Senioren, gewesenen Minister und aktiven Minister, führende Männer der Wissenschaft und des Wirtschaftslebens ohne die Mühen und Fährlichkeiten eines Wahlkampfes in das Parlament zu bekommen. So muß damit gerechnet werden, da $B$ der Versuch einer Beseitigung der Reichsliste auf nicht geringe Schwierigkeiten stoßen wird. Auch begegnet man vielfach der Ansicht, daB mit der Reichsliste ein geeignetes Mittel in Wegfall käme, politisch führende Frauen in den Reichstag zu bringen.

Gerade im Hinblick auf die Reichsliste hat man in Deutschland geglaubt, der Lösung des Führerproblems um einen Schritt näher gekommen zu sein. Es gibt zu denken, da $B$ in der französischen Presse, wenn von Deutschlands parteipolitischer Misere die Rede ist, nicht selten der Ausdruck "le führerproblem « zu finden ist. Man weiß, da $B$ der Franzose im allgemeinen sich nicht so leicht entschlieBt, ein Fremdwort in seinen Sprachschatz zu übernehmen. Tut er es aber, und zwar ohne Französierung, dann ist das ein Beweis dafür, daß es den betreffenden Begriff im Französischen nicht gibt. Dem Franzosen ist der Führerbegriff etwas so Selbstverständliches, $\mathrm{da} B$ er dafür kein besonderes Wort nötig hat. Wir Deutsche haben daraus ein Problem gemacht und haben geglaubt, es mittels des nach der Staatsumwälzung ein- 
geführten Wahlrechts, insbesondere mittels der Reichsliste, seiner Lösung zuführen zu können.

Es ist eine Tatsache, daß es in Deutschland politische Köpfe gibt, die sich nichi entschließen können, auf dem Wege über den Kampf und Schmutz einer Wahl zu politischer Führung aufzusteigen. Man hatte bei der Einführung der Verhältniswahl gehofft, dieses System werde den Wahlkampf entpersönlichen und veredeln, es werde tüchtigen Politikern den Weg freimachen zum Führertum. Man versprach sich als Frucht des neuen Wahlrechts eine wesentliche Erleichterung richtiger Führerauslese. Die Optimisten sind mittlerweile recht kleinlaut geworden. Den gewiß insgesamt nicht unbeachtlichen Gründen für die Beibehaltung der Reichsliste steht die Forderung nach Herstellung persönlicher Fühlung zwischen Bewerbern und Wählern gegenüber, der Wunsch, die Unmittelbarkeit der Wahl wieder stärker hervortreten zu lassen, die tiefwurzelnde Abneigung gegen die Diktatur der zentralen Parteiinstanzen, das Vordrängen jüngerer Parteipolitiker, vor allem aber der Wille, den übermäßigen Druck großer Interessenverbände mehr auszuschalten, als dies jetzt möglich ist. Und diesen Stimmungen und Wünschen wird auch der Reichstag, wenn er an die Beratung der Reformvorlage herantritt, in irgendeiner Weise Rechnung tragen müssen.

Aber geschieht dies zweckmäßig durch völlige Beseitigung der Reichsliste? Man darf nicht übersehen, daß dabei zahlreiche Stimmen unter den Tisch fielen, zumal wenn § 21 des Entwurfs vom August 1930 Gesetz wird. Danach bekommt eine Partei, die in den zu einer Ländergruppe gehörenden Verbänden keinen Sitz erobert hat, auch in der Ländergruppe kein Mandat, mögen hier noch so viele Reststimmen zur Verfügung stehen.

Man sollte es sich doch reiflich überlegen, ob nicht auch unter Beibehaltung der Reichsliste dem Wunsche nach engerer persönlicher Verbindung von Abgeordneten und Wählern Rechnung getragen werden könnte. Das liegt durchaus im Bereich des Möglichen. Ich möchte empfehlen, eine personell gebundene Reichsliste ${ }^{1}$ ) zur Auswertung der Reststimmen zuzulassen und

1) Anmerkung des Fakultatsassistenten Dr. Sauer-Breslau: Das vorliegende Referat druckfertig zu machen und in unwesentlichen Punkten zu erganzen, war der letzte Auftrag meines Lehrers und vaterlichen Freundes Professor Heinrich Pohl. Da ich fürchte, daB der neuartige Vorschlag Pohls, eine sogenannte personell gebundene Reichsliste zur Auswertung der Reststimmen zuzulassen, auf Mißverstăndnisse stoßen könnte, halte ich mich für verpflichtet, hier Ausführungen Pohls mitzuteilen, die sich in einem am 16.1.31 an Herm Ministerialrat Dr. Kaisenberg gerichteten Brief finden. Es heißt dort unter anderem: „Der Entwurf der Wahlrechtsnovelle will die Reichsliste beseitigen. Man könnte aber m. E. auch unter Beibehaltung der Reichsliste eine Verbindung zwischen Wahlern und auf der Reichsliste gewahlten Abgeordneten sicherstellen, und zwar in einer Weise, die zugleich in der Richtung der Bekampfung der Splitterparteien 
in der Weise vorzugehen, daB die Reichsreststimmen nur solchen Persönlichkeiten zugute kommen, die in einem Wahlkreise als Spitzenkandidaten eine Liste führen. Niemand sollte mit Reichsreststimmen gewählt werden können, der nicht in einem Wahlkreise die Verteilungszahl erreicht. Der so gewählte Spitzenkandidat gilt als mit Reichsreststimmen gewählt, und in seinem Wahlkreis rückt der nach ihm auf der Kreisliste Stehende als gewählt vor. Reicht die Zahl der Reichsreststimmen nicht aus, so kommen bei ihnen nur die höchstbestimmten Spitzenkandidaten zum Zuge.

Bei diesem System der personell gebundenen Reichsliste würde erreicht, daB niemand in den Reichstag einzieht, der nicht in einem Wahlkreise gearbeitet und im Feuer gestanden hat. Auch der eventuell Vorrückende sähe sich genötigt, am Wahlkampfe sehr aktiv teilzunehmen. Die Verbindung zwischen Wählern und Gewählten wäre unter Beibehaltung der Reichsliste erzielt.

Wer als Ziel der Reform rdie Wiedereinsetzung der Persönlichkeit in das Wahlgetriebe " bezeichnet, wird dem System der personell gebundenen Reichsliste seine Sympathie nicht versagen können. Eine wirklich starke politische Persönlichkeit muß so viel Werbekraft besitzen, daß sie in einem Wahlkreise die Wahlzahl erreicht und damit als durch die Reichsreststimmen gewählt gilt.

Das vorgeschlagene System begünstigt Kandidaten der engeren Heimatzugehörigkeit. Darin vermag ich keinen Nachteil zu erblicken. Im Gegenteil; der Wähler möchte nicht nur

zu wirken geeignet wăre. Man könnte nămlich in der Weise vorgehen, daß nur solche Bewerber auf die Reichsliste gesetzt werden dürfen, die in einem Wahlkreis als Spitzenkandidaten eine Liste führen, und daB niemand als auf Grund der Reichsliste gewăhlt erklart werden kann, der nicht in einem Wahlkreise durch Erreichen der Verteilungszahl $(70000)$ gewahlt ist. Ist er so gewahlt, dann gilt er als auf Grund der Reichsliste gewahlt, sofern auf die Reichsliste seiner Partei die erforderlichen Reststimmen entfallen, und in seinem Wahlkreise rückt der nach ihm auf seiner Kreisliste Stehende als gewahlt vor. Die im Wahlkreise Gewahlten kommen auf der Reichsliste zum Zuge in der Reihenfolge, die sich durch die für die betreffenden Kreislisten aufgebrachten Stimmzahlen ergibt; sind die Stimmen auf der Reichsliste erschópt, so sind und bleiben die nicht auf ihr zum Zuge kommenden Bewerber auf ihrer Kreisliste gewahlt, und ein Vorrücken auf der Kreisliste findet nicht statt. Wird die auf der Reichsliste zur Verfügung stehende Stimmzahl nicht erschöpft, weil nicht genügend in ihrem Wahlkreis erfolgreiche Bewerber vorhanden sind, so bleiben die Reststimmen der Reichsliste unberücksichtigt. So würde erreicht, daß niemand in den Reichstag kommt, der nicht in einem Wahlkreise gearbeitet und im Feuer des Wahlkampfes gestanden hat. Auch der eventuell Vorrückende wăre genotigt, sich im Wahlkampfe seines Wahlkreises sehr aktiv zu betätigen. Die Verbindung zwischen Wăhlern und Gewăhlten wăre so unter Beibehaltung der Reichsliste erzielt. Die hierauf erfolgte Rückaußerung Dr. Kaisenbergs vom 30.1.31 hat Prof. Pohl im Referat selbst noch sachlich gewürdigt. 
einen Mann seiner Gesinnung, sondern zugleich den Mann entsenden, der mit dem Bezirke verwachsen ist, den man dort kennt, der mit den Bedürfnissen und Wünschen des Bezirks vertraut ist, dessen Werdegang und öffentliche Betätigung vor seinen Augen sich vollzogen haben, den Mann, der nicht bloß zum Zweck der Wahlwerbung tönende Reden hält und Versprechungen macht. Diese Einstellung ist vielfach ganz zu Unrecht als Enge des Horizonts, Kurzsichtigkeit, Dorfpolitik usw. getadelt worden. Aber die Dinge liegen keineswegs so, daß bei Berücksichtigung der Heimatzugehörigkeit nicht auch die politische Gesinnungsgemeinschaft voll zur Geltung kommen kann. Der Kandidat bewerbe sich da, wo er wurzelt. Wer im Wahlrecht jede Unterteilung nach örtlichen Gesichtspunkten und jede endgültige Mandatszuweisung unterhalb einer zentralen Reichsliste als Durchbrechung des Proporzes grundsätzlich ablehnen zu müssen glaubt, dem wird die Verbindung des Wahlkreis- mit dem Reichslisten-Gedanken unannehmbar sein. Wer glaubt, die Wahlkreise zu bloßen Stimmsammelbezirken degradieren zu sollen, wer sie im wesentlichen nur zu Zählzwecken beibehalten will, muß dem Vorschlag der personell gebundenen Reichsliste ablehnend gegenüberstehen.

Das System der personell gebundenen Reichsliste würde eine im gesamtstaatlichen Interesse sehr zu wünschende parteipolitische Konzentration herbeiführen helfen. Es ist nicht einzusehen, warum der Gesetzgeber darauf verzichten müßte, durch zweckmäßige Gestaltung des Wahlrechts an der Zusammenfassung der Kräfte mitzuarbeiten, sich anbahnende Konzentrationen zu fördern. Ich bin pessimistisch genug, von politischer Einsicht des Bürgertums allein nur wenig zu erhoffen.

Den kleinen und kleinsten Parteien würde die personell gebundene Reichsliste abträglich sein, da sie nur selten dem von mir aufgestellten Erfordernisse für einen Sitz auf der Reichsliste gerecht werden könnte. Unmittelbar im Wahlkreis, d. h. ohne Verrechnung im Verband, wird eine Splitterpartei kaum in der Lage sein, die Verteilungszahl zu erreichen. Das dürfte ein großer Vorteil des Systems der personell gebundenen Reichsliste sein.

Natürlich ist dagegen der Einwand zu erwarten, da $B$ dieses System dem Gleichheitsprinzip 2) Abbruch tue. Das ist gewiB nicht zu bestreiten. Aber nicht minder berechtigt scheint mir der Hinweis darauf zu sein, daß die dabei erzielte Auswertung der Reststimmen auf der Reichsliste, die der Entwurf vom August 1930 beseitigen möchte, dem Gleichheitsprinzip wieder zugute kommt. Das Gleichheitsprinzip wird also zwar auf der einen

2) Vgl. die Ausführungen von Jellinek S. 624 u. Wenzel S. $611 \mathrm{ff}$. im Handbuch des Deutschen Staatsrechts Bd. 1. 
Seite beeinträchtigt, dafür aber auf der andern Seite besser gewahrt. Praktisch bedeutet mein Vorschlag eine Begünstigung der großen, örtlich massierten Parteien. Darin liegt ein unverkennbarer Vorteil. Die Schaffung klarer Mehrheitsverhältnisse ist nur durch große Parteien zu erreichen, nicht durch zusammenhanglose, über das ganze Reich verstreute Einzelstimmen oder Parteigrüppchen. $\mathrm{DaB}$ die örtlich massierten Parteien bei dem System der personell gebundenen Reichslisten gut wegkommen, liegt auf der Hand. Denn bei diesem System ist das Erreichen der Verteilungszahl im Wahlkreis zugleich auch entscheidend für die Auswertung der Reststimmen auf der Reichsliste. Das bedeutet keineswegs die Einführung eines blanken Willkürmoments in die Wahlgesetzgebung. Parteien, die in keinem Wahlkreis wirklich festen $\mathrm{FuB}$ fassen konnten, so daB sie die Verteilungszahl erreichen, mögen im Parlament unvertreten bleiben. Das Erfordernis starker lokaler Stützpunkte ist übrigens keine grundstürzende Neuerung. Sie bedeutet ebensowenig eine Preisgabe des Grundgedankens der Verhältniswahl wie der dritte Satz des $\$ 32$ des Reichswahlgesetzes, in dem eine gewisse lokale Basis verlangt und von einer vollkommenen Verrechnung der Reststimmen abgesehen wird.

Der sehr wesentliche Einwand gegen die Reichsliste, sie begünstige das "Bonzentum", wird zwar bei dem System der personell gebundenen Reichsliste nicht völlig ausgeschaltet, aber doch wesentlich abgeschwächt. $\mathrm{Muß}$ doch der Bonze sich bequemen, irgendwo auch im Wahlkreis selbst zu seinem Volke herabzusteigen. Daher werden sich die örtlichen Parteiinstanzen nicht ohne weiteres irgendeinen Bonzen als Spitzenkandidaten oktroyieren lassen. Zieht er nicht, dann bedeutet das Sti.nmverlust, und so werden die örtlichen Instanzen dagegen aufbegehren, wenn die Reichsparteileitung den Bonzen in einem guten Wahlkreis an erster Stelle placieren will und die örtliche Parteileitung durch die Zusage zu beruhigen sucht, daB es sich nur um einen Strohmann zur Auswertung der Reichsreststimmen handle. Auch der Versuch, hinter einen beliebten Spitzenkandidaten, der voraussichtlich die Verteilungszahl erreicht, einen weniger beliebten Bonzen zu setzen, dürfte wenig aussichtsreich sein; man wird ihn nicht ohne weiteres schlucken.

Geht man zum System der personell gebundenen Reichsliste über, dann läßt sich die Bestimmung des Entwurfs vom August 1930, wonach nicht mehr als drei Namen auf den Stimmzetteln erscheinen dürfen, nicht aufrechterhalten. Die Möglichkeit für Ersatz wird sonst zu gering. Denn wenn der Spitzenkandidat auf der Reichsliste zum Zuge kommt, sind zur Besetzung der Sitze, die nach dem Wahlergebnis im Wahlkreis selbst - auch nach Verrechnung im Verband und in der Ländergruppe - anfallen, 
unter Umständen nicht mehr genügend Bewerber vorhanden. Man wird sich also, wenn man die personell gebundene Reichsliste annimmt, entschließen müssen, vier oder fünf Bewerber auf einem Stimmzettel zuzulassen. Ob drei oder vier oder fünf Namen darauf stehen, ist kein so wesentlicher Unterschied; die Liste ist dann immer noch verhältnismäßig klein.

9. Das dem Gedanken des Minderheitsschutzes dienende Verhältniswahlrecht kann unmöglich jeder kleinsten Gruppe von Wählern eine verhältnismäßige Vertretung im Parlament verschaffen wollen. Ein Versuch in dieser Richtung müßte zu einem Reichstag von Tausenden von Abgeordneten führen. Gibt es doch Parteien von minimaler Anhängerzahl, welche die Wahlzahl entfernt nicht erreichen. Denken wir nur daran, daß es mehr als einen Professor gibt, von dem man sagen kann: er ist das einzige Mitglied seiner Partei. Wenn auch den Männern von Weimar der Gedanke vorgeschwebt hat, daß die Stärke der Fraktionen proportional sein soll der Stärke der Parteien, so kann doch keine Rede davon sein, daß nach ihrem Willen jede kleinste Wählergruppe im Parlament zur Geltung gelangen soll. Schon die Aufstellung einer Wahl- oder Verteilungszahl zeigt, da $B$ daran nicht gedacht worden ist. Treibt man den Proporzgedanken in seine äußersten Konsequenzen, dann ists aus mit dem Repräsentativsystem, dann landet man bei der unmittelbaren Demokratie, deren Durchführung in großen Staatswesen unmöglich ist. Diesem Ergebnis kann man nur in der Weise ausweichen, daß man gewissen kleinen und kleinsten Gruppen den Anspruch auf Repräsentation versagt. Daher ist vom Standpunkte der repräsentativen Demokratie aus unbedingt die Forderung zu erheben, daß jede Gruppe, der noch ein Mandat zufallen soll, eine Mindeststärke hat. Ein Verhältniswahlrecht ohne jede die Splitterparteien einschränkende und benachteiligende Bestimmung ist nicht haltbar.

Freilich darf der Gesetzgeber, wo die Verfassung für die Wahlen zum Parlament das Verhältniswahlsystem vorschreibt, die Grenzen, die er ziehen muB, nicht nach Willkür ziehen. Er hat sie so zu ziehen, daß wenigstens allen politisch bedeutsameren Strömungen im Volke die Möglichkeit bleibt, sich im Parlament zur Geltung zu bringen, und so, daB schließlich allen Gruppen gleiche Chancen offengehalten werden. Aus diesen Einschränkungen, die geradezu als dem Verhältniswahlsystem immanent bezeichnet werden können, ergibt sich ohne weiteres, da $B$ dem verfassungsrechtlichen Postulat der Wahlrechtsgleichheit da, wo das Verhältniswahlrecht vorgeschrieben ist, niemals ganz Genüge getan werden kann. Beide, Proporz und Gleichheit, müssen sich bescheiden, wenn sie nebeneinander leben sollen. In die äußersten Folgerungen getrieben schließen sich beide Gedanken aus. 
Nach einer bekannten Entscheidung des Reichsstaatsgerichtshofs soll der Grundsatz der Gleichheit der Wahl durch seine Verbindung mit der Verhältniswahl einen Bedeutungswandel erfahren haben und nicht mehr nur Ablehnung eines Klassen- oder Pluralwahlrechts, sondern darüber hinaus auch noch das Erfordernis gleichen Erfolgswertes jeder Stimme zum Inhalt haben.

Diese Auffassung geht fehl. Das Reichswahlgesetz ist von derselben Nationalversammlung beschlossen worden, die auch die Verfassung mit den grundlegenden Wahlrechtssätzen verabschiedet hat. Man darf also annehmen, daß der Verfassungsgesetzgeber in dem Reichswahlgesetz seine Auffassung vom Inhalt des Gleichheitsprinzips nicht wieder gleich verlassen hat. In dem Wahlgesetz finden wir aber die Beteiligung bei der Verwertung der Reststimmen abhängig gemacht von der Erlangung gewisser Mindeststimmenziffern. Außerdem wird hier die Zahl der auf die Reichswahlvorschläge durch die Reststimmenverwertung erlangbaren Mandate auf die Zahl der den Kreiswahlvorschlägen zugefallenen Mandate beschränkt ${ }^{3}$ ).

Einer allzu starken Zersplitterung der Stimmen könnte dadurch wirksam begegnet werden, daB man einen Mindestprozentsatz aller im Reich abgegebenen Wahlstimmen verlangt, ohne dessen Erreichung der Partei kein Mandat zugewiesen wird. Nehmen wir eine Gesamtwählerzahl von 40 Millionen an, so sollte keine Partei zum Zuge kommen, die nicht mindestens $1 \%$, also 400000 Stimmen aufgebracht hat. Unbestreitbar würde bei Ziehung einer solchen Niedrigstgrenze den verfassungsmäßigen Postulaten der Gleichheit und der Verhältniswahl nicht restlos entsprochen. Aber es ist überhaupt schlechterdings unmöglich, ihnen in vollem Umfange Rechnung zu tragen. Ihre Rechtfertigung finden notwendige Ausnahmen in der Erkenntnis, da $B$ bei völliger Durchführung die in der Verfassung aufgestellten Wahlrechtsprinzipien in heillose Kollision geraten müBten, daß also eine solche Durchführung, weil unmöglich, nicht von der Verfassung gewollt sein kann. Ohne Ausnahmen ist nicht durchzukommen. Das doch auch von der Verfassung vorgeschriebene parlamentarische System wäre undurchführbar, wenn der Reichstag zum Tummelplatz zahlreicher kleiner und kleinster Gruppen gemacht werden dürfte. Und so gilt denn auch bereits im heutigen Wahlgesetz ( $\S 32$ ) die mit strengster Auslegung der verfassungsrechtlichen Postulate unvereinbare Bestimmung: "Einem Reichswahlvorschlage kann höchstens die gleiche Zahl der Abgeordnetensitze zugeteilt werden, die auf die ihm angeschlossenen Kreiswahlvorschläge entfallen sind *. Die hier verlangte örtliche Grund-

3) Vgl. Hans Nawiasky in den Münchner Neuesten Nachrichten Nr. 78 vom 21. Marz r930. 
lage stellt unzweifelhaft eine in keiner Verfassungsvorschrift ausdrücklich zugelassene Ausnahme von den Prinzipien der Gleichheit und der Verhältniswahl dar.

10. Die im Entwurf vom August 1930 vorgesehene Heraufsetzung der Verteilungszahl von 60000 auf 70000 würde eine nicht unwesentliche Verkleinerung der Mitgliederzahl zur Folge haben, vorausgesetzt, daß die Wahlbeteiligung annähernd die gleiche bleibt und die Zahl der Wahlberechtigten nicht steigt. Mit Rücksicht auf die Finanzlage des Reichs kann eine solche Verringerung der Zahl der Parlamentsmitglieder nur gebilligt werden. Handelt es sich doch nicht nur um ziffernmäßig erhebliche Gesamtbezüge der Abgeordneten an Diäten, sondern auch um die Kosten der Freifahrt auf den Eisenbahnen ("Freie Eisenbahn dem Tüchtigen ! () und um die durch die Abgeordnetenzahl prozentual beeinflußten sachlichen Kosten des Reichstags. Im Hinblick auf die Kostenfrage und die räumlichen Verhältnisse des Reichstagsgebäudes, des Sitzungssaales wie der Nebenräume, muB die Zahl der Abgeordneten heruntergedrückt werden; anders lassen sich zur Zeit mancherlei praktische Unzuträglichkeiten nicht vermeiden. Nicht unerwähnt bleibe auch der Gesichtspunkt, daB sich das Nebeneinander zweier großer Parlamente in Berlin für den Gedanken des Parlamentarismus um so ungünstiger auswirken muB, je zahlreicher die Mitglieder sind.

Es braucht wohl nicht befürchtet zu werden, da $\mathrm{B}$ infolge einer sich in mäßigen Grenzen haltenden Einschränkung der Abgeordnetenzahl Qualität und Tempo der Reichstagsarbeit leiden müßten. Wenn die Sprechchöre und Liedervorträge dann nicht so voll klingen, so ist das eben nicht zu vermeiden. Die Zahl der wirklich intensiv mitarbeitenden Parlamentarier ist nicht allzu groß. Den Fleißigen und Befähigten wird immer ein gewaltiges MaB von Arbeit, namentlich in den Ausschüssen, aufgebürdet werden. Es kann nur gute Folgen haben, wenn die Parteien sich gezwungen sehen, bei der Aufstellung der Kandidaten mehr als bisher auf die Gewinnung fähiger und arbeitsfreudiger Kräfte Bedacht zu nehmen. Auch wäre es wohl nicht unangebracht, etliche Ausschüsse auf ihre Existenzberechtigung nachzuprüfen; es würde sich vielleicht herausstellen, da $B$ der eine oder andere sehr wohl entbehrlich wäre.

Man könnte die meisten Ausschüsse mit weniger Mitgliedern besetzen und ihnen das Recht geben, für einzelne Aufgaben sachverständige, nicht dem Parlament angehörige Persönlichkeiten zu kooptieren. So wäre man in der Lage, wertvolle Kräfte, Führer auf ihrem Gebiet, zu beratender Mitwirkung heranzuziehen, die sonst nicht zu haben sind. Es sind vielfach gerade die Tüchtigsten, die sich nicht für eine Reichstagskandidatur hergeben wollen, Persönlichkeiten, denen Zeit und Kräfte zu kostbar sind, um sie 
in den vielfach so geist- und sinnlosen Alltagskampf der Fraktionen einzusetzen. Schon heute haben nach der Geschäftsordnung die Ausschüsse dảs Recht, in besonderen Fällen andere A bgeor dnete zu ihren Verhandlungen mit beratender Stimme zuzuziehen. Man sollte den Kreis dieser Mitberater erweitern und auch Nichtparlamentarier zu Mitgliedern mit beratender Stimme zulassen. Das wäre freilich ein Novum. Im Kommunalrecht ist der Gedanke ja nicht neu. Man könnte ihn um so unbedenklicher in das Parlamentsrecht einführen, als ja die großen endgültigen Entscheidungen nicht in den Ausschüssen, sondern im Plenum fallen. Und man wäre ja auch kein moderner Mensch, wenn man nicht einer -Auflockerung " das Wort redete!

III.

Welches Schicksal die Wirthsche Reformvorlage im Reichstag haben wird, wie die politischen Parteien sich dazu stellen werden, läBt sich zur Zeit auch nicht mit annähernder Sicherheit vorhersagen. Professoren sollen nicht unter die Propheten gehen, weder unter die großen noch unter die kleinen. Wir Staatsrechtslehrer haben uns aber in der Satzung unserer Vereinigung die Aufgabe gestellt, Gesetzgebungsfragen aus unserem Arbeitsgebiet durch Aussprache in unseren Versammlungen zu klären und in wichtigen Fällen zu Fragen des öffentlichen Rechts Stellung zu nehmen. Man wird uns daher die Kompetenz zur Stellungnahme zu der vor ihrer Entscheidung stehenden Wahlreform nicht bestreiten können. Die Wahlrechtsspezialisten der Parteien haben zum Glück das politische Denken nicht gepachtet, wenn sie's auch dem Stimmvieh einreden möchten, das sich natürlich nie bei der eigenen, sondern immer und nur bei der gegnerischen Partei befindet.

Man würde es uns verdenken, man würde uns als weltfremde Stubengelehrte belächeln, wenn wir hier dem zur Zeit Unerreichbaren nachjagen und darauf verzichten wollten, an einer kleinen Reform mitzuarbeiten und dazu im einzelnen Stellung zu nehmen, weil eine von vielen als notwendig erachtete große Reform, die Beseitigung der Verhältniswahl, nicht durchsetzbar erscheint. -Alles oder nichts \& ist eine schlechte Parole in politischen Dingen.

So hat sich dieser Bericht im wesentlichen darauf beschränkt, an dem Wirthschen Entwurf Kritik zu üben, auf Mängel hinzuweisen und Besserungsvorschläge zu machen. Das letztere ist mit einigem Zagen geschehen. Denn manches, was hier zu sagen ist, wurde gewiß von anderen längst viel besser und überzeugender dargetan. Und ob das wenige, was erstmals hier zur Erörterung gebracht worden ist, wirklich neu ist - wer weiß das? Die Wahlrechtsliteratur ist unübersehbar groß. Prioritätsstreitigkeiten sind eine üble Sache, und wer möchte als Mann der zweiten Ent- 
deckungen auftreten? Was aber besonders bedenklich stimmen mußte, ist der Gedanke, daß dieses Referat durch die Drucklegung in weitere Kreise dringen wird. Da verzichtet der Referent am besten von vornherein in aller Form vor allen künftigen Lesern seines Berichts auf den Anspruch, Erfinder einer beachtenswerten Wahlrechtsverbesserung zu sein. Auf einen unglücklichen Wahlrechtstheoretiker, das lehrt die Erfahrung, schlägt ja alles ein, am heftigsten die eifersüchtige Konkurrenz. Er tut gut, sich mit der Fabel zu trösten, die vor Jahresfrist im schönen Schwabenlande, wo man sich etwas derb auszudrücken pflegt, jemand am Schlusse seines Vortrags über die Änderung des württembergischen Landtagswahlgesetzes seinen Zuhörern erzählte: 'Als Pythagoras seinen berühmten Lehrsatz entdeckt hatte, freute er sich so, da $B$ er eine Hekatombe opferte, d. h. er opferte hundert Ochsen. Daher kommt es, so sagt man, daB die Ochsen immer brüllen, wenn etwas Neues entdeckt wird."

\section{Leitsätze zum Referat von Heinrich Poh1 uiber die Reform des Wahlrechtes.}

Aufgestellt von Friedrich Giese.

I. Die Gestaltung des Wahlrechts ist eines der wichtigsten und aktuellsten Probleme. Eine durchgreifende Wahlreform erscheint dringend geboten. Die Staatsrechtshehrer sind zur Mitarbeit daran berufen.

Wichtigste Neuerungen des Wirth'schen Reichswahlgesetzentwurfes:

I. Ersatz der langen Listen durch Stimmzettel mit höchstens drei Bewerbern.

2. Erhebliche Verkleinerung =Vermehrung der Wahlkreise.

3. Fortfall der Reichsliste; Verwertung der Resistimmen in Wahlkreisverbärden und in Landesverbänden.

4. Fortfall des amtlichen Stimmzettels.

5. Ersatz des Wahlvorschlagverfahrens durch ein vereinfachtes Anmeldeverfahren für die Stimmzettel.

II. Kritik und Besserungsvorschläge des Referenten gegenüber dem Wahlgesetzentwourf und dem geltenden Wahlrecht.

I. Das Frauenstimmrecht dïrfte auf legalem Wege nicht zu beseitigen sein. 
2. Die Herabsetzung des Wahlalters auf 20 Jahre war verfehlt, seine Herau/setzung ist geboten.

3. Es ist unzweckmäßig, nur die dawernd, nicht auch die vorïbergehend in einer Anstalt befindlichen Geisteskranken und Geistesschwachen vom Wahlrecht auszuschließen.

4. Das Wahlrecht der Auslanddeutschen ist zu fordern; seine Ausübung hat durch in Deutschland ansässige Wahlmänner zu erfolgen.

5. Den im Reich ansässigen nichtreichsangehörigen Deutschen, insbesondere Österreichern sollte das Wahlrecht gewährt werden.

6. Die Einführung der Wahlpflicht ist untunlich.

7. An der Wahlkreiseinteilung überhaupt ist festzuhalten, doch erscheint eine andere Wahlkreisabgrenzung geboten, um dem Wähler wieder stärkeren Einfluß auf die Auswahl der Kandidaten zu geben.

8. Anstatt der Beseitigung der Reichsliste empfiehlt sich die Einführung der personell gebundenen Reichsliste: Die Reichsreststimmen kommen nur den Wahlkreis-Spitzenkandidaten zugute; doch kann mit Reichsreststimmen nur gewählt werden, wer in einem Wahlkreis die Verteilungszahl erreicht hat.

9. Der Proporz ist so durchzuführen, daß alle politisch bedeutsameren Strömungen des Volkes im Parlament vertreten sind und daß allen Gruppen gleiche Chancen eröfnet werden.

Io. Die Verteilungszahl ist heraufzusetzen, da eine Verringerung der Zahl der Abgeordneten zu billigen ist. 


\section{Die Wahlrechtsreform und ihre Grundlagen.}

2. Mitbericht von Professor Dr. Gerhard Leibholz, Göttingen.

Bei der Wahlrechtsreform handelt es sich nicht nur um ein mathematisch-technisches, sondern vor allem um ein politischsoziologisches Problem. Es ist nicht möglich, etwa allein mit Hilfe der Wahltechnik ${ }^{1}$ ) aus der Fülle der aufgestellten wie entworfenen Wahlrechtssysteme ein sogenanntes bestes Wahlsystem zu konstruieren, das allgemein und somit auch für unsere Verhältnisse empfohlen werden könnte. Ein solches bestes Wahlsystem gibt es nicht und kann es nicht geben, weil jedes Wahlrecht zugleich strukturell aufs engste mit den politisch-soziologischen Grundlagen einer Verfassung zusammenhängt, für die es seiner Funktion nach eine ganz bestimmte integrierende Bedeutung hat. Wird doch der Ruf nach einer Wahlreform nicht zufällig gerade deshalb so häufig erhoben, weil das Wahlrecht mehr mathematisch rechnerisch konstruiert als politisch dynamisch gewachsen ist.

Hiernach ist die Einschaltung gewisser politischer Wertungen in die vorliegende Betrachtung unvermeidbar. Bei diesen Wertungen handelt es sich aber wie bei jeder soziologisch verfassungstheoretischen Analyse, wie gegenüber einzelnen Äußerungen der letzten Zeit hervorgehoben werden muB, nicht um rein subjektive, allein parteipolitisch bedingte, sondern sachhingegebene, politische Wertungen, d.h. Wertungen, die an dem Phänomen der objektiven Wirklichkeit orientiert, ihrem immanenten Gehalt entnommen sind ${ }^{2}$ ), und die deshalb politische sind, weil die zu analysierende Wirklichkeit selbst eine politische ist. Einer hierüber hinausgehenden, persönlich politisch wertenden Stellungnahme bedarf es nur dort, wo die Grenzen einer solchen, objektiv-gehaltenen, verfassungstheoretischen Analyse überschritten werden.

In diesem Sinne soll zunächst der tiefere Zusammenhang des modernen Wahlrechts mit den Grundlagen des repräsenta1930.

1) Dazu jetzt etwa Hellmuth, Die Technik der politischen Wahlen

2) Dazu die schōnen Bemerkungen von Holstein in Hochschule und Staat in Das akademische Deutschland Sep. Abdruck S. 8 v. Arch. f. $8 f f$. Recht N. F. Bd. 11 S. $27 \mathrm{ff}$. 
tiven Parlamentarismus überhaupt angedeutet und sodann der Bedeutungswandel aufgezeigt werden, den das Wahlrecht im Parteienstaat der Gegenwart, insbesondere und gerade auch in den letzten Jahrzehnten, erfahren hat.

Jede politisch-repräsentative, also insbesondere auch parlamentarische Instanz kann, wie in anderem Zusammenhang näher ausgeführt worden ist ${ }^{3}$ ), ihre repräsentativen Funktionen nur erfüllen, wenn sie durch die repräsentierte Volksgesamtheit dazu legitimiert wird. Eine solche Legitimierung fordert, $\mathrm{da} B$ der Anspruch, auf Grund dessen eine Instanz das Volksganze zu repräsentieren behauptet, von der repräsentierten Volkseinheit als dem Grunde nach zu recht bestehend anerkannt wird. Es genügt somit nicht, $\mathrm{da} B$ eine Instanz sich als zur repräsentativen Herrschaftsausübung legitimiert betrachtet oder sich als Repräsentant geriert. Hinzukommen muß vielmehr stets entscheidend der Glaube des Volkes an den Legitimitätsanspruch der repräsentativen Instanzen. Erst hierdurch entsteht der "contact ", die "correspondence ", das Vertrauensverhältnis zwischen Repräsentanten und Repräsentierten.

Dieser Legitimitätsanspruch wird nun in der Demokratie im Gegensatz zur Monarchie nicht transzendent, sondern immanent, d. h. mit dem Willen der zu repräsentierenden Volksgemeinschaft begründet. Insbesondere das Parlament kann - und zwar nicht nur in der Demokratie - seine repräsentative Legitimität nur in dieser Weise begründen. Niemals in der Geschichte ist die repräsentative Parlamentsherrschaft religiös und damit transzendent-irrational gerechtfertigt worden. Und die Wahlen haben in diesem Zusammenhang den parlamentarischen Körperschaften gegenüber die Funktion, den Glauben an deren immanent repräsentative Legitimität in der Volksgemeinschaft zu begründen und $\mathrm{zu}$ erhalten ${ }^{3 a}$ ).

Hiermit soll nicht gesagt sein, daB jede immanente d. h. auf den Volkswillen zurückgehende Legitimierung einer repräsentativen Instanz auch in der Demokratie auf Volkswahlen beruhen muß. Die repräsentativen Instanzen können auch heute noch auf andere Weise legitimiert werden, etwa durch das Charisma des Führers, mit Hilfe traditionaler Kräfte, möglicherweise auch durch einen der Intention nach repräsentationsbegründenden Verfassungssatz. Immerhin ein an den politischen Entscheidungen maßgeblich beteiligtes Parlament, das den Anspruch auf Repräsentation des Volksganzen erhebt, wird in der Gegenwart seine

3) Năher Leibholz, Das Wesen der Repräsentation 1929 S. $140 \mathrm{ff}$.

sa) Wie völlig unzulanglich die hisher allein sog. juristischen Versuche der Analyse des Wahlaktes sind, zeigen etwa die Ausführungen von Hatschek, Das Parlamentsrecht des deitschen Reiches 1915 S. 349 ff. und die dort erwahnten Theorien. 
immanent repräsentative Legitimität ohne Volkswahlen nicht tatsächlich begründen können. Oberhäuser in der typischen Gestalt des 19. Jahrhunderts sind heute, auch wenn deren Mitglieder von den Verfassungen als Repräsentanten bezeichnet und formal-juristisch den Mitgliedern der zweiten Kammern gleichgestellt werden, als politisch entscheidende, repräsentative Instanzen nicht mehr denkbar. Die rein normative Legitimität genügt heute nicht mehr, um legitimierend und damit repräsentationsbegründend $\mathrm{zu}$ wirken. Daher hatten die Liberalen aller Schattierungen und aller Länder in einem gewissen Sinne Recht, als sie zur Zeit der Entstehung des klassischen Repräsentativsystems in der konstitutionellen Monarchie die Volkswahlen, die an sich nicht in einem wesensnotwendigen Zusammenhang mit dem politischen Begriff der Repräsentation stehen, in diesem Zusammenhang doch als zum Wesen des Repräsentativsystems gehörig bezeichneten und dem König das Recht bestritten, sich in die Bildung der Volkskammer einzumischen, da hierdurch der repräsentative Charakter derselben zerstört und sie zu einem "künstlichen Organ ", einem "Teil der Regierung " gemacht werden würde.

Wiè nun diese legitimierend und repräsentationsbegründend wirkenden Volkswahlen auch im einzelnen beschaffen sein mögen, sicher ist, daß diese niemals den Tatbestand der parlamentarischen Repräsentation mathematisch zu erklären vermögen. Auch das demokratischste Wahlrecht in seiner konsequentesten Form, das Verhältniswahlsystem der gebundenen Liste, wird immer nur einen Bruchteil der Bevölkerung, niemals aber die Volksgesamtheit erfassen ${ }^{\text {sb }}$ ), die aber ihrerseits nach dem Grundgedanken des repräsentativen Parlamentarismus die allein durch das Parlament repräsentierte, ideelle Einheit darstellt.

Weiter ist sicher und wird durch die Geschichte des parlamentarischen Wahlrechts ") belegt, daß ganz verschiedene konkrete Wahlsysteme die reprësentativen Qualitäten einer parlamentarischen Körperschaft $\mathbf{z u}$ begründen vermögen. In England z. B. ist die parlamentarische Repräsentation auf einem ausgesprochen aristokratisch-plutokratischen Boden erwachsen und funktionierte das parlamentarische Repräsentativsystem tatsächlich zu der Zeit am besten, als das Wahlrecht der Masse noch in einem gewissen Sinne plutokratisch gebunden war. In dem gleichen Sinne hat in Preußen-Deutschland die Staatstheorie im letzten Jahrhundert eine Beschränkung des Wahlrechts auf bestimmte Personenkreise und die Bindung des Wahlrechts an

ab) Uber die komplexe Masse der Nichtwahler Meyer, Annalen des Deutschen Reiches Bd. 64 (1931) S. 253 ff.

4) $\mathrm{Zu}$ dieser vor allem Georg Meyer, Das parlamentarische Wahlrecht 1901 Erstes Buch.

Tagung der Staatsrechtslehrer, 1930, Heft 7. 
ein bestimmtes Vermögen oder Einkommen oder eine Staffelung nach plutokratischen Maßstäben - etwa im Sinne des preußischen Dreiklassenwahlsystems - für mit den Grundlagen der parlamentarischen Repräsentation vereinbar gehalten. An sich ist also unter Umständen ein nach der politischen Gewichtigkeit der Staatsbürger abgestuftes, dynamisches oder aristokratisches oder plutokratisches Wahlsystem ebenso in der Lage, die repräsentativen Qualitäten einer parlamentarischen Körperschaft sicherzustellen, wie das der modernen Staatspraxis geläufige, allgemeine und gleiche Wahlrecht.

Diese Einsicht schließt nicht aus, daB gewisse Wahlrechtssysteme, die früher einmal tatsächlich legitimierend und damit repräsentationsbegründend gewirkt haben, in der Gegenwart diese politische Kraft nicht mehr besitzen. Es ist nicht nur denkbar, sondern wird durch die politische Wirklichkeit immer wieder von neuem bezeugt, daB innerhalb einer Gemeinschaft die politischen Wertvorstellungen gegenüber einem konkret geltenden Wahlverfahren sich ändern, und da $B$ diese dann dazu führen, da $B$ Wahlsysteme, die in einer bestimmten historischen Situation die Funktion der Legitimierung gegenüber parlamentarischen Körperschaften besessen haben, diese Kraft und Fähigkeit zur repräsentationserzeugenden Legitimierung einbüßen.

Was nun insbesondere die früher üblichen Beschränkungen des Wahlrechts angeht, so sind diese ebenso wie der klassische repräsentative Parlamentarismus, dem sie seine Entstehung verdanken, letzthin ein Produkt des Liberalismus d.h. der auf Emanzipation des Bürgertums gerichteten Bewegung. Nach dem Grundgedanken dieses politischen Systems sollen die Glieder der parlamentarischen Körperschaften, die auf Grund einer schöpferischen Diskussion und eines freien wechselseitigen Meinungsaustausches Beschlüsse von besonderem, inhaltlichen Werte fassen sollen, auch Träger eines bestimmten personalen Eigenwertes sein. Nach dieser Auffassung soll sich das Parlament aus der Elite, der Aristokratie des Volkes, aus den, wie es bei bekannten liberalistischen Schriftstellern heißt, nicht durch Geburt, sondern durch "Geist, Scharfsinn und Bildung " ausgezeichneten Persönlichkeiten zusammensetzen, die ihrerseits auf die durch sie geführte Gemeinschaft integrierend zurückwirken sollen. In diesem Sinne ist die heute immer wieder erhobene Forderung nach einer Persönlichkeitswahl als einer besonderen Art Führerauslese eine Forderung, die sich tatsächlich institutionell aus dem repräsentativen Parlamentarismus ergibt.

Nach der herrschenden Ideologie des fortschrittlich rechtsstaatlich denkenden Bürgertums dienten nun diese früher üblichen verschiedenartigen Beschränkungen des aktiven und passiven Wahlrechts, vor allem soweit sie plutokratischer oder bildungs- 
mäBiger Natur waren, dazu, um die Staatsbürger, die angeblich einen höheren Wert besaßen als die undifferenzierte Masse der Staatsgenossen, von dieser zu unterscheiden. Durch diese Beschränkungen sollte nach dieser Auffassung rein äußerlich die gröBtmögliche Gewähr für die Wahl tatsächlich nur staatsmännisch begabter, integrierend wirkender Persönlichkeiten gegeben sein.

Sicher ist nun, daB eine parlamentarische Repräsentation des Volkes auf Grund von Bildung und Besitz in der Gegenwart und nicht nur bei uns - nicht möglich ist, und daß die typischliberalistischen Wahlrechtsbeschränkungen heute in einer parlamentarisch repräsentativen Demokratie dazu führen würden, $\mathrm{da} B$ dem konkret geltenden Wahlverfahren der repräsentationsbegründende, legitimierende Charakter abgesprochen werden müßte. Die allgemeine politische Entwicklung, die sich in dem Ubergang vom "Obrigkeitsstaat "zum "Volksstaat " vollzogen hat, spiegelt sich auch in der Geschichte des parlamentarischen Wahlrechts wieder. Ihren Ausdruck findet diese fortschreitende Demokratisierung des Wahlrechts im letzten Jahrhundert in dem ständig sich weiter radikalisierenden, ailgemeinen und gleichen Wahlrecht, das auch äuBerlich noch monarchisch strukturierte Staaten allmählich entscheidend demokratisiert hat.

Ein Irrtum ist es allerdings, zu glauben, als wäre das allgemeine und gleiche Wahlrecht eine Erfindung der modernen Demokratie. In Wirklichkeit gibt es überhaupt nicht einen ein für allemal feststehenden, apriorischen Begriff des allgemeinen und gleichen Wahlrechts ${ }^{5}$ ). Dieses ist vielmehr in seiner konkreten Gestalt von den zeitlich wie räumlich bedingten, sozialen und politischen Verhältnissen abhängig. Auch ein aristokratischplutokratisches Wahlrecht im Sinne der konstitutionellen Monarchie kann möglicherweise allgemein und gleich sein. Entscheidend ist immer, welchen konkreten politischen Gehalt eine Gemeinschaft für eine bestimmte historische Situation mit dem Begriff des allgemeinen und gleichen Wahlrechts verbindet.

Für die moderne, auf die politische Emanzipation der Unterschicht gerichtete Demokratie ist, wie schon früher von Thoma ${ }^{\circ}$ ) klargestellt worden ist, für den Begriff der Wahlrechtsgleichheit eine auf sozialer Motivation beruhende, weitgehende Formalisierung charakteristisch ${ }^{7}$ ). Nur deshalb bezeichnet man so häufig

5) Vgl. etwa auch W. Jellinek, Verfassung und Verwaltung 1927 S. 49; Nevermann, Die Auflösung der Hamburgischen Bürgerschaft 1931, S. 27 f., 68.

-) Erinnerungsgabe für Max Weber 1923 Bd. II S. 39 ff.

7 Dazu die Nachweise in der Jur. Woch. 1929 S. 3042 f.; ferner W. Jellinek, Archiv d. off. Rechts N. F. Bd. 15 S. 111; E. Jacobi in einem ungedruckten Gutachten zur Rechtsgultigkeit d. preuB. Wahlgesetres: Hartmann in der Ehrengabe für den deutschen Juristentag in Labeck 1931 S. $205 \mathrm{f}$. 
- und funktionell gesehen nicht mit Unrecht - die auf dem modernen, allgemeinen und gleichen Wahlrecht beruhende Demokratie als eine Formaldemokratie. Unbeschadet der sozialen Wertverschiedenheit der einzelnen Glieder des Staatsganzen wird in dieser jede Stimme grundsätzlich absolut gleich bewertet. Deshalb ist wohl ein Klassen- und Pluralwahlrecht mit der formalen Wahlrechtsgleichheit unvereinbar, nicht aber etwa der AusschuB der Frauen vom Wahlrecht, weil dieser nicht im erwähnten Sinn sozial motiviert sein würde.

Die formale Struktur der Wahlrechtsgleichheit zeigt sich auch in der üblichen theoretischen Aufspaltung dieses Begriffes, nämlich der Unterscheidung zwischen der Gleichheit und der Allgemeinheit der Wahl ${ }^{8}$ ). Während das Gebot der Gleichheit der Wahl bekanntlich verbieten soll, das Stimmgewicht der zur Wahl zugelassenen Wählermassen willkürlich etwa nach Bildung, Wohnsitz, Klasse, Vermögen $z \mathbf{u}$ differenzieren - in diesem Sinn hat die Weimarer Reichsverfassung die Wahlrechtsgleichheit rezipiert - , soll die Allgemeinheit der Wahl den unberechtigten Ausschluß der Staatsbürger vom Wahlrecht überhaupt verbieten, also etwa den AusschluB bestimmter oder doch jedenfalls bestimmbarer Personen ebenso wie den willkürlich allgemeinen Ausschluß etwa bestimmter Berufsstände, Konfessionen, Volksklassen und Bildungsschichten. In Wirklichkeit gehören die so formalisierten Begriffe der Allgemeinheit und Gleichheit der Wahl zusammen und enthält das Gebot der Allgemeinheit der Wahl nichts anderes wie eine nach bestimmter Richtung hin konkretisierte Forderung der formalen Wahlrechtsgleichheit. Denn ob auf Grund einer sozial unzulässigen Motivation bestimmte Bevölkerungsschichten vom Wahlrecht überhaupt ausgeschlossen oder durch eine Minderbewertung ihres Stimmgewichts schlechter behandelt werden als andere Schichten, ist nicht von sachlich unterscheidender Bedeutung.

Diese formale Wahlrechtsgleichheit widerstreitet an sich bereits der klassischen liberalistischen Grundauffassung vom Wesen des repräsentativen Parlamentarismus, nach dem wesentlich Verschiedenes auch verschieden behandelt werden $\mathrm{muB}^{\mathrm{8a}}$ ). Insofern steht dieser Satz der Wahlrechtsgleich heit auch im Gegensatz zu dem allgemeinen Satz von der Gleichheit vor dem Gesetz, der nicht in dieser Weise radikalisiert ist und in seiner umfassenden Bedeutung noch heute liberalistisch, wenn auch bereits stark sozial affiziertes, rechtsstaatliches Gedankengut enthält.

Hiernach wird auch verständlich, warum mit der fortschreitenden massendemokratischen Formalisierung des allgemeinen

-) Zu diesen Begriffen aus der jüngsten Literatur etwa Pohl, Handbuch d. deutschen Staatsrechtes I (1930) S. $387 \mathrm{f}$;; Wenzel ebenda S. 610.

a) Auf diesen Widerspruch hat auch schon Hasbach. Die moderne Demokratie 1921 S. 287 f. aufmerksam gemacht. 
und gleichen Wahlrechts bereits unter dem Mehrheitswahlsystem die Grundlagen des repräsentativen Parlamentarismus fragwürdig zu werden anfingen. Schon unter diesem Wahlrecht wurde in einem gewissen Sinn die reine Persönlichkeitswahl problematisch und die EntschlieBungsfreiheit der Abgeordneten, die wesensmäßig zum politischen Begriff der Repräsentation gehört, durch die Parteien beengt, wenn nicht aufgehoben. Wie bedroht der repräsentative Parlamentarismus bereits Mitte und Ende des 19. Jahrhunderts war, zeigt vielleicht am deutlichsten der Kampf, der während dieser Zeit in den verschiedenen kontinental europäischen Staaten gegen die Anerkennung und Legalisierung der Parteien geführt und für Preußen-Deutschland von Trie pel ${ }^{8 b}$ ) des näheren jüngst eindrücklichst geschildert worden ist.

Diese Entwicklung ist durch die Einführung des Verhältniswahlrechts entscheidend weiter fortgeführt worden. Dies zeigt sich besonders deutlich bei der Umbildung der allgemeinen Wahlrechtsgrundsätze durch das Verhältniswahlrecht.

Zunächst ist der Grundsatz der Allgemeinheit und Gleichheit der Wahl durch den Proporz noch weiter formalisiert worden. Im Gegensatz zum Mehrheitswahlsystem hat jetzt auch jede Stimme grundsätzlich gleiche Kraft, also nicht nur gleichen Zählwert, sondern auch gleichen Nutz- und Erfolgswert. Allerdings liegt auch dieser weiter formalisierten Wahlrechtsgleichheit auch heute noch letzten Endes eine materiale oder, wenn man will, relative Gleichheit zugrunde $\%$ ). Ihrer Radikalisierung sind auch in der Gegenwart noch gewisse wertbezogene Grenzen gesetzt. Beschränkungen des Wahlrechts, die sich aus der Natur, dem Wesen des Verhältniswahlrechts ergeben oder aus zwingenden staatspolitischen Gründen heraus sachlich vernünftig gerechtfertigt werden können, sind auch heute noch zulässig.

Hiernach hat der Staatsgerichtshof Recht, wenn er in seiner bekannten Rechtsprechung zur Rechtsgültigkeit der einzelnen Landeswahlgesetze ${ }^{\text {an }}$ immer und immer wieder bemerkt hat, daß die Gleichheit im Sinne des Art. 17 RV. " eine erweiterte Bedeutung bekommen hat und "formal gefaßt werden $m u B *^{\text {ob }}$ ).

8b) Staatsverfassung und die politischen Parteien 1988 S. 12 f.; Einzelheiten etwa auch noch bei Treitschke, Politik I (1918) S. $147 \mathrm{f}$.

-) Dies wird vielfach verkannt; z. B. jüngst wiederum von Rosenberg, Art. 17 der Reichsverfassung, Diss. 1930 S. 65 ff. Im Sinne des Textes naher Leibholz, Jur. Woch. 1929 S. 3042 f.; auBer der dort erwahnten Literatur noch Apelt, Archiv d. 8ffentl. Rechts N. F. 18 S. 124 f.

m) Hierzu jetzt die zusammenfassende Ubersicht bei $U_{\mathbf{r}} \mathrm{b}$ ich. Die Entscheidungen des Staatsgerichtshofes uber Wahlgesetze in den Annalen für das Deutsche Reich Bd. 63 (1930) S. 384 ff.

b) Lammers-Simons, Die Rechtsprechung des Staatsgerichtshofes usw. z. B. Bd. I (1929) S. 336, 347, 405 und Bd. II (1930) S. 142. Dazu etwa auch noch Urbich a. a. O. $390 \mathrm{f}$. 
Aber nicht minder Recht hat der Staatsgerichtshof, wenn er in der Folge bemerkt, daB das $\mathrm{MaB}$ der Wahlrechtsgleichheit sich nur im Rahmen des jeweiligen Wahlrechtsganzen bestimmen läßt ${ }^{10}$ ), und wenn er später in tatsächlich sachlicher Abänderung seiner ursprünglichen Stellungnahme in der Entscheidung zur Rechtsgültigkeit des preußischen Landeswahlgesetzes den Wahlgleichheitsbegriff ausdrücklich nicht mehr für einen logisch mathematischen Begriff erklärt, der » für irgendwelche Bewertungen keinen Raum läBt ", sondern für einen Rechtsbegriff, d. h. einen Begriff, in dem wertbezogene "Ubergänge und $\mathrm{Ab}$ stufungen denkbar und möglich " sind ${ }^{11}$ ).

Und ebenso wie die Bestimmungen des preußischen Landeswahlgesetzes für rechtsgültig erachtet werden müssen ${ }^{12}$ ), müssen auch die meisten anderen, auf der gleichen Motivation beruhenden Beschränkungen der Wahlrechtsgleichheit, wiè sie sich etwa im Reich, den deutschen Ländern, den verschiedensten Wahlreformprojekten (insbes. z. B. dem Entwurf des demokratischen Arbeitsausschusses) und in anderen Staaten ${ }^{13}$ ) finden, für zulässig gehalten werden. In diesem Sinne hat auch der österreichische Verfassungsgerichtshof in Anlehnung an die Judikatur des deutschen Staatsgerichtshofs mit Recht die Grundmandatsbestimmung der österreichischen Nationalratswahlordnung für gültig erachtet $\left.{ }^{14}\right)$. II S. 146.

10) Lammers-Simons, Die Rechtsprechung des Staatsgerichtshofs

11) Ausgewahlte Entscheid. des Staatsgerichtshofs f. d. Deutsche Reich usw. herausgegeben von Bumke H. 2 (1930) S. 15.

12) Denn die Beschrankungen dieses Gesetzes halten sich noch winnerhalb der engen Grenzen, die dem Gesetzgeber gezogen sind ... und über deren Innehaltung der Gesetzgeber zu entscheiden hat (năher a. a. O. 15, 16). Diese Entscheidung des Staatsgerichtshofs befindet sich in Ubereinstimmung mit der Entstehungsgeschichte (dazu Koch, Jur. Woch. $1930 \mathrm{~S} .106 \mathrm{f}$ ) wie der Rechtsprechung des preußischen wie des Wahlpräungsgerichtes des Reiches (dazu RuPr. V. Bl. Bd. 51 S. 106 u. Jur. Woch. 1930 S. 1253 f.). Auch die entsprechenden Bestimmangen des preuBischen Wahlgesetzes für die Provinziallandtage und Kreistage v. 7. Oktober 1925 sind vom Staatsgerichtshof am 21. Nov. 1930 für verfassungsmäßig erkdart worden; vgl. RGE. in ZS. Bd. 130 Anhang S. $9 \mathrm{ff} .17 \mathrm{ff}$.

18) Belege bei Braunias, Rechtsgleichheit und Staatspolitik in Zeitschrift f. Politik Bd. 19 S. 476 ff.

16) Ebenso Seipel in Das neue Reich Bd. 13 (1930) S. 179 . Insbesondere zu den Entscheidungen des Verfassungsgerichtshofes auf Grund der Beschwerden des Landbundes für Österreich und der dentschen nationalsozialistischen Arbeiterpartei Kier, Grundmandat und Splitterpartei i. Zeitschrift f. off. Recht Bd. XI H. 2 S. 279 ff., der im Gegensatz zum Verfassungsgerichtshof allerdings einschrankende Bestimmungen gegen die Splitterparteien nur insoweit für rechtsgultig erklart, als sie den rein mathematischen Wahlquotienten oder den Pernoletschen Quotienten (Zahl der Wahlberechtigten dividiert durch die Zahl der Abgeordneten) zur Grundlage haben. 
Eine Frage für sich ist dagegen bereits z. B., ob die vom bayrischen Staatsgerichtshof ${ }^{15}$ ), wenn auch unter Vorbehalt für gültig erachteten Bestimmungen des bayrischen Landeswahlgesetzes, nach denen die Einwohnerzahl und nicht die Zahl der Wahlberechtigten für die Zahl der im einzelnen Wahlkreis zu wählenden Abgeordneten maßgebend ist, verfassungsrechtlich bedenkenfrei sind. Denn durch diese Wahlkreisgeometrie wird und zwar ohne zwingenden Grund oder, wie der Reichsstaatsgerichtshof sagen würde, ohne "wirklich dringendes Bedürfnis" ein verstecktes, das Stimmgewicht differenzierendes Pluralwahlrecht geschaffen, indem einem Wahlkreis mit einer geringen Anzahl Wahlberechtigter der gleiche Einfluß eingeräumt wird wie einem Wahlkreis mit verhältnismäBig viel Wahlberechtigten $\left.{ }^{16}\right)$. Aus dem gleichen Grunde würde eine etwaige Proportionalisierung der vorrevolutionären Wahlkreiseinteilung unzulässig sein, der schließlich weder die Einerzahl noch die Zahl der Wahlberechtigten, sondern objektiv gesehen die reine Willkür zugrundegelegen hat und bestehen gegen den $\S 21$ des letzten offiziellen Entwurfes des Reichsinnenministeriums, der zum Teil zu groben Mißständen führen würde, erhebliche verfassungsrechtliche Bedenken.

Auch der Grundsatz der Unmittelbarkeit der Wahl erfährt durch das Verhältniswahlrecht einen grundlegenden Wandel. In der Regel pflegt man allerdings zu sagen, daß dieser Grundsatz bei uns, insbesondere durch die parteimäßig gebundene Kandidatennominierung wie durch das Reststimmenverwertungsverfahren, in verfassungsrechtlich zulässiger Weise modifiziert worden ist ${ }^{17}$ ). Dies ist indessen nicht richtig. Es gibt nicht modifiziert unmittelbare, sondern in Wirklichkeit nur unmittelbare oder mittelbare Wahlen. Und tatsächlich ist die Wahl heute bei uns - das hat schon sehr richtig die der Nationalversammlung zugeleitete Regierungsvorlage zum heutigen Reichswahlgesetz bemerkt - durch die Verhältniswahl im Sinne des Art. 17 RV. zu einer mittelbaren Wahl geworden ${ }^{172}$ ). Von einer solchen

15) Bayerische Verwaltungsblatter Bd. 78 (1930) S. $90 \mathrm{f}$.

10) Zahlenbelege bei Schauff, Neues Wahlrecht 1929 S. 223 f; vgl. auch Urbich, Annalen des Deutschen Reiches Bd. $63 \mathrm{~S}$. $398 \mathrm{f}$. Ob dabei die Chancen für die einzelnen Parteien in den Wablkreisen an sich die gleichen sind (so Lent, Bayer. Verwaltungsblatter $1930 \mathrm{~S}$. $184 \mathrm{f}$.), ist demgegenüber unerheblich. Mit diesem Hinweis könnten auch die gröbsten VerstöBe gegen eine gerechte Wahlkreisgeometrie als mit dem Begriff der Wahlgleichheit vereinbar bezeichnet werden.

17) Aus der Rechtsprechung z. B. Lammers-Simons, Die Rechtsprechung des Staatsgerichtshofes Bd. I S. 328, 329 und ausgew. Entscheid. d. StGH. 8. a. O. 13; ferner der bayrische Staatsgerichtshof in Gesetz u. Verordnungsblatt f. d. Freistaat Bayern 1930 S. 87.

17a) $\mathrm{Zu}$ dieser Feststellung bedarf es nicht der Annahme eines besonderen Bedeutungswandels, wie v. Jan, Bayr. Verwaltungsblatter. Bd. 79 
muB man nämlich nicht nur dann sprechen, wie dies bei uns auf Grund historischer Erfahrungen meist geschieht, wenn zwei förmliche Wahlgänge stattfinden, ein Wahlgang, bei dem die Wähler die Wahlmänner und ein zweiter Wahlgang, bei dem die Wahlmänner die Abgeordneten wählen, sondern schon dann, wenn der Aktivbürgerschaft die Möglichkeit genommen ist, die zukünftigen Abgeordneten selbsttätig zu bestimmen. Man hat nicht ganz mit Unrecht das heutige, oligarchisch organisierte, monopolartige Benennungsrecht der Parteien, das geradezu zu einem Kooptationsrecht wird, wenn diese die Kandidaten an sicherer Stelle placieren, als ein lediglich die übliche Reihenfolge der mittelbaren Wahl umkehrendes Wahlsystem bezeichnet ${ }^{18}$ ), bei dem üblicherweise der zu zweit vorgenommene Wahlakt zuerst und zwar in den Delegiertenversammlungen der Parteien stattfindet.

$\mathrm{Ob}$ die einzelnen Wahlbewerber dabei wie in der Regel vor der Wahl oder wie z. B. nach der früheren Bestimmung des bayrischen Landeswahlgesetzes nach der Wahl als sogenannte Landesabgeordnete von den Parteien benannt werden, ist sachlich nicht von entscheidender Bedeutung. Der Entscheidung des bayrischen Staatsgerichtshofes, in der allein ein solch nachträgliches Benennungsrecht als mit dem Grundsatz der Unmittelbarkeit der Wahl unvereinbar bezeichnet wurde, ist daher mit Recht entgegengehalten worden, da $B$ es bei der Frage - ob Unmittelbarkeit oder Mittelbarkeit der Wahl - nicht entscheidend auf den zufälligen Zeitpunkt abgestellt werden könne, in dem die Parteien ihr Nominationsrecht ausüben ${ }^{19}$ ). Bei den auf der Reichs- oder Landeswahlliste $\mathrm{zu}$ wählenden Kandidaten sowie etwa der nachträglichen Benennung der Atgeordneten durch die Parteien tritt die Zurückdrängung des unmittelbaren Einflusses der Aktivbürgerschaft in Wirklichkeit nur besonders deutlich in Erscheinung.

Nur so wird auch verständlich, warum heute in so weiten Kreisen gerade die Aufhebung der Unmittelbarkeit der Wahl beklagt und die Forderung nach Wiederherstellung eines unmittelbar persönlichen Vertrauensverhältnisses zwischen Ab-

(1931) S. 114 offenbar will. Zur grundsātzlichen Unvereinbarkeit der Unmittelbarkeit der Wahl und der Verhaltniswahl auch schon Pfister, Verhăltniswahl ohne Wahlvorschläge i. d. Annalen des Deutschen Reiches 1918 Sep. Abdruck S. $15 \mathrm{ff}$.

10) Pfister, Zeitschr. f. öff. Recht Bd. VIII (1929) S. 200; im gleichen Sinn etwa auch Mierendorff in Schauff, Neues Wahlrecht S. 19. Naher über das gesamte Nominationsverfahren, vor allem den Nominationsakt selbst und dessen Verbindung mit den allgemeinen Wahlrechtsgrundsatzen jetzt noch Hartmann. Die politische Partei in der tschechoslowakischen Republik 1931 S. 141 ff.

10) v. Jan, Bayer. Verwaltungsblatter Bd. 78 (1930) S. 67. 
geordneten und Wähler erhoben wird. Hat doch diese Forderung dazu geführt, daß verschiedene Wahlreformprojekte, darunter auch der letzte amtliche Entwurf, die Aufhebung der Reichsliste oder sogar darüber hinaus des ganzen Listenwahlsystems empfohlen haben.

Diese strukturellen Veränderungen der Wahlrechtsgrundsätze durch den Proporz sind nur Auswirkungen des Grundgedankens des Verhältniswahlrechts überhaupt. Beim Mehrheitswahlsystem soll, wie bekannt ist, der Wahlakt das Volk unmittelbar in die Lage versetzen, in freier schöpferischer Willensbildung nach Möglichkeit von den Parteien unabhängige, politische Persönlichkeiten zu wählen ${ }^{20}$ ). Durch diesen wirklichen Kampf um die politische Führung erhält das Mehrheitswahlsystem den ihm eigenen, lebendigen, höchstpersönlichen Charakter und der Wahlakt, wie Smend sagt, seine besondere, schöpferisch dialektische Funktion ${ }^{21}$ ). Bei dem Verhältniswahlsystem kommt es dagegen nicht auf Sieg und Kampf, sondern allein entscheidend auf die zahlenmäßig exakte und damit gerechte Erfassung der Stimmen der Aktivbürgerschaft an ${ }^{22}$ ). Je besser das Rechenverfahren, um so vollendeter das Verhältniswahlsystem. Georg Meyer hat aus diesem Grunde nicht ganz mit Unrecht schon 1901 das Verhältniswahlrecht mehr als ein Wahlrecht der Mathematiker als der Politiker bezeichnet ${ }^{23}$ ). Und durch dieses Streben erhält der Proporz die ihm eigene, rational unpersönliche Struktur, von der alle Einrichtungen, die vom Proporz ergriffen werden, affiziert werden. Dies wirkt sich hin bis zur Wahlprüfung aus, von der jüngst mit Recht bemerkt

20) Der Grundsatz der Unmittelbarkeit der Wahl gehört, wie gegenüber Nawiasky, Archiv d. off. Rechts N. F. Bd. 20 S. 170 f., insbes. S. 173 bemerkt werden mu日, wesensmaßig zur Persönlichkeitswahl des Mehrheitswahlsystems.

21) Demgegenüber liegt die Frage nach der Gerechtigkeit des Wahlergebnisses auf einer ganz anderen Ebene. Vgl. auch GeBler, Die Trager der Reichsgewalt 1931 S. 62. Deshalb kann auch gegen das Mehrheitswahlsystem aus der Tatsache, daB dasselbe zu einem versteckten Pluralwahlrecht der raumlich massierten Parteien oder wie z. B. bei den französischen Arrondissementswahlen dazu führt, daB nur $50 \%$ der ihr Wahlrecht ausübenden Bürgerschaft durch die Abgeordneten rechrerisch erfaBt werden, kein entscheidender Einwand hergeleitet werden. Beim relativen Mehrheitswahlsystem erlangt im übrigen sogar nicht selten eine absolute Minderheit die absolute Mehrheit der Parlamentssitze. In England, dessen Wahlsystem Loyd George gelegentlich mit dem Roulettespiel von Monte Carlo verglichen hat, hatten z. B. 1924 die Konservativen nur $48 \%$ der Gesamtstimmen, aber doch $66 \%$ aller Mandate auf sich vereinigt.

in) So auch Kelsen, Vom Wesen und Wert der Demokratie 2. Aufl. 1929 S. $58 \mathrm{f}$. Zuvor schon im gleichen Sinne aus der Fülle der Literatur etwa v. Recklinghausen, Zeitschrift f. Politik Bd. XI (1918) S. 82. 2) Wahlrecht a. a. O. 648 . 
worden ist $\left.{ }^{24}\right), \mathrm{da} B$ diese heute, gleichgültig ob zur Ausübung der Wahlprüfung Gerichte oder parlamentarische Körperschaften berufen sind; fast vollständig ihren früheren politischen Charakter verloren hat und eine im wesentlichen technische, also unpolitische Tätigkeit geworden ist.

Kurzum, das Verhältniswahlsystem erfüllt nicht mehr wie das Mehrheitswahlsystem im repräsentativen Parlamentarismus repräsentationsbegründende oder, wie Smend ${ }^{25}$ ) sagt, integrierende, sondern nur noch - und hierin zeigt sich der grundlegende inhaltliche Bedeutungswandel der Wahl, auf den auch $\mathrm{C}$. Schmit t aufmerksam macht - rechenmäBig statistische Funktionen $\left.{ }^{26}\right)$. Der Wahlakt führt nicht mehr wie beim Mehrheitswahlsystem zur Überwindung der im Volke vorhandenen Gegensătze, sondern lediglich zur Offenbarung ihrer zahlenmäßigen Stärke $\left.{ }^{27}\right)$. Er ist in Wahrheit heute eine Heerschau, eine Bestandsaufnahme der in Parteien zusammengefaßten Aktivbürgerschaft, aber nicht mehr eine wirkliche "Wahl $\left.{ }^{28}\right)$; diese wäre an sich überhaupt entbehrlich, wenn die gesamte Aktivbürgerschaft, wie es vom Parteienstaat an sich vorausgesetzt wird, an die politischen Parteien organisationsmäßig gebunden sein oder sich doch jedenfalls an diese gebunden fühlen würde. Solange dieser im Sinne des Parteienstaates ideale Status nicht zu verwirklichen ist und er ist nicht zu verwirklichen, da die Aktivbürgerschaft in jedem Parteienstaat nur zu einem geringen Prozentsatz, bei uns z. B. nur zu knapp 10\%, organisiert ist -, haben die Wahlen außer den rein statistischen Funktionen noch die weitere, die nicht organisierte Wählerschaft, die an sich organisiert sein sollte, zum politischen Bekenntnis im Sinne des Parteienstaates zu zwingen. Nur um die nichtorganisierte und sich nicht gebunden fühlende Wählerschaft geht heute eigentlich der Wahlkampf, der insoweit, wie schon sehr richtig Carl Schmitt bemerkt hat, in Wirklichkeit ein rein plebiszitärer, d.h. der unmittelbaren Demokratie zugehöriger Vorgang ist. Wenn dieser Wahlkampf im Gegensatz zu seiner wesensmäßigen Tendenz und auch den Erfahrungen des letzten Jahrzehntes wiederum heute bei uns einen so intensiven Spannungsgrad erreicht, so liegt dies allein an der abnormen S. $207 \mathrm{ff}$.

24) Ball, Das materielle Wahlprafungsrecht 1931 insbesondere

$\left.{ }^{25}\right)$ Verfassung und Verfassungsrecht 1928 S. 91.

2) C. Schmitt (Der Hüter der Verfassung 1931 S. 87; vgl. anch schon D. Jur. Zeit. 1931 Sp. 10) spricht in diesem Sinne schon von dem Wahlakt als veiner statistischen Gruppierang und Aufteilung der Wahlermassen nach einer Mehrzahl von Parteilistenk.

$\left.{ }^{27}\right)$ Dazu auch Hula, Zeitschrift f. off. Recht Bd. VI S. 224; Kelsen, Demolratie S. 69; E. Kaufmann, Zur Problematik des Volkswillens 1931 S. $17 \mathrm{f}$.

$\left.{ }^{28}\right)$ Vgl. etwa auch Wieser, Gesetz der Macht S. 60. 
Gegenwartssituation, die ihre besonderen bekannten Ursachen hat, und die dem plebiszitären Unsicherheitsfaktor, der sich aus der mangeinden parteimäBigen Organisierung der Aktivbürgerschaft ergibt, sein über das normale $\mathrm{MaB}$ hinausgehendes, besonderes Gewicht leiht. Diese Tatsache darf aber nicht darüber hinwegtäuschen, daß diese Spannung eine im Grunde genommen mehr zufällige und nicht zwangsläufig bedingte ist wie beim Mehrheitswahlsystem ${ }^{29}$ ).

Tatsächlich sind die angedeuteten strukturellen Verschiedenheiten zwischen Mehrheits- und Verhältniswahlsystem letzten Endes nichts anderes wie der äußere Ausdruck des Gegensatzes von repräsentativem Parlamentarismus, der demokratisch sein kann, aber - man denke etwa an die konstitutionelle Monarchie nicht sein muB, und des modernen massendemokratischen Parteienstaats, der, sofern nicht diktaturförmig regiert wird, die Ausdrucksform des politischen Lebens der Gegenwart ist. Das Verhältniswahlrecht, dessen Einführung, wie schon Thoma bemerkt, im Sinne des konsequenten oder besser radikalen und nicht liberal egalitären Demokratismus gelegen hat, ist nur das dem modernen Parteienstaat entsprechende Wahlrecht. Dieses setzt den Bestand der politischen Parteien, die in den großen Flächenstaaten allein die Möglichkeit haben, die Massen zu politisch aktionsfähigen Gruppen zusammenzuschließen, als zulässige Organisationen voraus und verlangt die schon vielfach literarisch (und zwar aus den verschiedensten Gründen) geforderte Legalisierung der politischen Partei ${ }^{30}$ ). Und weiter ist es nur folgerichtig, daß in einem so strukturierten Gemeinwesen die Parteien und - von ihnen abhängig - die Fraktionen auch im Sinne der in ihnen zusammengeschlossenen Aktivbürgerschaft auf den Staat zu wirken und dabei den Abgeordneten die Möglichkeit zu nehmen suchen, im Sinne des repräsentativen Parlamentarismus noch selbsttätig politische Entscheidungen zu treffen ${ }^{\mathrm{II}}$ ). Das Parlament kann eben auch die Stätte sein, wo nicht im Sinne des repräsentativen Parlamentarismus, sondern des massendemokratischen Parteienstaates - nicht auf Grund der Repräsentation, sondern der Identität - die volonté générale der Gemeinschaft gebildet wird. Damit ist zugleich die Korrekturbedürftigkeit des üblichen Einteilungsschemas unmittelbare-mittelbare Demokratie dargetan. Der Parteienstaat ist im Sinne dieses Schemas

25) Daher nicht richtig Nawiasky, Archiv d. 6ff. Rechts N. F. 20 S. 188, der die These von der durch den Proporz bedingten Entleerung des politischen Kampfes durch die gegenwătigen Spannungen für widerlegt betrachtet.

(o) Statt vieler 2. B. Kelsen, Allgemeine Staatslehre 1925 S. 351 und Radbruch, Handbuch des deutschen Staatsrechts I (1930) S. 289 f., 294.

a) Dazu naher meine Reprasentation etwa $S$. $117 \mathrm{ff}$. und jetrt noch das dritte Kapitel von Hartmann, Die politische Partei S. 159 ff. 
mittelbare Demokratie und doch in Wahrheit eine Demokratie, die strukturell der unmittelbaren Demokratie verwandt und daher systematisch wie verfassungstheoretisch bei dieser zu behandeln ist.

Ist das Verhältniswahlrecht nur Ausdruck des Strukturwandels der Demokratie von der repräsentativ-parlamentarischen zur parteienstaatlichen Massendemokratie, so kann das Verhältniswahlrecht mit Recht als demokratiezerstörend nur insoweit bezeichnet werden, als unter Demokratie die parlamentarisch-repräsentative, nicht aber die parteienstaatliche Massendemokratie verstanden wird ${ }^{32}$ ). Auch entspricht dieser Entwicklung nur, da $B$ in steigendem MaBe, vor allem seit Ende des letzten und Anfang dieses Jahrhunderts, insbesondere nach dem Kriege, die europäischen Demokratien, wenn auch in verschiedenen Formen, das Verhältniswahlsystem eingeführt und überwiegend trotz im einzelnen auch rückläufiger Bewegungen und Korrekturen ${ }^{33}$ ) - ebenso wie im übrigen auch grundsätzlich der letzte amtliche Wahlreformentwurf - an diesem Wahlrecht festgehalten haben ${ }^{34}$ ).

In der Weimarer RV. selbst kommt diese ganze Entwicklung zum massendemokratischen Parteienstaat ebenso wie in vielen anderen Verfassungen nur in der Einführung der Verhältniswahl selbst zum Ausdruck, während im übrigen in den wichtigsten Bestimmungen an dem klassischen säkularen Bekenntnis zum repräsentativen Parlamentarismus festgehalten wird. So ergibt sich der innere, auch durch eine andere konstruktive Deutung des Art. 21 RV. nicht $\mathrm{zu}$ behebende, im übrigen bereits mehrfach, insbesondere in der Nationalversammlung von Naumann bemerkte Widerspruch ${ }^{25}$ ), da $\mathrm{B}$ die Reichsverfassung das massendemokratische Verhältniswahlrecht und den klassischen reprä-

a) Dies wird hăufig übersehen; 2. B. bei Teipel in Schauff, Neues Wahlrecht S. 10.

33) Hierzu Bra unias, Zeitschr. f. Politik Bd. 17 S. 59 f., Bd. 20 S. 115 f.

u) Auch in Frankreich sind trotz des zum sscrutin uninominal zurúckkehrenden Gesetzes v. 21. Juli 1927 die Reformbestrebungen zugunsten der Einführung des reinen Proportionalsystems allgemein (auf der Rechten wie der Linken) so stark, daB nach Sche uner, Jahrbuch d. 8ffentl. Rechtes Bd. 19 (1931) S. 151 ^die Möglichkeit einer Änderung des Wahlrechts noch vor den Wahlen von 1932 nicht ausgeschlossen ist. - Für die Einführung des bei uns von vielen (z. B. Gerland, D. Jur. Zeit. Bd. 33 (1928) Sp. 759 ff.) propagierten Mehrheitswahlsystems entfallt nach der aufgezeigten Entworzelung des reprasentativen Parlamentarismus verfassungstheoretisch die innere Berechtigung.

w) Dazu Naumann, Beratungen des Verfassungsausschusses d. Nationalversammlung S. 242; G. Meyer, Wahlrecht 642; Pfister, Zeitschr. f. off. Recht Bd. VIII S. 188/189; Heuss, Zeitschr. f. Politik Bd. 20 S. 314; Hula, Zeitschr. f. off. Recht XI (1931) S. 368 f. In der gleichen Richtung auch die Darstellung von GeBler, Träger der Reichsgewalt S.34 ff., insbes. S. 66. 
sentativen Parlamentarismus nebeneinanderstellt $\left.{ }^{36}\right)$. - Dieses Festhalten an den repräsentativ-parlamentarischen Grundlagen vermag fernerhin auch erst den Einbau der plebiszitären Einrichtungen (wie Volksbegehren und Volksentscheid) durch die Verfassung zu rechtfertigen, für die in Wirklichkeit nach dem Strukturwandel der Demokratie kein Raum mehr ist. Denn für die parteienstaatliche Massendemokratie als das Surrogat der unmittelbaren Demokratie im Flächenstaat ist, sofern die Aktivbürgerschaft nicht im Sinne des Parteienstaates an die Parteien gebunden ist und diese damit unter die Kontrolle eines täglichen Plebiszits stellt, der Wahlakt der plebiszitäre, beliebig wiederholbare Akt, neben dem für sonstige plebiszitäre ÄuBerụngen, wie die politische Entwicklung in England in klas-

36) Uber verschiedene literarische Versuche, die in der Richtung gehalten sind, durch eine andere Interpretation des Art. $21 \mathrm{RV}$. diesen Widerspruch zu beheben, meine Reprasentation S. $106 \mathrm{ff}$. Nach dem jüngsten, in der deutschen Literatur von Radbruch, Handbuch d. deutschen Staatsrechts I (1930) S. 292 f. unternommenen Versuch, die politische Wirklichkeit gewordene, parteienstaatliche Massendemokratie mit Art. 21 RV. zu versobhnen, soll der einzelne Abgeordnete, der im Interesse der Parteidisziplin das personnliche Opfer seiner Uberzeugung bringt, trotzdem unur seinem Gewissen unterworfen und an Auftrage nicht gebunden" sein, wenn wein Handeln nicht durch den Auftrag seiner Partei motiviert ist, sondern durch die Gewissenspflicht, um der Gesamtaufgabe der Partei willen ... einen kleineren Schaden in Kauf zu nehmen *. Hierdurch soll der tatsachlich unfreie zum rechtlich angeblich freien Abgeordneten im Sinne des Art. 21 RV werden. Auch der weitere Hinweis, daB der Abgeordnete trotz seiner engen Parteiangehorigkeit sich nicht als Beauftragter lokaler, beruflicher, nationaler, religiőser Bruchteile des Volkes fühlen darf ist rein psychologistisch und konstruktiv, da der Abgeordnete auch einer großen Partei doch in Wirklichkeit lediglich - und dies entspricht auch nur den Forderungen parteienstaatlicher Massendemokratie - das Sprachrohr der ihn kreierenden Wahlerschaft ist, die doch stets irgendwie nur einen beruflichen, nationalen, religiősen Bruchteil des Volkes darstellen wird. Denn auch die Partei nimmt schlieBlich doch nur die bestenfalls gesamtheitsbezogenen Interessen des in ibr organisierten Bruchteils der Aktivbürgerschaft wahr. Wenn nach alledem der Abgeordnete, der lediglich im Rahmen der Gesamtaufgabe seiner Partei tatig, also tatsachlich unfrei ist, im Sinne des Art. 21 freir sein soll, so vermag Radbruch selbst diesem circulus nur durch die Einführung des sunechten. Parteibegriffs zu entgehen, um damit aber zugleich den Relativismus preiszugeben, den er gleich Kelsen - wenn auch zu Unrecht (hierzu jetzt Kottgen Blatter für deutsche Philosophie Bd. V H. 2/3 (1931) S. 195 f.) - als die Weltanschauung der Demokratie bezeichnet. Denn wie soll man von einer relativistischen Grundhaltung zu einem absoluten Urteil uber die Echtheit oder Unechtheit der Partei gelangen? In Wirklichkeit zeigt auch diese Konstruktion, da $\beta$ es unmöglich ist, einer institutionell eindeutig festgelegten Bestimmung einen ihr sachfremden, wenn auch an der politischen Wirklichkeit orientierten Inhalt zu geben.

Uber in der gleichen Richtung liegende Versuche, in der Tschechoslowakei die entsprechende Verfassungsbestimmung der Wirklichkeit anzupassen, auch Hartmann, Die politische Partei, S. $246 \mathrm{ff}$. 
sischer Deutlichkeit zeigt, die innere sachliche Berechtigung fehlt ${ }^{362}$ ).

Die gekennzeichnete strukturmäßige Gegensätzlichkeit von massendemokratischem Parteienstaat und Verhältniswahlsystem auf der einen Seite, von repräsentativem Parlamentarismus und Mehrheitswahlsystem auf der anderen Seite macht endlich erst verständlich, warum Verhältnis- und Mehrheitswahlsystem sich letzten Endes gegenseitig ausschlieBen, und warum man nicht, ohne sich in Widersprüche zu verwickeln, die Proportionalwahl im Ergebnis wollen und sich der Formen der Mehrheitswahl bedienen kann und umgekehrt ${ }^{37}$ ). Es ist kein Zufall, daB die zahlreichen Versuche, die bei uns in den letzten Jahren im Gefolge der Wahlreformbewegung gemacht worden sind, um die Verhältniswahl unter Beseitigung des als schwer erträglich empfundenen Listenwahlsystems mit der Einwahl des Mehrheitswahlsystems zu kombinieren ${ }^{38}$ ), dieses Ziel nicht erreicht haben. Es ergibt sich nämlich - dies zeigt die Anlage zu dem letzten amtlichen Wahlreformentwurf ganz deutlich - da $B$ man, will man im Rahmen des automatischen Verhältniswahlsystem oder außerhalb desselben die Verhältniswahl im Einzelwahlkreis durchführen, den Grundgedanken des Einer- und Mehrheitswahlsystems verfälschen muß, indem man einzelne Wahlkreise mehrfach, andere dagegen garnicht vertreten sein läßt. Zu dieser Art Wahlreformvorschlägen gehören systematisch trotz erheblicher Verschiedenheiten im einzelnen aus der jüngsten Zeit ${ }^{38 a}$ ) etwa die Vorschläge von Erdmannsdörfer ${ }^{39}$ ), v. Hippel ${ }^{40}$ ), Kaisenberg ${ }^{41}$ ), Klöcker ${ }^{42}$ ) $\mathrm{Külz}{ }^{43}$ ) und Kelsen ${ }^{44}$ ) sowie des demokratischen Arbeitsausschusses. Zu einem im wesentlichen gleichen Ergebnis gelangt man aber auch dann, wenn man die einzelnen Wahlkreise nicht

362) Vgl. auch Mirkine-Guetzévitch, Les nouvelles Tendances du Droit Constitutionnel 1981 S. 151 f. und Le Referendum et le Parlamentarisme dans les nouvelles Constitutions i. d. Rapports $f$. d. Institut International de Droit public $1930 \mathrm{~S} .31 \mathrm{f}$.

37) In diesem Sinne etwa schon v. Campe, Deutsche Stimmen 1929 S. 1 f.; Entwurf eines Reichswahlgesetzes 1930 S. 29. Vgl. auch Schauff, Neues Wahlrecht S. 202 ff.

38) Die năheren literarischen Nachweise der verschiedenen Wahlreformvorschläge bei Kaisenberg, Zeitschrift f. d. gesamte Staatswissenschaft Bd. 90 (1931) insbesondere S. $461 \mathrm{f}$.

s8a) Aus der Vorkriegszeit vgl. z. B. Kantorowicz, Zeitschrift für Politik Bd. III (1909) S. 663 f.

30) Zeitschrift für Politik Bd. $20 \mathrm{~S} .174 \mathrm{f}$.

10) D. Jur. Zeit. Bd. 32 (1927) Sp. $1511 \mathrm{f}$.

1) Handwörterbuch d. Rechtswissenschaft Bd. 5 (1928) S. 61.

42) Germania Nr. 506 vom 6. Dezember 1928; zur Kritik Anlage zum Entwurf d. Reichsinnenministeriums S. $24 \mathrm{ff}$.

4) Juristische Rundschau 1928 S. 1 f.

M) Z. B. Frankfurter Zeitung vom 8. September 1930; dazu naher Fleischer, Osterreichische Wahlreform 1928 S. $12 \mathrm{ff}$. 
im eben erwähnten Sinne als Stimmsammelbezirke, sondern die auf die Einzelwahlkreise entfallenden Abgeordneten im Sinne des Mehrheitswahlsystems tatsächlich als gewählt betrachtet. Denn auch dann muB, wie dies auch in jüngster Zeit etwa in den Vorschlägen von Heile ${ }^{45}$ ) und W. Jellinek ${ }^{46}$ ) geschehen ist um die Verhältnismäßigkeit des Gesamtergebnisses zu sichern, nachträglich eine Korrektur desselben durch Kürzung der zu stark und durch Ergänzung der zu schwach vertretenen Parteien vorgenommen werden ${ }^{47}$ ). Die Tatsache einer mehrfachen Vertretung eines Wahlkreises u. a. auch durch Abgeordnete, die nicht einmal Höchstzahlen zu erreichen brauchen, bleibt sogar dann bestehen, wenn man im Rahmen der Einerwahl die nachträgliche Berichtigung auf die Ergänzung beschränken und von der Kürzung ganz absehen würde, indem man etwa den von Jellinek verbesserten Heileschen Vorschlag zugrundelegt, nach dem 75\% der Abgeordneten in Einzelwahlkreisen fest gewählt und $25 \%$ der Kandidaten nachträglich den Parteien zur ergänzenden Verteilung vorbehalten werden ${ }^{48}$ ) oder etwa diese Kandidaten einer von den Parteien aufgestellten Reichsliste entnimmt ${ }^{9}$ ). Dabei sei im übrigen bemerkt, daB man, um die Verhältnismäßigkeit der Wahl zu wahren, der Zahl der Ergänzungskandidaten nicht die Reichstagswahlen der siebziger und achtziger Jahre, sondern die heutigen Verhältnisse zugrundelegen muß und dementsprechend den Prozentsatz der Ergänzungsmandate auf $\mathbf{5 0 \%}$, wenn nicht $\mathbf{7 5 \%}$ der Gesamtzahl erhöhen müßte.

Ebensowenig wie man die Einerwahl des Mehrheitswahlsystems im Rahmen der Verhältniswahl verwirklichen kann,

45) Frankfurter Zeitung vom 29. Januar 1926; zur Kritik Anlage zum Entwurf d. Reichsinnenministeriums S. $4 \mathrm{f}$., $15 \mathrm{f}$.

16) Archiv d. off. Rechts N. F. Bd. 11 S. $71 \mathrm{ff}$.

17) Ein solches Verfahren hat wiederum seine besonderen Mißstande, auf deren Milderung eigens eine Reihe von Vorschlagen hinzielt. Hierher gehorren vor allem die Vorschlage Jellineks, nach denen nur Wahlbewerber, die die zweithöchste Stimmenzahl im Wahllereis auf sich vereinigt haben, bei dem nachträglichen Kürzungs- und Berichtigungsverfahren berücksichtigt werden sollen und im Sinne eines Ringtausches eine dritte Partei, die - selbst weder kürzungspflichtig noch erganzungsberechtigt - in das Berichtigungsverfahren möglicherweise eingeschaltet werden soll. $\mathrm{Zu}$ den besonderen, die praktische Verwirklichung dieser Vorschlage ausschließenden Mangeln wiederum naher die Anlage der Denkschrift des Reichsinnenministeriums.

4) In der gleichen Richtung bewegt sich etwa der Vorschlag von Bornemann, Zeitschrift für Politik Bd. 20 (1930) S. $43 \mathrm{f}$. und aus der früheren Wahlrechtsliteratur der Vorschlag von Geyerhahn, Das Problem der verhaltnismabigen Vertretung $1902 \mathrm{~S}$. $12 \mathrm{ff}$.

4) So R. Schmidt, Verhaltniswahl und Führerauslese 1928 (Kieler Dissert.) S. $75 \mathrm{ff}$. und in Schauf, Neues Wahlrecht S. $181 \mathrm{ff}$. 
kann man etwa mit dem bayrischen Staatsgerichtshof ${ }^{50}$ ) die Wahlrechtsgrundsätze der Allgemeinheit, Gleichheit und Unmittelbarkeit in der ihnen durch das Mehrheitswahlsystem gegebenen traditionellen Gestalt selbständig und unverändert neben das Verhältniswahlrecht stellen. Denn dies würde nicht, wie der bayerische Staatsgerichtshof meint, eine Kombinierung von Mehrheits- und Verhältniswahl bedeuten, sondern - weil das Wahlsystem als konkretes Ganzes eine Einheit ist - auf eine nach der Verfassung nicht zulässige Modifizierung des Proporzes, auf dem nach der Intention des Grundgesetzes der entscheidende Akzent liegen soll, zugunsten des Mehrheitswahlsystems hinauslaufen.

Die Erschütterung des repräsentativen Parlamentarismus in der Gegenwart geht aber nicht ausschlieBlich auf diese Entwicklung zum massendemokratischen Parteienstaat zurück. Vielmehr läuft daneben noch eine andere Entwicklung, die für den repräsentativen Parlamentarismus ebenfalls von schicksalhafter Bedeutung geworden ist. Damit meine ich die nachhaltigen Einwirkungen, die die moderne kapitalistische Wirtschaftsordnung und ihre Gegebenheiten auf den Staat und die politische Wirklichkeit ausüben.

Schon vor dem Kriege ist von Smend in Anknüpfung an Lorenz von Stein, die französischen Sozialisten und letzten Endes Hegel klargestellt worden, wie die an sich außerhalb des Staates stehenden, gesellschaftlichen $d . h$. vor allem klassenmäBig bestimmten Kräfte auf den Staat einzuwirken und sich desselben zur Durchsetzung ihrer besonderen wirtschaftlichen Interessen zu bedienen suchen. Von dem modernen politischen Wahlrecht und dem Parlament gilt dies in einem besonderen Maße. Im Parlament vor allem kommt seit vielen Jahrzehnten der Kampf zwischen dem politisch akzentuierten citoyen und dem allein wirtschaftlich interessierten unpolitischen Individuum zum Ausdruck. Das Parlament ist so schon in der Vorkriegszeit nach einem Ausdruck Smends zum Zwischenbau von Staat und Gesellschaft geworden ${ }^{\text {som }}$ ).

50) Bayerische Verwaltungsblatter Bd. 78 (1930) S. $89 \mathrm{f}$. und Lent ebenda S. $177 \mathrm{f}$. insbesondere 181 . Der bayerische Staatsgerichtshof befindet sich hiermit im Widerspruch zur Rechtsprechung des Reichsstaatsgerichtshofes. Vgl. z. B. RGE. in ZS. Bd. $128 \mathrm{~S}$. $11 \mathrm{f}$.

coa) In Anlehnung an Lorenz v. Stein und Gneist; die naheren literarischen Belege hierfür bei Leibhol z, Das Wesen der Reprasentation $\mathrm{S}$. $113 \mathrm{f}$. Historisch zu der geschichtlichen Entwicklung dieses zentralen Gegensatzes von Staat und Gesellschaft, vor allem bei den franzdsischen Sozialisten (insbes. Proudhon), der historischen Rechtsschule, v. Mohl, einzelnen Syndikalisten bis hin zu Ehrlich, die wertvollen Ausfuhrungen bei Gurvitch, L'Idée du Droit Social 1931 S. 359 ff., 470 ff., 616 ff., 621 ff. und Le Temps présent et l'idee du Droit social 1931 S. 267 ff.; zu Lorenz v. Stein insbesondere noch Landshut, Kritik der Soziologie 1929 
Auf die konkrete Gestalt des geltenden Wahlverfahrens kommt es dabei nicht entscheidend an. Schon unter dem Mehrheitswahlsystem haben sich in einer Reihe von Ländern eigene Berufs-, insbesondere Bauernparteien gebildet ${ }^{51}$ ), und es ist kein Zweifel, daß der heutige Status der politischen Parteien in den auf dem Verhältniswahlsystem beruhenden Demokratien sich weitgehend erhalten würde, auch wenn diese Staaten zum Mehrheitswahlsystem zurückkehren würden. Immerhin hat der Proporz dieser ganzen Entwicklung neuen Antrieb gegeben, dadurch daß durch ihn auch Organisationen, die räumlich nicht über eine geschlossene Anhängerschaft verfügen, sondern als Querschicht über das ganze Land verstreut sind, parteifähig geworden sind. Insbesondere in den östlich gelegenen Staaten ist in dieser Weise die Bildung reiner Interessentenorganisationen wie dèr Beamten, Angestellten, Handwerker, in Danzig sogar der Fischer, Mieter, Hausbesitzer üblich geworden, ganz zu schweigen von den Gruppen, die wie z. B. bei uns die Aufwertungsanhänger oder Altgläubiger konkrete wirtschaftliche Anlässe der Parteibildung zugrundegelegt haben.

Aber auch gerade die politischen Weltanschauungsparteien sind von diesem durch den Proporz geförderten, gesellschaftlichen Auflösungsproze $B$ ergriffen worden. Diese Durchdringung unseres gesamten staatlich-politischen Lebens durch die verschiedenen gesellschaftlichen Interessen ist soweit gediehen, daB C. Schmitt ${ }^{52}$ ) jüngst - wenn auch zu Unrecht - von dem gegenwärtigen Staat geradezu als einem zur "Selbstorganisation der Gesellschaft gewordenen, pluralistischen Koalitionsparteienstaat" gesprochen hat ${ }^{63}$ ). Das ist schon deshalb

S. $99 \mathrm{ff}$.; dort auch S. 163 die sehr richtige Bemerkung, daB sdie Reziprozitat von Staat und Gesellschaft . . . der Index für die Möglichkeit aller sozialer und politischer Widersprüche ist, aus denen der Impuls zu soziologischer Forschung erwuchs t. Uber die Zeit vor Hegel v. Unruh, Dogmenhistorische Untersuchungen über den Gegensatz von Staat und Gesellschaft. 1928; endlich zu den verschiedenen möglichen Lossungsversuchen dieser Antinomie Freyer, Soziologie als Wirklichkeitswissenschaft $1930 \mathrm{~S} .288 \mathrm{ff}$.

s1) Belege bei Braunias in Schauff, Neues Wahlrecht S. $113 \mathrm{ff}$.

52) Der Hüter der Verfassung $S$. 73 ff., insbesondere $S .78,88$; in gleichem Sinne auch C. Schmitt, Der Begriff des Politischen 1932 S. 11 f.

53) $\mathrm{DaB}$ nach C. Schmitt nicht zwischen staatlich-politischen und gesellschaftlich unpolitischen Angelegenheiten unterschieden werden kann, hangt mit der Begriffsbestimmung des Politischen durch $C$. Schmitt zusammen, nach dem es ein eigentliches Materiale des Politischen nicht gibt, dieses vielmehr jeweils seine inhaltliche Grundlage anderen Lebenskraften entnimmt. Nur wird diese Einsicht nicht konsequent festgehalten. Für das 19. Jahrbundert wird so z. B. des ofteren von dem zwischen Staat und Gesellschaft bestehenden Gegensatz gesprochen, ohne daß klar wäre, worin eigentlich für diese Zeit das sperifisch politische Substrat des Staates bestehen soll. Ebenso bleibt auch dort, wo C. Schmitt sehr mit Recht bemerkt, dab die staatliche Einheit nicht pluralistisch erklart werden könne (2. B. a. a. O. 89, 100), unklar, worin inhaltlich das eigentlich politisch Integrierende der neutralen tiberparteilichen Krafte, die nach Schmitt 
nicht überzeugend, weil der Staat bei uns auch in seiner gegenwärtigen Gestalt als spezifisch politische Einheit real existent ist und diese Einheit weder pluralistisch noch allein mit den neutralen, überparteilichen Gegenkräften der Verfassung (vor allem dem Reichspräsidenten) begründet werden kann. In Wirklichkeit besteht heute bei uns der alte Gegensatz von Staat als politischer Einheit und Gesellschaft als apolitischer Vielheit in einem zwar quantitativ sehr erheblich gesteigerten, aber nicht qualitativ veränderten $\mathrm{MaBe}$ weiter fort ${ }^{54}$ ). Dieser Gegensatz zeigt sich heute insbesondere in dem Kampf, den die politischen Organisationen, die Parteien, gegenüber den in ihnen nach Ausdruck ringenden, unpolitischen gesellschaftlichen Mächten zu führen haben, und der so häufig die Glieder der parlamentarischen Körperschaften als reine Sachwalter bestimmter, gesellschaftlich, vor allem klassenmäBig bestimmter Interessen erscheinen läBt ${ }^{54 a}$ ).

So hat der klassische repräsentative Parlamentarismus, der - unbeschadet der sich bekämpfenden, teils mehr fortschrittlich, teils mehr konservativ eingestellten Gruppen - doch immer noch eine gesellschaftiich nicht gespaltene Grundlage besaß, auch seine soziologische Homogenität, die eine Voraussetzung seines Funktionierens war, mit der Zeit eingebüßt. Nicht nur politisch durch Massendemokratie und deren Wahlrecht, den Proporz, sondern auch gesellschaftlich sozial ist somit heute die liberal egalitäre, repräsentative Demokratie endgültig in Frage gestellt ${ }^{\text {S4b)}}$.

heute allein die Einheit des Staates begründen sollen, besteben soll. Zweifelnd offenbar auch Huber, Blatter für deutsche Philosophie Bd. V S. 312.

be) Neuestens im Sinne des Textes gegen die Identitat von Staat und Gesellschaft auch in der heutigen liberalparlamentarischen Demokratie Huber, Das deutsche Reich als Wirtschaftsstaat 1931 S. 26 f.: andererseits auch Kelsen in Die Justiz, Bd. VI (1931) S. $604 \mathrm{f}$. Auch der Wegfall des für das 19. Jahrhundert typischen Dualismus 2wischen Regierung und Volk ist nicht ausreichend, um diese Sachlage zu verandern. Im übrigen war das Volk auch im 19. Jahrhundert nicht nur Gesellschaft, sondern daneben zugleich auch noch ebenso wie heute politische Einheit.

64a) $\mathrm{DaB}$ die Parteien im Parteienstaat trotz ihrer gesellschaftlichen Durchsetzung im wesentlichen aber auch heute noch politische Parteien und keine reine Interessentenparteien sind, bemerkt mit Recht auch Kroner, Kulturphilosophische Grundlegung der Politik 1931 S. 83.

sb) Zustimmend Grueneberg in Die Tat Bd. 23 (1982) S. $816 \mathrm{f}$. Ebenso sind heute auch die Institutionen erschüttert, die in einem geistigen Zusammenhang mit den Grundlagen des liberal-egalitàren, reprasentativen Parlamentarismus stehen. Die Krise der kommunalen Selbstverwaltung ist z. B. zu einem Teil auf die stăndig sich radikalisierende Formalisierung des Wahlrechts zurückzuführen, das, wie Kottgen. Die Krise der kommunalen Selbstverwaltung $1931 \mathrm{~S}$. $18 \mathrm{f}$. sehr richtig bemerkt hat, das Gemeindeleben weitgehend verauBerlicht und um seine innere Substanz gebracht hat. Erst auf Grund dieses Sachverhaltes ist die Gemeinde heute weitgehend zu einer politischen Zelle der parteienstaatlichen 
Von dieser grundsätzlichen Einstellung zur heutigen Gesamtsituation ergibt sich eine von der üblichen zum Teil erheblich abweichende Einstellung zu den einzelnen Argumenten, die in der literarischen Diskussion über die Wahlreform immer wieder zugunsten des Mehrheitswahlsystems oder zum mindesten zugunsten einer Abschwächung des Proporzes im Sinne des Mehrheitswahlsystems geltend gemacht werden und damit auch zu der Wahlreformwelle, die das Reichsinnenministerium im August vorigen Jahres der Offentlichkeit zugänglich gemacht hat ${ }^{56}$ ).

Alle Reformbestrebungen und damit auch die der letzten Novelle gehen mit Recht von der Notwendigkeit aus, die Massen der Wähler zu aktivieren und diese von der weitgehend als Tyrannis empfundenen Parteiherrschaft $z u$ befreien ${ }^{56}$ ). Man verspricht sich von einer solchen Wiederbelebung des Einflusses der Aktivbürgerschaft ein stärkeres Gefühl der Staatsunmittelbarkeit der Individuen, eine bessere, weil freiere Auswahl von politischen Persönlichkeiten, die wieder instand gesetzt werden sollen, sich ihren Wahlkreis selbst zu erobern, ein unmittelbar persönliches Vertrauensverhältnis im Sinne einer lebendigen Wechselwirkung zwischen Wählern und Abgeordneten. Der letzte amtliche Wahlreformentwurf sucht diese Ziele durch einen vorsichtigen Kompromi $\mathfrak{z u}$ erreichen, indem er von vornherein darauf Verzicht leistet, in kleineren Wahlkreisen die Einerwahl mit der Verhältniswahl zu kombinieren ${ }^{57}$ ), und sich darauf beschränkt, in Zweibis Drei-Männer-Wahlkreisen dem Wähler das Recht einzuräumen, sich die Liste nach Belieben selbst zusammenzustellen ${ }^{58}$ ). Doch ist, auch wenn man die großen Mängel des schon der Regierungsvorlage von 1920 zugrundeliegenden freien Listenwahlsystems

Massendemokratie geworden. Zur Politisierung der Selbstverwaltung noch Forsth off, Die offentliche Korperschaft im Bundesstaate 1931 S. $174 \mathrm{f.}$ und gegen die These von der Gemeinde als ausschlie日lich okonomischer Einheit, die schon deshalb nicht richtig ist, weil das Wirtschaftliche niemals einheitstiftend $\mathrm{zu}$ wirken vermag, Kóttgen a. a. O. $29 \mathrm{ff}$.

${ }^{\text {B5) }}$ Zu diesem Entwurf auch Kaisen berg, D. Jur. Zeit. 1930 Sp. $1153 f$. und Zeitschr. f. d. gesamte Staatswissenschaft Bd. 90 (1931) S. 465 ff.; allgemeiner Künzer, D. Jur. Zeit. 1931 Sp. $120 \mathrm{ff}$.

) hus der Fülle der jüngsten Vorschläge noch etwa Tecklenburg, Personenwahl, nicht Parteienwahl 1931.

${ }^{87}$ ) In der richtigen Erkenntnis nămlich (dazu die Bemerkungen von Kaisenberg, Zeitschr. f. d. gesamte Staatswissenschaft Bd. 90 S. 459 , 478), da $B$ der Gedanke der auf dem Mehrheitswahlsystem beruhenden Einerwahl sich mit der Verhaltniswahl letzten Endes nicht konsequent vereinigen laßt.

58) Er soll also nicht nur das Recht haben wie bei der lose gebundenen Liste, die Rangordnung der Liste zu bestimmen (in diesem Sinne etwa eine Reihe von Vorschlagen in Schauff, Neues Wahlrecht a. a. O. (z. B. Decker, Ulich-Beil) und der Vorschlag von Thoma, Reform des Wahlrechts 1925; dazu Anlage zum Entwurf d. Reichswahlgesetzes von 1930 S. 6, 20 f). 
(wie Erschwerung des Wahlgeschäftes, persönliche Rivalitäten

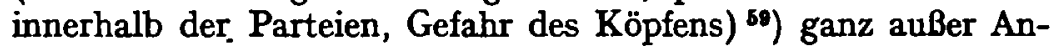
satz läßt, nach der geschilderten, politisch soziologischen Situation der heutigen Massendemokratie sicher, daß die erstrebten Ziele, vor allem die Beseitigung der Herrschaft der Parteizentrale, auf diese Weise nicht erreicht werden werden. Vielmehr werden die Parteien stets - auch nach der etwa zum Gesetz erhobenen Novelle - schon aus äußeren, finanziellen und technischen Gründen, insbesondere bei den Nominierungen ihren bestimmenden Einfluß auf die Massen behalten. Selbst wenn es bei uns etwa wie in Frankreich, Nordirland und Griechenland gelingen sollte ${ }^{60}$ ), das Mehrheitswahlsystem in irgendeiner Form einzuführen, und wenn somit die Aktivbürgerschaft äußerlich vollkommen frei in der Wahl der Abgeordneten sein sollte, würden die Wählermassen, ähnlich wie es in den Vereinigten Staaten der Fall ist, doch die von den Parteien, wenn auch inoffiziell, empfohlenen Kandidaten wählen, und nicht die sich ihnen etwa präsentierende, zugkräftige Persönlichkeit. Denn der Gedanke der freien politischen Persönlichkeitswahl wirkt, worauf auch Nawiasky ${ }^{61}$ ) mit Recht hingewiesen hat, werbend heute nur noch auf die der $Z$ ahl nach verhältnismäßig geringen, traditionsgebundenen bürgerlichen Mittelschichten. Die politische Persönlichkeit ist eben in der modernen Massendemokratie nicht mehr die freie repräsentative Persönlichkeit des 19. Jahrhunderts, die wie etwa zur Zeit der Frankfurter Nationalversammlung als Träger eines hohen ideellen Wertes einen Teil der geistigen Aristokratie der Nation darstellte, sondern tatsächlich, wie der Kultusminister Grimme gelegentlich seines Amtsantritts im Landtag bemerkt hat, im wesentlichen allein noch der "Exponent der politischen Partei" ${ }^{82}$ ).

Hiermit stimmen auch die Erfahrungen überein, die bereits früher in Ländern mit der freien Liste in Verbindung mit dem Panachierungsrecht gemacht worden sind. Hier hat stets der größte Teil der Aktivbürgerschaft, nämlich die große Masse der disziplinierten Wähler sich streng an die Parole der Partei gehalten und die Minderheit, die von dem zustehenden freien Bestimmungsrecht Gebrauch gemacht hat, ist mehr als eine Gruppe von Querulanten und Eigenbrödlern als eine Gruppe von freien Persönlichkeiten betrachtet worden.

50) Ein Kumulieren von Stimmen wie etwa in der Schweiz (im Bund und der Mehrheit der Kantone) und Luxemburg gibt es nach dem Entwurf nicht.

60) Wobei zu bemerken ist, daB das französische Gesetz von 1919 kein reines Verhalltniswahl-, sondern im wesentlichen ein Majoritatsgesetz (wune loi essentiellement majoritairé) war. S. $165 \mathrm{ff}$.

i) D. Jur. Zeit. 1931 Sp. 466 und Archiv d. öf. Rechts N. F. Bd. 20

"2) Vgl. auch Warburg in Die Gesellschaft Bd. 7 S. 245. 
Ist dies aber richtig, so entfällt damit zugleich auch die Voraussetzung für die Entwicklung eines persönlichen Vertrauensverhältnisses zwischen den Wählern eines Wahlkreises und den Gewählten, das heutc auch schon aus technischen Gründen nicht durchführbar wäre. Auch würde eine lokale Bindung der politischen Kräfte der Struktur der parteienstaatlichen Massendemokratie widersprechen. Denn durch diese haben die früheren territorialen, landschaftlichen und lokalen Gegensätze, die in abgeblaßter Form noch heute dem Verhältniswahlsystem bei der Wahlkreiseinteilung zugrundeliegen, und die, wie die Verhältnisse in Frankreich und den Vereinigten Staaten zeigen, leicht die Deputierten zu reinen Lokalgrößen und Kirchturmsinteressenten machen, im wesentlichen ihren Sinn und ihre Berechtigung verloren. Entscheidend sind heute nicht mehr persönliche oder lokale, sondern allgemeine, in den Parteiprogrammen zum Ausdruck kommende Gegensätze politisch ideeller wie wirtschaftlicher Natur, die im Gegensatz zur bisherigen vertikalen Schichtung der Bevölkerung zu einer horizontalen Querschichtung derselben geführt haben.

Es zeigt sich in dieser ganzen Entwicklung lediglich die Folge der Verschiebung des politischen Schwergewichts vom Parlament hin zur Aktivbürgerschaft und zu den diese politisch organisierenden Parteien. Diese Entwicklung ist im Rahmen der Demokratie unentrinnbar, auch wenn man sie persönlich im Hinblick auf den hohen politisch-kulturellen Wertgehalt des Zeitalters des repräsentativen Parlamentarismus bedauern und negativ bewerten mag. Im übrigen würde die politische Führerauslese im repräsentativ parlamentarischen Sinne auch nicht etwa durch den diktaturförmigen Einparteienstaat wieder belebt werden. Daher ist es auch nicht richtig, in dem Ausfall der letzten Septemberwahlen gerade eine Verurteilung des gegenwärtig geltenden Wahlsystems und eine Entscheidung zugunsten des Mehrheitswahlsystems sehen zu wollen. Denn äie Wählermassen haben durch die Wahl der radikalen Parteien sich gleichzeitig zu einem Führerauslesesystem bekannt, das abgesehen von der diktatorialen Spitze noch in einem ganz anderen Maße als das modern-massendemokratische bewußt auf die Herausstellung seibständig dezidierender, parlamentarischer Führerpersönlichkeiten Verzicht leistet.

Nur noch in den parlamentarischen Demokratien, in denen die klassische repräsentative Tradition sich noch in einem breiteren $\mathrm{MaBe}$ als bei uns erhalten hat, vermag das Mehrheitswahlsystem noch in einem repräsentativ-parlamentarischen Sinn elektiv zu wirken. Das gilt vor allem von dem französischen Parlament, in dem es noch heute - abgesehen von Sozialisten und Kommunisten - ähnlich wie zu der Zeit des Frühkonstitutionalismus 
parteimäßig in unserem Sinne eng zusammengeschlossene Organisationen überhaupt nicht gibt, sondern lediglich lose parlamentarische Gruppen, in denen sich häufig Persönlichkeiten ganz verschiedener Prägung ohne engere fraktionelle Bindung zusammenfinden und das personalistische Ethos sich noch nahezu in völliger Freiheit von den Verbandsorganisationen zu entfalten vermag ${ }^{62 a}$ ). Das gilt in einem gewissen Sinne auch heute noch von dem englischen Parteienstaat, in dem, wie u. a. auch Koellreutter ${ }^{63}$ ) mehrfach bemerkt hat, trotz des frühen parteimäßigen Zusammenschlusses der Abgeordneten die klassischliberale und später demokratisch abgewandelte repräsentativparlamentarische Einstellung sich weitgehend bis auf den heutigen Tag erhalten hat.

Außer mit der Herstellung einer freien politischen Persönlichkeitswahl und eines lebendigen Vertrauensverhältnisses zwischen Wähler und Gewähltem wird die Wahlreform bei uns weiter mit der Bekämpfung der Parteizersplitterung gerechtfertigt und zwar merkwürdigerweise - denn hierin liegt ein offener Widerspruch ${ }^{64}$ ) - überwiegend von Kreisen, die gleichzeitig von der Wahlreform eine Wiederbelebung der Persönlichkeitswahl im repräsentativ-parlamentarischen Sinne erhoffen. Würde nämlich das Mehrheitswahlsystem oder ein in diesem Sinne abgeschwächtes Verhältniswahlsystem tatsächlich noch personell elektiv wirken, so würde die Parteizersplitterung nicht vermindert, sondern nur gesteigert werden ${ }^{65}$ ). Im übrigen ist die politisch-religiöse wie landsmannschaftliche Zersplitterung, die unser ganzes parteigeschichtliches Leben durchdringt, tief durch die Geschichte der Vergangenheit bedingt. Es ist kein Zufall, $\mathrm{da}$ das Mehrheitswahlsystem vor dem Kriege bei uns zu einer im wesentlichen nicht geringeren Parteizersplitterung geführt hat wie das nachrevolutionäre Verhältniswahlsystem $\left.{ }^{66}\right)$. Allerdings würde heute auf Grund der anormalen, vom Gesichtspunkt der

62a) Dazu aus der neuesten Literatur etwa Rohden in Demokratie und Partei 1932 S. 11, 136 ff.; weitere Nachweise Leibholz, Repräsentation a. a. O. 100 An 3 .

6) Zuletzt Reichstagswahlen und Staatslehre 1930 S. 27 ff. Vgl. etwa auch Loewenstein, Die britischen Parlamentswahlen im November 1922, 1923 S. $19 \mathrm{f}$.

44) In diesem Sinne z. B. auch schon Nawiasky, Zeitschr. f. Politik Bd. 16 S. 545; Bredt, PreuBische Jahrbücher Bd. 223 (1931) S. 242 f.

65) Entsprechendes gilt von der so hăufig beklagten Parteizersplitterung bei den Wahlbewerbungen. Auch hier würde durch ein Mehrheitswahlsystem oder ein im Sinne des Mehrheitswahlsystems abgeschwachtes Verhaltniswahlsystem die Gefahr, daß von vornherein Stimmen ohne Aussicht auf Erfolg abgegeben und damit ihrer politischen Wirkungskraft beraubt werden, nicht gebannt, sondern nur erheblich gesteigert werden.

6) Nahere Belege bei Dix, Reichstagswahlen und Volksgliederung 1930 z. B. S. $21,25$. 
parteienstaatlichen Massendemokratie aus geradezu als pathologisch zu bezeichnenden, parlamentarischen Situation der Gegenwart das Mehrheitswahlsystem oder ein in diesem Sinne abgeschwächtes Verhäitniswahlsystem zu einer nicht unerheblichen Verminderung des gegenwärtigen Parteibestandes, wenn auch natürlich nicht zu den klassischen englischen Verhältnissen führen, die ihre Klassizität bereits selbst längst verloren haben und in der Gegenwart noch immer mehr verlieren. Diese Verminderung der Parteien würde aber nicht die großen Parteien, die im Gegenteil - im übrigen schon nach einem alten, von dem französischeı Mathematiker Poisson ${ }^{67}$ ) 1837 unter Beweis gestellten Gesetz zahlenmäBig sogar wachsen würden, sondern allein die kleineren, d. h. praktisch gesehen die bürgerlichen, nicht katholischen Mittelparteien treffen, die über keine massierte Anhängerschaft verfügen und im wesentlichen von den Diaspora-Stimmen leben. Würde z. B. die Bestimmung der letzten amtlichen Wahlreformnovelle Gesetz werden, nach der in den neuen Ländergruppen die Parteien Mandate nur noch erhalten können, wenn sie in einem der neuen, unseren heutigen Wahlkreisen etwa entsprechenden Wahlkreisverbänden ein Mandat erhalten haben, so würden z. B. 1928 ca. 6 Millionen, die im wesentlichen für die nicht katholischen bürgerlichen Mittelparteien gestimmt haben, ihr Wahlrecht nicht mit Erfolg ausgeübt haben ${ }^{68}$ ). Diese Konsequenzen sind heute bei solchen Abschwächungen des Verhältniswahlsystems unvermeidbar, weil mit dem vielfach und auch vom Entwurf erwarteten Äquivalent, nämlich der Bildung einer großen, zusammenfassenden evangelischen Mittelpartei nicht gerade als politischer Realität gerechnet werden kann ${ }^{69}$ ).

Aber selbst dann, wenn durch eine solche Änderung des Wahlrechts, wie sie etwa die letzte Wahlreformnovelle vorsieht, das Parlament in etwa fünf bis sechs größere parlamentarische Gruppen zerfallen würde, würde dasselbe nicht, wie so häufig schließlich noch gemeint wird, politisch funktionsfähig gemacht werden und in die Lage gesetzt sein, im Sinne eines maker of the government roder einer zur Approbation oder Reprobation befähigten Körperschaft ${ }^{70}$ ) eine politisch aktionsfähige Regierung herauszustellen. Denn die vielfachen Regierungskrisen in den letzten Jahren gehen letzten Endes auf die mangelnde Homo-

$\left.{ }^{07}\right)$ Recherches sur la probabilité des jugements S. $241 \mathrm{ff}$.

e8) Naher Erdmannsdörfer, Wahlrecht in Gefahr $1930 \mathrm{~S} .22,38 \mathrm{f}$. Bei Zugrundelegung der Wahlen von 1930 wïrde sich die erwahnte Ziffer noch erheblich erhöhen.

99) Nawiasky, Archiv d. 8 ff. Rechts N. F. Bd. 20 S. $176 \mathrm{ff}$. (vgl. auch S. 189) hat in diesem Zusammenhang nicht mit Unrecht von einem bürgerlichen Selbstmord gesprochen. S. 18.

70) Im Sinne von Erich Kaufmann, Problematik des Volkswillens 
genität und Regierungsunfähigkeit gerade auch und vor allem der großen Parteien zurück ${ }^{\mathbf{1}}$ ), die bei einer Verminderung der Parteienanzahl nicht nur nicht behoben, sondern noch schärfer akzentuiert hervortreten würde. Tatsächlich würde das Verschwinden der nichtkatholischen bürgerlichen Mittelparteien bei uns heute, da diese Parteien jedenfalls im großen und ganzen auf die bestehenden politischen Gegensätze mildernd $d$. h. koalierend wirken, die Regierungsbildung in Wirklichkeit nur erschweren ${ }^{72}$ ). Wollte man bei uns tatsächlich unbedingt die Voraussetzungen für eine sichere Regierungsbildung schaffen, müßte man schon zu grundsätzlich der Struktur der parteienstaatlichen Massendemokratie widersprechenden, wenn auch an sich nicht undemokratischen Radikalkuren im Sinne der faschistischen Wahlreform von 1923, d. h. zu einem Prämiensystem mit Zuschlagsmandaten für die relativ stärkste Partei greifen, das aber in der gegenwärtigen Situation den Bestand der Weimarer Verfassung sofort und endgültig in Frage stellen würde ${ }^{\text {72nan }}$.

Für die letzte amtliche Wahlreformnovelle ergibt sich hiernach, daB diese - jedenfalls von der politisch Wirklichkeit gewordenen, modernen parteienstaatlichen Massendemokratie aus gesehen - durch die Abschwächung des Proporzes eine Verschlechterung des geltenden Wahlverfahrens bringt. Aber auch praktisch politisch sind von der Einstellung der Weimarer Verfassung aus die Konsequenzen dieser Reform nicht positiv zu werten. Weder wird die politische Persönlichkeitswahl gesichert noch die Regierungsbildung erleichtert. Lediglich das Stimmgewicht der bürgerlichen, die strukturellen Grundlagen der Verfassung im großen und ganzen bejahenden Mittelschichten wird minder bewertet. Das ist um so grotesker, als das Ziel, um dessentwillen diese capitis diminutio erfolgt, nämlich die durch die Novelle angestrebte Persönlichkeitswahl, wenn überhaupt, ge-

71) Auch hierauf weist Nawiasky, D. Jur. Zeitschr. 1931 Sp. 467 und Archiv a. a. O. 175 hin.

72) Hatte man beispielsweise im September 1930 nach dem Mehrbeitswahlsystem gewahlt, so wäre die allgemein-parlamentarische Situation nur noch kompliziert und die Bildung einer regierungsfahigen Mehrheit noch mehr erschwert worden.

72a) In der deutschen Wahlrechtsliteratur bewegt sich in der Richtung der faschistischen Wahlreform von 1923 vor allem der Vorschlag von Pfister, Zeitschrift f. offentl. Recht VIII S. 188 ff. und in Der Meister Bd. 6 (1930) H. 2, der mit Hilfe eines sog. Vertretertages der relativen Mehrheit der Staatsbürger die absolute Parlamentsmehrheit geben will. Dieser Vorschlag hat vor den meisten anderen Projekten den Vorteil, daß er sich auf die Sicherung der Regierungsbildang beschralnkt und die anderen antiquierten Argumente der Wahlrechtsreform unberücksichtigt laBt. Für die Weimarer Verfassung ist dieser Vorschlag - zum mindestens heute - nicht akzeptabel, da er eine politische, durch die Substanz der Verfassung bestimmte Homogenitat der Parteien voranssetst, die in Wirklichkeit nicht mehr besteht; dazu die Schlubshtze des Referates. 
rade bei diesen Parteien noch realisierbar erscheint, während sie sonst ebenso wie das angestrebte persönliche Vertrauensverhältnis zwischen Wähler und Gewăhlten in Wirklichkeit eine Illusion ist.

SchlieBlich noch ein Wort zu dem projektierten Wegfall der Reichsliste. Gewiß haben sich die an die Reichsliste geknüpften Auslesehoffnungen infolge der verbreiteten Abgabe sicherer Sitze an die Interessenvertreter bei uns weitgehend nicht erfüllt. Aber diesem Mißstand hätte mit einer Kontingentierung der Reichsliste ${ }^{73}$ ), die die Parteien zwingt, auf die sicheren Plätze ibre politischen Führer zu setzen, oder mit der personell gebundenen Reichsliste im Pohl'schen Sinne ${ }^{74}$ ) begegnet werden können. Auch ist nach der Novelle die Position der Interessenvertreter selbst gar nicht so sehr verschlechtert. Sie müssen sich nur in sicheren oder mehreren Wahlkreisen aufstellen lassen. An die Stelle des Kampfes um den sicheren Platz auf der Liste würde lediglich der Kampf um die Zahl und Güte der Wahlkreise treten. Und was den Grundsatz der Unmittelbarkeit der Wahl angeht, um dessentwillen man die Reichsliste ebenfalls geopfert hat, so ist gewiB richtig, da $B$ mit diesem die Nominierung auf der Reichsliste an sich unvereinbar ist. Aber gezeigt ist, daB dieser Wahlrechtsgrundsatz, der verfassungstheoretisch zum Mehrheitswahlsystem und damit zum klassischen repräsentativen Parlamentarismus genört, letzten Endes mit dem Verhältniswahlsystem überhaupt nicht $\mathrm{zu}$ vereinigen ist, tatsächlich durch das heute bei uns in Geltung befindliche Listenwahlsystem aufgehoben ist und, wenn die Novelle Gesetz werden sollte, auch in Zukunft, nämlich bei der Reststimmenübertragung aus dem Nachbarwahlkreis, zu einem großen Teil - man hat nach den Wahlen von 1930 ausgerechnet zu $80 \%$ - aufgehoben sein würde.

Letzten Endes sind die Hoffnungen, die sich so weitgehend an die Wahlreform und damit auch die Wahlreformnovelle knüpfen, deshalb trügerisch, weil der ganzen Wahlreformbewegung eine geistige Haltung zugrundeliegt, die aus dem Geiste des 19. Jahrhunderts, aus liberalistischem Geiste im Sinne des repräsentativen Parlamentarismus geboren ist, und die der geschilderten soziologischen Struktur des modernen massendemokratischen Parteienstaates nicht mehr entsprichí. Die Wahlreformbewegung ist

rocht S. $164 \mathrm{f}$.

74) Vgl. auch schon Kaisenberg, Dio Wahl zum Reichstag 1930 S. 8. Sie gibt es auch z. B. in der Tschechoslowakei bereits in einer bestimmten Form. Hier mulssen Personen, die auf der Reichsliste kandidieren, gleicbreitig auch auf der Kreisliste sich um ein Mandat bewerben; sie kommen auf der Reichsliste allerdings - im Gegensatz zum Pohlschen Vorschlag nur dann zum Zuge, wenn sie auf der Kreisliste nicht gewahlt sind. 
tatsächlich im Grunde genommen eine rein bürgerlich-liberale Angelegenheit ${ }^{75}$ ). Für die eigenen Gesetzen folgende Massendemokratie ist aber Gestalt und Methode des einzelnen Wahlverfahrens überhaupt nicht mehr von entscheidender, strukturwandelnder Bedeutung ${ }^{70}$ ).

$\mathrm{Da} \beta$ dem tatsächlich so ist und die Wahlreformbewegung letzten Endes aus liberalistischem Geiste gespeist wird, zeigt auch die Haltung der politischen Parteien. Die großen Massenparteien als die Träger dieser Art Demokratie mit EinschluB des an sich reformfreundlichen und parlamentarisch in dieser Hinsicht sehr aktiven Zentrums halten bei uns überwiegend an dem massendemokratischen Verhältniswahlrecht fest, trotzdem gerade diese Parteien durch das Mehrheitswahlsystem erheblich begünstigt werden würden. Die Sozialdemokratie hätte z. B., wenn 1919 nach dem Mehrheitswahlsystem bei gleicher Wahlkreiseinteilung gewählt worden wäre, die absolute Mehrheit in der Nationalversammlung erhalten. Immerhin ist diese Haltung der Sozialisten eine zum mindesten aus taktischen Grïnden nicht allgemeine. In Frankreich z. B. haben die Sozialisten bei der letzten Wahlreform im Gegensatz zu ihrer grundsätzlichen Haltung ${ }^{77}$ ), lediglich um von dem kompromittierenden Wahlrecht von 1919 loszukommen, eine freiere Haltung eingenommen und sind ebenso wie die Radikalsozialisten für die Rückkehr zum Einerwahlsystem eingetreten.

Umgekehrt entspricht dieser Haltung der Massenparteien, da $B$ die liberalistischen Parteien ${ }^{78}$ ) und die liberalistischen Elemente in den anderen, vor allem den Massenparteien ${ }^{79}$ ) für die Wahlreform in einem nur gradmäßig verschiedenen Sinn eingetreten sind. Dabei entbehrt es nicht einer gewissen Tragik, zu sehen, daB die liberalistischen Parteien dadurch, daß sie mit dieser Konsequenz an dem liberalistischen Dogma festhalten, heute jedenfalls soweit sie für eine Abschwächung des Proporzes im Sinne des Mehrheitswahlsystems oder sogar für dessen Einführung eintreten - den Bestand ihrer ohnehin schon kleinen Organisationen mehr oder weniger endgültig in Frage stellen. Lediglich die englischen Liberalen nehmen, soweit ich sehe, heute eine Ausnahmestellung ein. Denn gerade sie sind es hier, die auf Grund der durch das Mehrheitswahlsystem geschaffenen Situation

75) So vor allem auch Nawiasky, Archiv des offentlichen Rechts N. F. Bd. 20 S. 191.

70) In der gleichen Richtung auch Hula, Zeitschr. f. off. Recht Bd. 6

S. 229 f. Ferner noch Koellreutter, Zeitschrift f. Politik Bd. 21 (1931) S. 475 .

iv) Und der ihres frtheren Fahrers Jaures.

7) Dazu z. B. Koch, Verhandlungen des Reichstags 1920 Bd. 361 S. 12536; Fischer ebenda 12660; Schiffer ebenda Bd. 67 S. 9122; Pachnicke Bd. 354 S. 6875; Külz. Jur. Rundschau $1928 \mathrm{~S}$. I f. Vgl. auch den Bericht von Beyerle ebenda Bd. 361 S. $12365 \mathrm{f}$. 
im Gegensatz insbesondere zu den Konservativen, die grundsätzlich an dem seiner Natur nach liberalistischen Mehrheitswahlsystem festhalten, die Einführung des massendemokratischen Verhältniswahlsystems befürworten. Diese grundsätzlich antiliberalistische Einstellung hat die englischen Liberalen allerdings aus taktischen Gründen nicht gehindert, sich für die Zukunft mit der Arbeiterpartei über die Einführung eines versteckten absoluten Mehrheitswahlsystems zu einigen ${ }^{80}$ ).

Will man die Wahlreformbewegung aus der traditionellen geistigen Umklammerung des 19. Jahrhunderts befreien, so muB man sich entsprechend den Forderungen parteienstaatlicher Massendemokratie darauf beschränken, die Wählermassen zu aktivieren und die weitgehend als Diktatur empfundene Herrschaft der Parteibürokratie zu brechen. Diè anderen so häufig beklagten Erscheinungen unseres heutigen Wahlsystems sind letzten Endes nur wesensmäßige Auswirkungen der Massendemokratie, die man in Kauf nehmen muß, wenn man deren Bestand nicht mehr oder weniger überhaupt in Frage stellen will. Und auch die Aktivierung der Wählermassen ist nicht mehr mit den antiquierten Mitteln eines parlamentarisch-repräsentativen Liberalismus, sondern nur durch Demokratisierung der Parteien selbst zu erreichen ${ }^{81}$ ). Die Parteibürokratie selbst muß wieder in näheren Kontakt mit den aktivierten Massen gebracht, der NominationsprozeB vor allem aufgelockert werden. Dieses wäre vielleicht möglich durch die sog. Vorwahlen, die Primary Flections, wie sie etwa in fast allen Staaten der Union heute auf Grund besonderer gesetzlicher Bestimmungen in Utbung sind ${ }^{82}$ ). Hiernach haben die Parteimitglieder das im einzelnen näher geregelte Recht, an dem Parteileben sich zu beteiligen, vor allem innerhalb der Partei an der Nominierung der Kandidaten und der Ausschei-

79) Aus dem Kreise der sozialdemokratischen Partei z. B. Mierendorff in Neues Wahlrecht S. $14 \mathrm{ff}$. und Eckstein, Klassenkampf 1930 S. $570 \mathrm{f}$.; ferner etwa vom Zentrum Wirth und von den Volksnationalen Frey in Der Meister 1930 S. 10.

80) Zur Entstehung dieses Kompromisses und seinen wahrscheinlichen Folgen Braunias, Zeitschr. f. Politik Bd. 21 (1931) S. 192 f.

81) Vgl. auch Graf Dohna in der Kölnischen Zeitung vom 8. Mărz 1931. Dazu schon die Bemerkung von Tecklenburg. Schmollers Jahrbuch $f$. Gesetzgebung Bd. 50 S. 983.

82) Dazu naher Triepel, Staatsverfassung und die politischen Parteien S. $21 \mathrm{ff}$. und jetzt auch Hartmann, Die politische Partei S. $147 \mathrm{f}$. Vgl. ferner Ernst C. Meyer, Wahlamt und Vorwahl 1908 S. 109 ff.; Bryce, Amerika (Deutsche Ubersetzung von Singer) 1924 Bd. II S. 61 ff. Aus der angelsächsischen Literatur etwa Commons, Proportional Representation $^{2} 1907$ S. 153 ff., 285 ff.; Merriam, Primary Elections 1909; Beman, The Direct Primary 1926; Hoag-Hallett, Proportional representation 1926; Mr. Chesney Sait, American Parties and Elections 1927 S. 377 ff.; Beard, American Government and Politics, 1928 S. 646 ff.; MerriamGosnell, The American Party System 1929 S. $242 \mathrm{ff}$. 
dung unbeliebter, korrumpierter, wie vor allem rein interessenmäBig eingestellter Wahlbewerber mitzuwirken. Nur durch eine jedenfalls grundsätzlich in dieser Richtung liegende Wahlreform ist heute, wenn überhaupt, noch eine wirkliche Aktivierung der in den Parteien organisierten Aktivbürgerschaft, ein Bruch der Herrschaft der Parteibürokratie, insbesondere bei der Nominierung des Kandidaten, wie nicht zuletzt auch eine Milderung der gesellschaftlichen Durchsetzung der Parteien möglich und denkbar ${ }^{82 a}$ ). Eine solche Demokratisierung des Parteibetriebes setzt nur voraus, daß die Massen sich tatsăchlich aktiv am Parteileben beteiligen. Tun sie dies aber nicht, lassen sie ihren Einfluß bei den Mitgliedern und Vertreterversammlungen ungenützt, so haben sie ihrerseits das Recht verwirkt, sich über den beherrschenden Einfluß der Parteibürokratie zu beklagen.

Problematisch ist allerdings in der gegenwärtigen politischen Situation auch der Erfolg einer solchen Wahlreform, da der allgemeine Entliberalisierungsproze $B$ bereits die Parteien selbst ergriffen hat ${ }^{83}$ ). Die hierarchisch gegliederten, diktaturförmig strukturierten Parteien, die bewußt im Sinne des Elitegedankens das von unten nach oben durch das von oben nach unten ersetzt haben, bedienen sich nur aus taktischen Gründen der Formen der heutigen, liberalistischen Massendemokratie, ohne selbst in diesem Sinn massendemokratisch organisiert zu sein. Für diese Verbandsparteien, für die die Wahlen mit der Machtergreifung überhaupt entbehrlich werden, entfällt aber letzten Endes die Berechtigung, die Frage der Wahlreform überhaupt sinnhaft zur Diskussion zu stellen.

82a) Vgl. in diesem Zusammenhang insbesondere das mir im Manuskript vorliegende Projekt von H. Graichen, Das Wahlrecht in der refrasentativen Demokratie 1931, der fur die Kandidatennominierung eino im einzelnen naher ausgeführte Verbindung der amerikanischen Vorwahlen mit demDelegiertensystem, d. h. einem System anstrebt, bei dem nicht nur die Parteien, sondern auch die nichtorganisierten Wahler mit Hilfe von bindenden Petitionen nominationsberechtigt sein sollen.

83) Daru naher Liermann, Partei und Bund in d. Blattern fur dentache Philosophie Bd. V H. 2/3 (1931) S. 236 ff., der nur zu Unrecht (2. B. S. 243) auch den liberalistischen Massenparteien heute ihren liberalistischen Charakter abspricht. 


\section{Leitsätze des Mitberichterstatters}

\section{Gerhard Leibholz.}

r. Bei der Wahlreform handelt es sich in erster Linie um ein politisch soziologisches und nicht um ein technisches Problem.

2. Die "Wahlen "haben im Rahmen des repräsentativen Parlamentarismus die Funktion, die repräsentativen Qualitäten der parlamentarischen Körperschaften sicherzustellen. Was unter dem Begriff der Volkswahlen inhaltlich näher zu verstehen ist, läßt sich nicht eindeutig festlegen, sondern ist nach Zeit und Ort verschieden.

3. Für den Begriff des modernen, allgemeinen und gleichen Wahlrechts ist eine auf den Ausschlu $\beta$ sozialer Motive gerichtete, weitgehende Formalisierung charakteristisch, die ihrer grundsätzlichen Tendenz nach bereits dem repräsentativen Parlamentarismus widerstreitet.

4. Die Wahlrechtsgrundsätze haben ihre klassische Gestalt durch das Mehrheitswahlsystem erhalten, das sich an Hand des repräsentativen Parlamentarismus entwickelt hat. Sie erfahren durch das Verhäliniswahlsystem eine Umbildung. Der Satz der Gleichheit und Allgemeinheit der Wahl wird durch den Proporz noch weiter in einem formalen Sinn radikalisiert. während der Satz der Unmittelbarkeit der Wahl durch das Verhältniswahlsystem autgehoben wird.

5. Diese Umbildung der Wahlrechtsgrundsätze geht auf die wesensmäßige Verschiedenheit von Mehrheits- und Verhältniswahlsystem zurïck, die selbst nur Ausdruck des Gegensatzes von repräsentativem Parlamentarismus und modernem Parteienstaat ist. Der Wahlakt erfüllt beim Verhältniswahlsystem nicht mehr repräsentationsbegründende, sondern nur noch rechenmäßig-statistische wie rein plebiszitäre Funktionen. Das massendemokratische Verhältniswahlrecht ist das detn modernen. Parteienstaat entsprechende Wahlrecht und nur Ausdruck des Strukturwandels, der sich innerhalb der Demokratie in den letzten Jahrzehnten vollzogen hat.

6. Daher ist es widerspruchsvoll, wenn die Weimarer Verfassung sich zum repräsentativen Parlamentarismus (und damit indirekt zum Mehrheitswahlsystem) und gleichzeitig zum Verhältniswahlsystem bekennt. Ebensowenig möglich ist es, Mehrheitsund Verhältniswahlsystem miteinander "organisch" zu verbinden.

7. Außer durch den massendemokratischen Parteienstaat wird der repräsentative Parlamentarismus durch die gegenzeärtige soziale Gesellschaftsordnung erschïttert. Auch die durch diese Entwicklung herbeigeführte Krise wird durch das Verhältriswahlrecht gefördert und verschärft. 
8. Aus der politisch-soziologischen Situation der heutigen Massendemokratie ergibt sich für die Wahlreformbewegung

a) Für eine Persönlichkeitswahl und ein persönliches Vertrauensverhältnis zwischen Wählern und Gewählten im repräsentativ-parlamentarischen. Sinne fehlen heute im großen und ganzen die politisch-soziologischen Voraussetzungen. Auch die letzte amtliche Wahlreformnovelle würde nicht mehr in diesem Sinne wirken. Denn die politische Persönlichkeit ist heute ganz überwiegend allein noch der "Exponent der politischen Partei".

Auch widerspricht eine lokale Bindung der Abgeordneten der Struktur der parteienstaatlichen Massendemokratie, für die der Bestand umfassender, in den Parteiprogrammen zum Ausdruck kommender Gegensätze politisch-ideeller wie wirtschaftlicher Natur charakteristisch ist.

b) Die Parteizersplitterung ist bei uns im wesentlichen durch die Geschichte bedingt. Allerdings würde das Mehrheitswahlsystem oder ein in diesem Sinne abgeschwächtes Verhältniswahlsystem (s. letzter amtlicher Entwurf) in der gegenwärtigen politischen Situation die Parteizersplitterung vermindern, die im wesentlichen aber auf Kosten der nichtkatholischen, bürgerlichen Mittelparteien gehen würde. Dagegen wiirde ein solches Wahlsystem weder die Regierungsbildung erleichtern noch eine stabile Regierungsführung sichern.

c) Es empfiehlt sich nicht, die letzte amtliche Wahlreformnovelle zum Gesetz zu erheben. Besonders ist auch der projektierte Wegfall der Reichsliste nicht zu rechtfertigen.

9. Die Wahlreformbewegung wird im wesentlichen von liberalistischem Geiste im klassisch-repräsentativ-parlamentarischen Sinne getragen. Die Haltung der Parteien zur Wahlreform bestimmt sich grundsätzlich nach dieser politischen Haltung.

ro. Eine Wahlreform im Sinne des massendemokratirchen Parteienstaats verlangt eine Beseitigung der autoritären Parteiherrschaft und beschränkt sich auf eine Aktivierung der Aktivbürgerschaft. Diesem Ziel würde eine auf gesetzlicher Grundlage erfolgende Demokratisierung des gesamten Parteibetriebes entsprechen. 


\section{Aussprache am 2. Tage. Wahlrechtsreform.}

Herrfahrdt - Greifswald.

Ich stimme Herrn Leibholz zu im negativen Ergebnis, daB eine Wahlreform im Sinne des klassischen Repräsentativsystems unmöglich ist. Anders aber sehe ich die Frage, ob wir den "massendemokratischen Parteienstaat * befestigen und reformieren sollen. Zunächst: Haben wir wirklich heute einen massendemokratischen Parteienstaat? Nein! Was bei uns heute wirklich als Staat funktioniert, beruht nicht auf Demokratie, und was auf Demokratie beruht, funktioniert nicht. Z. B. ein Minister oder Beamter, der durch eine Partei in sein Amt gebracht ist, bleibt entweder Parteimann im Sinne des massendemokratischen Parteistaats; dann gewinnt er nicht die Autorität als Staatsorgan. Oder er stellt sich unter dem Eindruck der Verantwortung seines Amtes um, dann wird er fähig, Staatsorgan zu sein, aber eben nicht im Sinne des Parteienstaats; denn er verliert den Einfluß auf seine Partei. - Wichtiger ist mir aber die Frage: Sollen wir die Entwicklung zum massendemokratischen Parteienstaat fördern? Diese Frage muB ich entschieden verneinen. Der Parteienstaat würde überhaupt kein Staat sein, sondern ein Chaos, ein Verlorengehen des spezifisch Staatlichen unter Mißbrauch der äußeren staatlichen Formen, z. B. zum Zweck der bloßen Ämterverteilung. $\mathrm{DaB}$ man den Parteienstaat durch Reformen zu einem wirklichen Staat machen könnte, ist meist so gedacht, daB durch eine Wahlreform die radikalen Parteien mehr durch regierungsfähige Parteien verdrängt werden. Ein solches künstliches Regierungsfähigmachen des Parlaments wäre aber der schlimmste Versto B gegen die Aufgabe, eine unserem Volke angemessene staatliche Lebensform zu schaffen. Gerade die radikalen Parteien - ich würde lieber sagen entschiedene Parteien * - sind heute der einzig richtige Ausdruck dessen, was wirklich im deutschen Volke vor sich geht. Aber auf solche Parteien läßt sich natürlich nicht das System der parlamentarischen Regierung anwenden. Ein abwechselndes Regieren etwa von einer entschieden nationalistischen und einer entschieden sozialistischen Partei würde nur bedeuten, daß jede neue Regierung das begonnene Werk ihrer Vorgăngerin wieder zerstört. Ich komme zu dem Ergebnis: Wir können durch keine Wahlreform 
ein lebensfähiges Staatswesen schaffen, weder im Sinne des klassischen Parlamentarismus, noch in dem des Parteienstaats. Das Aufrollen des Wahlreform-Problems ist heute nicht nur überflüssig, sondern auch schädlich, denn es macht den absterbenden Parlamentarismus wieder interessant. Die ganz anderen Wege, die ich sehe, gehören nicht in diesen Zusammenhang. Ich habe sie wiederholt dargelegt und brauche nur auf zwei meiner letzten Aufsätze zu verweisen : "Der Staat des XX. Jahrhunderts « (Blätter für Deutsche Philosophie Bd. 5 Heft 2/3) und "Reform des Parlamentarismus in den deutschen Ländern " (Reich und Länder Juni 1930). Ich erwarte die Reform unserer Parlamente nicht von einer Anderung des Wahlrechts, sondern von einer Reform ihrer Aroeitsweise, durch die ihre Mitglieder zum Bewußtsein der Verantwortung gegenüber dem Ganzen erzogen werden.

Graf zu Dohna-Bonn teilt die vom zweiten Referenten vorgetragenen Bedenken gegen den Regierungsentwurf eines neuen Wahlgesetzes und nimmt seinerseits im kritischen Sinne zu diesem Entwurfe Stellung. Er bekennt sich zu der Úberzeugung, daß eine Zurückdrängung des Einflusses der Parteibürokratie auf das Wahlergebnis nur erreichbar ist auf dem Wege einer stärkeren Aktivierung der Wählerschaft und einer restlosen Demokratisierung des Parteiwesens.

Loewenstein-München: Beim Vortrag von Herrn Leibholz habe ich mich des Gefühls einer gewissen Erschütterung nicht erwehren können; er atmete eine Art "Untergang des Abendlandes *-Stimmung, die von fast tragischer Eindruckskraft war. Sie entspricht dem Gefühl der Hilflosigkeit und Machtlosigkeit, das jeden bewußten Wähler befällt, wenn er zur Wahlurne schreitet und sich dem seelenlosen Apparat gegenübersieht, den die zwangsläufige Entwicklung des massendemokratischen Parteienstaates an die Stelle des ursprünglich gemeinten ideologischen Sinns der lebendigen Staatswillensbildung gesetzt hat. Aber trotzdem muB ich der pessimistischen Konzeption von Leibholz, so logisch und geschlossen sie erscheint, widersprechen. Die ideologische Betrachtung führt nur allzu leicht zur Resignation im Handeln. Das Organisationsproblem des ciemokratischen Massenstaates ist in weitem Umfange auch ein staatstechnisches Problem. Solange staatstechnische Mittel vorhanden sind, um die aufgetretenen Stockungen und Fehlleitungen der Volkswillensbildung zu überwinden, müssen sie versucht werden. Der Staat, der sie erkennt und nicht benutzt, ist wert, zugrunde zu gehen. Der vorliegende Wahlreform-Entwurf ist allerdings kein brauchbares Mittel zur Funktionalisierung des in Unord- 
nung geratenen Willensbildungsprozesses des Staates; er kuriert den kranken Körper mit untauglichen Mitteln. Eine dieser staatstechnischen Möglichkeiten, die versucht werden sollten, ist bereits erwähnt worden: das System der amerikanischen Vorwahl zur Wahl der Kandidaten der Partei; ob die open primary oder die closed primary, bei der nur die eingeschriebenen Mitglieder der Partei stimmberechtigt sind, vorgezogen wird, ist dabei eine verhältnismäBig untergeordnete Frage. Wenn die primary election in Amerika nicht den erwarteten Erfolg gehabt hat, die richtigen Männer auf die Kandidatenliste zu bringen, so beweist das nicht, daß sie auch in Deutschland versagen muß; denn in Amerika gilt die Politik als schmutziges Geschäft, während die politische Wirksamkeit in Deutschland noch immer die vornehmste staatsbürgerliche Leistung ist. Ein anderer Weg, der versucht werden sollte, ist die Abschaffung des Proporzes. Bei uns hat er nur Schaden angerichtet: Nicht nur ist durch ihn die zahlenmäßige Zersplitterung des Parlaments bewirkt worden, er hat auch jene Entseelung des Parteilebens im Gefolge gehabt, die gerade die besten Geister der aktiven Politik entfremden mußte. Die Erfahrungen der anderen großen Demokratien sollten für Deutschland lehrreich sein; nirgends hat die Verhältniswahl Wurzel fassen können, und es ist zumindest auffällig, da $B$ alle Staaten ohne Proporz ein funktionierendes Parlament aufweisen. Weiter müBte Abhilfe gegen die Sabotierung der Staatswillensbildung im Parlament selbst versucht werden. Der Staat hat die Pflicht der Selbsterhaltung, sich dagegen zu wehren, da $\beta$ gerade den Parteien der parlamentarische Apparat zur Verfügung gestellt wird, die sich zum Programm gemacht haben, diesen Apparat zu zerschlagen. Die gewöhnlichen Mittel gegen parlamentarische Obstruktion reichen nicht aus. Die Parteien, welche programmatisch und durch die Tat den Parlamentarismus verwerfen, müßten von seiner Benutzung überhaupt ausgeschlossen werden; dazu wäre vielleicht nicht einmal eine Verfassungsänderung erforderlich, sondern eine Änderung der Geschäftsordnung genügend Der Staat, der von zwei radikalen Flügelparteien bewuBt bedroht wird, muB sich entschlossen dagegen zur Wehr setzen. Man sollte auch unter dem Eindruck der Darstellung von Leibholz nicht vergessen, daß der Parlamentarismus noch lebt; er funktioniert noch in zahlreichen wichtigen Ländern innerhalb und außerhalb Europas, wenn nicht reibungslos, so doch ausreichend und doppelt ausreichend gerade in Gefahrenzeiten. Die vorgestrigen Wahlen in England beweisen, daß selbst bei einem vom ideologischen Standpunkt aus miserablen Wahlrecht eine legale Form der Staatswillensbildung auf parlamentarischer Basis möglich ist, die alle Vorzüge der Machtkonzentration der Diktatur aufweist. Man darf sich nicht verleiten lassen, die dent- 
schen Erfahrungen der letzten Jahre zu generalisieren. Es wird sich vielleicht zeigen, daß selbst bei uns die Verfallserscheinungen nicht so grundlegender Natur sind, wie es uns im Augenblick der nächsten Distanz erscheinen mag.

Triepel-Berlin: Wie verschieden auch die beiden Vorträge, die wir heute gehört haben, in Anlage und Ziel gewesen sind, so haben sie doch beide eine so reiche Fülle von Anregungen geboten, $\mathrm{da} B$ es nicht möglich ist, in der Aussprache auf alles einzugehen, worïber es sich lohnen würde, ausführlich zu reden. So beschränke auch ich mich auf einige Bemerkungen.

Das Referat unseres verewigten Freundes Pohl, das uns Herr Giese so pietätvoll vorgestragen hat, beschäftigt sich in erster Linie mit Einzelproblemen einer künftigen Wahlreform, namentlich mit den Vorschlägen, die in bekannten Gesetzentwürfen der letzten Jahre gemacht worden sind. Auf diesem Gebiete könnte man natürlich über jede Einzelheit stundenlang diskutieren. Mich persönlich würde es reizen, die Frage der Wahlpflicht, die von Pohl berührt worden ist, und die ich, seit ich darüber vor mehr als dreißig Jahren eine kleine Studie geschrieben, immer im Auge behalten habe, im Rahmen der seit damals stark veränderten staatsrechtlichen und politischen Verhältnisse erneut zu erörtern. Ich muß mich mit dem einen Satze begnügen, daß ich auch heute noch ein entschiedener Gegner eines Abstimmungszwanges bin. Ein paar Worte möchte ich aber über den von Pohl gemachten Vorschlag äußern, daB man zu den Beratungen der parlamentarischen Ausschüsse aus den Kreisen der Nicht-Abgeordneten Sachverständige zuziehen möge, deren Mitwirkung, weil sie frei von aller parlamentarischen Bindung erfolge, die Objektivität der Verhandlung und Beschlußfassung der parlamentarischen Körperschaften fördern werde. Natürlich kann man nicht leugnen, daß die vorgeschlagene $\mathrm{Maßregel}$ in manchen Fällen Nutzen stiften würde. Aber man sollte das nicht überschätzen. Der zu einer parlamentarischen Beratung zugezogene "Sachverständige * wird, wenn er eine auf technischem oder wissenschaftlichem Gebiete angesehene Persönlichkeit ist, immer mit Achtung angehört werden. Aber die Parteifesseln, die der moderne Parlamentarier mit sich herumträgt, sind so stark, daß er sie auch in Ausschußberatungen, selbst wenn sie hinter verschlossenen Türen stattfinden, nicht abstreifen kann. Heutzutage kommt der Politiker, mag er Abgeordneter oder Minister oder Reichsratsmitglied sein, niemals ohne irgendwelche sBindung in einen AusschuB, nicht einmal in eine außerparlamentarische "Konferenz, und diese Bindung macht sich in Beratung und Abstimmung auch gegenüber den wsachlichsten * Einwendungen des überparteilichen Sachverstăndigen geltend. Dabei befindet sich der Sachver- 
ständige in keiner beneidenswerten Lage. Er ist ja nicht dazu da, dem Streite anderer im Gefühle sachlicher Uberlegenheit und Unbeteiligtheit mit Ruhe zuzuhören, sondern er ist zugezogen worden, um an einer gesetzgeberischen Aufgabe mitzuarbeiten, ist also geradezu verpflichtet, sich für das von ihm als richtig erkannte Ziel auch einzusetzen. Aber die Waffen, mit denen er kämpft, sind nicht dieselben, wie die Waffen der anderen AusschuBmitglieder, und man muß leider sagen, daB in diesem Kampfspiele die Waffe der Sachlichkeit zuweilen die stumpfere ist; die nur politisch eingestellten Mitspieler pflegen das, was ihnen nicht $\mathrm{paßt}$, nicht zu hören oder für unpraktische Theorie zu erklären. Was wird die Folge sein? Entweder wird der Sachverständige während der Verhandlung aus der Rolle des unparteilichen Helfers allmählich herausgedrängt; er wird ja in der Regel auch selber einer politischen Partei angehören oder ihr nahestehen, und, was freilich schlimm ist, man trifft vielleicht von Anfang an die Auswahl der Sachverständigen unter Berüoksichtigung ihrer Parteistellung, oder man nimmt, um das Gresicht zu wahren, gleich mehrere, jeden von einer anderen politischen Farbe. In allen diesen Fällen wird die ganze Einrichtung von vornherein kompromittiert. Oder aber - und das ist die andere Möglichkeit - der Sachverständige begnügt sich mit der bescheideneren Aufgabe, tatsächliche und wissenschaftliche Aufklärungen $z u$ geben, Material beizubringen, korrekte Formulierungen von Rechtssätzen vorzuschlagen usw. GewiB ist das für die Sache ganz nützlich. Aber reizvoll kann die Rolle, die dabei gespielt wird, ganz gewiß nicht genannt werden. Am wenigsten, wenn sich der Sachverständige, wie das ja wohl in parlamentarischen Ausschüssen immer der Fall sein wird, an der Abstimmung nicht beteiligen darf. Es macht unlustig, wenn man bei der Verhandlung lebenswichtiger Fragen zwar mitreden, aber nicht mitbeschließen darf.

Das Referat des Herrn Leibholz war von so imponierender Greschlossenheit, daß es für eine immanente Kritik meiner Ansicht nach kaum einen Angriffspunkt bietet. Nur in einer Beziehung glaube ich dabei eine Ausstellung erheben zu dürfen. Herr Leibholz hat Sympathie für die in den Vereinigten Staaten ausgebildete Einrichtung der Vorwahlen, der Primary Elections, bekundet. In der Tat haben ja die Amerikaner dieses Institut, wenigstens zum großen Teil, zu dem $Z$ wecke geschaffen, um das demokratische Prinzip der Beteiligung aller am Staatsleben auch in das Leben der Parteiorganisationen hineinzubringen, die Demokratie also bis in die letzten Verästelungen des politischen Lebens hinein konsequent durchzuführen. Aber soweit ich sehe, - ich habe mir Mühe gegeben, die Frage an der Hand amerikanischer Quellen zu studieren - hat sich das System nicht bewährt. Einmal deshalb nicht, weil es die Korruption, die drüben im Wahlkampfe herrschte, 
und die man durch die Beteiligung der Parteimitglieder an der Kandidatenaufstellung zu beseitigen oder doch zu mildern hoffte, nicht beseitigt hat; die Korruption ist nicht verschwunden, sie arbeitet jetzt nur an einer anderen Stelle, vielleicht auf breiterer Basis als vorher. Aber auch die erhoffte Demokratisierung des inneren Parteilebens ist nicht in dem Maße, wie man erwartet hatte, erfolgt. Denn die Parteibürokratie, die man schwächen wollte, macht, wie sie früher die Hauptwahlen gemacht hatte, so jetzt die Vorwahlen. Und da die Vorwahlen meist entscheidend sind - aus der Wahlbeteiligung bei den Kandidatenwahlen der einzelnen Parteien läßt sich das Ergebnis der Hauptwahl, wenn auch natürlich Uberraschungen vorkommen, gewöhnlich schon im voraus errechnen - so setzt selbstverständlich die Parteibürokratie den Hebel jetzt an dieser für das Ganze ausschlaggebenden Stelle an. Das würde auch bei uns vermutlich nicht anders sein.

Eine andere Frage und, wie ich meine, die wichtigste ist, ob man sich Herrn Leibholz in dem Punkte, von dem aus er seine überzeugungskräftige Deduktion genommen hat, wird anschließen können. Leibholz faßt die parlamentarische parteienstaatliche Massendemokratie als eine feststehende Tatsache und als den von der Verfassung sanktionierten Rechtszustand auf, und er hält offenbar die Fortbildung und absolut konsequente Durchbildung dieses Systems für einen unausbleiblichen Vorgang. In der Konsequenz seines Gedankengangs liegt es, daß die Massendemokratie schließlich an eine Stelle gelangen muß, wo sie sich selbst überschlägt. Es ist möglich, daß diese Ansicht - sie ist schon von den Vorrednern pessimistisch genannt worden - berechtigt ist. Ich würde daraus aber nicht die Folgerung ziehen, daß es nun gar keinen Sinn mehr habe, dem Rade in die Speichen zu fallen und Reformen des Wahlverfahrens zu versuchen, die nicht in der Linie der massendemokratischen Entwicklung liegen. Ich leugne natürlich nicht die parteienstaatlichen Elemente in unserer Verfassung. Aber ich kann nicht finden, daß die Verfassung selbst sie so absolut sicher ausgebaut und so stark untermauert habe, daB nicht sogar vom Boden der Verfassung aus andere Wege beschritten werden können. Die Verfassung enthält im Gegenteil - das hat ja Leibholz selbst anerkannt - auch Elemente aus einem anderen als dem massendemokratischen Gedankenkreise. Es steht also m. E. gar nichts im Wege, bei einer Wahlreform den Versuch zu machen, an diese Elemente anzuknüpfen. Man kann nichts damit ausrichten, daB man sie als viberal, oder diberalistisch * bezeichnet, in der Absicht, sie damit für überlebt, als zu den Toten geworfèn zu erklären. Heute wird mit dem Worte sliberal " - ich sage dies nicht zu Herm Leibholz, sondern denke an manche andere - ein wahrer MiBbrauch getrieben. 
Viele Rechtsgedanken, die der Liberalismus stark betont und organisatorisch entwickelt hat, ja die allerwertvollsten, sind gar nicht spezifisch liberal, sie sind viel älter als der Liberalismus, sie haben die Zeit des Liberalismus überlebt und sie werden uns überleben. Wenn man den ganz überzeitlichen Wert des Rechtsstaats mit dem Beiworte \#liberal * versieht, was gewöhnlich geschieht, um ihn dadv h zu verkleinern, wenn man ihn in derselben Absicht als "bürgerlichen " Rechtsstaat bezeichnet, was soviel wie Rechtsstaat der um ihre "Sekurität" besorgten Bourgeoisie bedeuten soll, wenn man als Gegensatz dazu einen "sozialen * Rechtsstaat konstruieren will - so sind das alle: Verzerrungen, gegen die wir Männer des Rechts, die wir doch wohl alle Anhänger des Rechtsstaats* sind, Verwahrung einlegen sollten. Denn hier wird ein Ewigkeitswert in den Staub des Irdisch-Kleinlichen herabgezogen.

Nun gibt es auch im Bereiche des Parlamentsrechts Einrichtungen und Verfahrensweisen, die zwar den im Vordringen befindlichen Gedanken des massendemokratischen Parteienstaats nicht entsprechen, die aber an sich praktisch und vernünftig sind, und deren Einführung oder Wiedereinführung deshalb allen Widerständen zum Trotze mindestens versucht werden sollte. Man kann gewiß nicht daran zweifeln, daß die Verhältniswahl ein der Massendemokratie adäquates Wahlsystem darstellt. Kommt man aber zu dem Ergebnisse, daB sich mit ihr in einem bestimmten Staate auf die Dauer nicht regieren läßt, so muß man hier eben prïfen, ob sich nicht das alte Mehrheitswahlsystem, mindestens in Verbindung mit dem Proportionalwahlverfahren, wiederherstellen läßt. Oder wenn man, wie ich es für meine Person tue, den Glauben hegt, daß es vernünftig sein würde, neben die in einem demokratischen Wahlverfahren gewählte Kammer eine in anderer Form gebildete Kammer, ein Oberhaus oder wie man es nennen will, zu stellen, so sehe ich nicht ein, warum es nicht gewagt werden sollte, diese Einfügung allen Widerständen zum Trotze durchzuführen. Ich kann nicht zugeben, daB Mehrheitswahlrecht und Zweikammersystem heute unmögliche Dinge geworden seien, weil ein Oberhaus und eine aus Mehrheitswahlen hervorgegeangene Kammer nicht mehr als nlegitime" Repräsentanten angesehen werden würden. Auch der heute so viel gebrauchte Ausdruck "Legitimierung 4, ein an sich gewiB wertvoller Begriff, ist bereits in Gefahr, zu einem Schlagworte zu werden, und es möchte sich empfehlen, einen vorsichtigen Gebrauch von ihm zu machen. In unsren Tagen möchte ich die Form parlamentarischer Repräsentation sehen, die wirklich allgemein als legitimiert betrachtet werden würde! Heute ist jedermann geneigt, alles, was ihm nicht gefällt; als nicht legitimiert zu bezeichnen. Jedenfalls aber gehört der Proporz meiner Ansicht nach nicht 
zu den von allen Seiten als innerlich notwendig, als allein berechtigt angesehenen Einrichtungen. $\mathrm{Er}$ wird heute in seinem Werte selbst von den Parteien, die vor noch nicht langer Zeit energisch für seine Einführung gekämpft haben, aufs stärkste angezweifelt. Man könnte sich auch über diese Frage natürlich lange unterhalten. Ich habe nur das Bedürfnis empfunden, mit einigen fragmentarischen Andeutungen zum Ausdrucke zu bringen, wie sehr das Referat des Herrn Leibholz zum erneuten Durchdenken alter Probleme anregen wird.

Koellreutter-Jena: Auch mich hat die geschlossene, beinahe tragische Haltung des ausgezeichneten Referates von Leibholz aufs tiefste berührt. Aus seinen Ausführungen schien mir hervorzugehen, da $B$ er jetzt den Parteienstaat als politische Wirklichkeit bejaht, während diese von mir schon seit Jahren vertretene These bei Herrn Triepel noch auf einen gewissen Widerspruch zu stoßen scheint.

Diese Nuancierung in der Bewertung der heutigen politischen Realitäten scheint mir dazu zu führen, da $\beta$ meine beiden Vorredner auch heute noch die Möglichkeit sehen, mit den rechtstechnischen Mitteln der Wahlreform der staatspolitischen Entwicklung eine andere Wendung geben zu können. Ich habe zwar nie an den guten Willen der Parteien geglaubt, eine im staatspolitischen Interesse nötige Reform des Wahlrechts wirklich herbeiführen zu wollen, und habe seit vielen Jahren diese Zweifel im Kolleg an der Hand des Schicksals aller bisherigen Wahlreformen belegt. Aber ich gestehe gern, da $B$ ich selbst immer die Notwendigkeit einer staatspolitischen Wahlreform, vor allem die Notwendigkeit der Beseitigung eines mechanisierten Proporzes immer vertreten habe. Ioh glaube aber, da $\beta$ zurzeit auch diese Möglichkeiten nicht mehr bestehen, weil die dafür erforderliche notwendige gemeinsame politische Grundbasis für eine solche Reform nicht gegeben ist und deshalb auch die Auswirkungen einer solchen Reform gar nicht zu übersehen wären.

$\mathrm{Da} B$ die von den Herren Leibholz und Triepel angeführten Mittel zur Reform des Parteilebens in den Vereinigten Staaten keinen Erfolg, vor allem, wie Herr Triepel richtig hervorhebt, die Demokratisierung des inneren Parteilebens nicht herbeigeführt haben, ist auch meine Meinung.

Das geltende englische Wahlrecht mag, wie Herr Löwenstein betont hat, vielleicht von einem ideologischen - ich möchte sagen liberalistisch-individualistischen - Standpunkte aus miserabel sein. Ich habe dagegen aber immer die politisch vereinheitlichende Funktion dieses relativen Mehrheitswahlrechtes betont, das wesentlich mit dazu beigetragen hat die Regierungsbildung in dem 
bisher noch immer funktionsfähigen englischen Parteienstaate sicherzustellen.

Der Ausfall der eben erfolgten Wahl in England scheint mir allerdings ein Zeichen dafür zu sein, daB der bisherige englische Parlamentarismus auch dort in den Beginn einer entscheidenden Krise getreten ist, die man auch in England nicht mehr mit rechtstechnischen Mitteln wird meistern können ${ }^{\mathbf{1}}$ ).

Mit Herrn Triepel gehe ich völlig darin einig, daB der Liberalismus Ewigkeitswerte besitzt. Vor allem möchte ich betonen, da $B$ jede wirklich wissenschaftliche Haltung wesensgemä $B$ auch immer liberal im echten Sinne wird sein müssen. Und dasselbe gilt von dem überzeitlichen Wert des Rechtsstaates, für dessen Erhaltung sich selbstverständlich gerade jeder Rechtslehrer wird einsetzen müssen.

Aber andererseits wird die politische und damit auch verfassungsrechtliche Ausgestaltung des Rechtsstaatsgedankens immer weitgehend durch die konkrete politische Situation, in der sich ein Volk befindet, bestimmt sein müssen, wenn diese Situation historisch bedingt ist und nicht nur den Ausfluß einer vorübergehenden Lage darstellt. In der heutigen wesentlich durch den Weltkrieg und seine Auswirkungen bedingten Situation des deutschen Volkes glaube ich aber allerdings, daB der liberalistischindividualistisch getönte Rechtsstaatsgedanke zugunsten seiner sozialen und vor allem auch nationalen Komponente zurückzutreten hat, daß wir damit einen Wandel in den tragenden politischen Ideen haben und sich daraus auch verfassungsrechtliche Konsequenzen ergeben müssen.

Merkl-Wien: Ich muß den wertvollen Reformvorschlägen, die wir gehört haben, mit beträchtlicher Skepsis begegnen, die in meinen heimischen Erfahrungen begründet ist. Denn gerade in den Punkten, in denen das österreichische und deutsche Wahlrecht in merkwürdiger Schicksalsverbundenheit am reformbedürftigsten ist, namentlich in bezug auf die starre Liste, stehen die Reformwünsche vor der eisernen Mauer des Parteiegoismus. Gewiß verschließen sich prominente Parteiführer nicht der sachlichen Erforderlichkeit einer Wahlreform, und auch die Partei-

1) Diese Ansicht hat durch den in der Presse mitgeteilten BeschluB des englischen Kabinetts vom 22. Januar d. J., der den in der Zollfrage von dem BeschluB der Mehrheit des Kabinetts dissentierenden Mitgliedern das Recht gibt, in freier Rede und Abstimmung ihre Ansicht kundzutun, eine rasche Bestatigung gefunden. Denn dieser BeschlnB des Kabinetts, der in der Geschichte der englischen parlamentarischen Regierung $m$. W. Kein Vorbild hat, scheint mir zu beweisen, daß trotz der großen parlamentarischen Mehrheit der englischen "Nationalregierung" die für das Funktionieren des parlamentarischen Systems notwendige Geschlossenheit in politischen Grundfragen auch in England erschittert ist. 
klubs wären wohl bereit, der günstigen optischen Wirkung einer solchen Reform die Chance des einen oder anderen Mandates zum Opfer zur bringen. Aber im allgemeinen zeigt sich doch bei den großen Parteien von rechts und links eine zum Teil prinzipienwidrige Beharrungstendenz, da sich die Auswirkungen einer einschneidenden Wahlreform schwer kalkulieren lassen. Für die politischen Parteien sind Wahlreformpläne erfahrungsgemäß bloße Fragen des Rechenstifts, und ihre Haltung hängt davon ab, ob ihnen das Reformprojekt voraussichtlich Mandatsgewinne oder Mandatsverluste bringen wird. Allerdings scheinen mir Vertreter solcher politischer Richtungen, die ein ihnen günstigeres Wahlrecht nur dazu benutzen wollen, um die parlamentarische Tribüne zu verschütten und mit dem Wahlrecht auch die Staatsform zu vernichten, nicht dazu legitimiert, die lautesten Rufer im Streite um die Wahlreform zu spielen.

Thoma-Bonn: Der Vortrag von Leibholz erschien mir durchaus nicht so pessimistisch, wie mehreren Vorrednern. Das Wesentliche an diesem Vortrag war seine strenge Wissenschaftlichkeit. Der Redner hat nicht als Politiker gesprochen. Er hat uns anschaulich zu machen versucht, wie die Dinge ineinander notwendig verkettet zusammenhängen. Wer als Soziologe mit wissenschaftlichen Augen irgendeine politische Institution betrachtet, wird immer finden, daB die Verwirklichung hinter der Idee zurückbleibt und Entartungserscheinungen aufweist. Insofern also wird eine wahrhaftige Analyse immer Untergangsstimmung tragen oder doch $\mathrm{zu}$ tragen scheinen.

Das Ethos der Demokratie besteht darin, daß sie alle Volksgenossen zu Bürgern macht und so alle am Staat mitarbeiten und mithelfen läßt. Wenn Sie heute das Verhältniswahlrecht abschaffen wollen, so werden Sie in den durch die Zufälligkeiten und Wahlbündnisse des Mehrheitswahlrechts um die gebührende Vertretung im Parlament betrogenen Gruppen das bittere Gefühl des Unrechts erzeugen. Sie würden ungezählte Volksbegehren in Gang setzen. Ich glaube auch nicht, daß die Sache in England so weiter funktioniert. Auf die Dauer geht das nicht, daB immer wieder einmal offensichtliche Minderheiten im Besitze wahltaktisch eroberter Parlamentsmehrheit der Nation das Gesetz und die Politik oktroyieren. Bei uns geht das schon ganz und gar nicht, solange Demokratie sein soll. Wenn man also zugibt, da $B$ die moderne Demokratie nicht wahrhaft durchführbar ist ohne Verhältniswahlsystem, so wird man sagen müssen, $d a ß$ man eben die Schattenseiten mit in Kauf nehmen muB. Wirkliche Unmittelbarkeit der Wahl wird man mit keinem Wahlsystem erreichen. Sobald über eine kleinere Gemeinde hinaus gewählt werden muB, braucht man Ausschüsse, Gruppen, die bestimmen, 
wer als Kandidat anerkannt wird. Im übrigen hat uns Herr Leibholz nur das Wahlrecht und das Parlament analysiert, das zurzeit durch das Anwachsen der beiden parlamentsfeindlichen Flügelparteien gelähmt ist. Ihm hat die Weimarer Verfassung noch andere Organe zur Seite und gegenübergestellt, und man kann sehr wohl sagen, daß sich das durchdachte und elastische Gesamtsystem unserer Verfassung in der gegenwärtigen Krisis bewährt. Ich möchte nicht einmal zugeben, daß das auf der Verhältniswahl und dem Vertrauensgrundsatz (Art. 54) beruhende parlamentarische Regierungssystem irgendwelches Unheil verschuldet habe. Die nahezu verzweifelte Lage, in der das deutsche Volk in diesen Winter geht, entspringt nicht daraus, daB am parlamentarischen System oder seiner demokratischen Basis etwas schlecht wäre, sondern unser großes Unglück ist die Summierung von Wirtschaftskrisen. Verfassungsreformen bringen uns über diese tiefen Abgründe nicht hinweg. Hier bleibt eben nur die Hoffnung auf bessere Zeiten. Man darf sich in dieser Hinsicht von den an sich wünschenswerten technischen Wahlrechtsreformen nichts versprechen; deshalb darf man auch noch nicht von Untergangsstimmung in bezug auf die Verfassungsformen reden. Sie sind schwer gefährdet, aber noch immer besteht die Möglichkeit, $\mathrm{da} B$ die Radikalisierung überwunden wird und Demokratie und Legalität gerettet werden. Nach der Uberwindung der Gefahren wird auch dás parlamentarische System wieder leidlich funktionieren, und besser als leidlich hat in der ganzen Weltgeschichte noch niemals irgendeine Herrschaftsform funktioniert, außer in kurzen, vergänglichen Episoden. Keine aber hat so viele Chancen der Regeneration, als die gesetzesachtende, gemäBigte Demokratie. Ich sah in Leibholz' Ausführungen eine klare Analyse und keinen Pessimismus. Die Parteizersplitterung - um dies noch anzufügen - war bisher nicht unser Unglück, sondern unsere Rettung. Denn in kontinentalen Verhältnissen bedeutet Zweiparteiensystem die unheilbare Klassenspaltung der Nation. Wenn aber schon mehr als zwei Parteien, dann ist in einem Vielparteiensystem (in gewissen Grenzen) die Bildung regierungsfähiger Koalitionen leichter, als wenn die vermittelnden kleineren Fraktionen fehlen.

Bilfinger-Halle: Für das eben gehörte schöne Referat, ebenso für die übrigen Referate möchte ich namens der Fakultät des Tagungsortes meinen Dank auszusprechen. - Herr Triepel hat über die Zuziehung von Sachverständigen zu Parlamentsberatungen gesprochen und ist $\mathrm{zu}$ dem Ergebnis gekommen, daB hierbei nicht viel herauskommen würde. Meinerseits möchte ich glauben, daB es sich vielleicht doch empfehle, wenn z. B. bei Haushaltsberatungen Sachverständige zugezogen werden könnten 
(in dem vom Vorredner gedachten Sinne). Dies führt mich aus AnlaB der mit dem Reichsrat zusammenhängnden Fragen und Erfahrungen zu dem Hinweis darauf, daß das Wahlrecht zum Parlament (Reichstag) schließlich in einem mittelbaren Zusammenhang mit den Fragen des Einkammersystems und Zweikammer systems steht. In diesem weiteren Zusammenhang (Reichsrat, Oberhaus, berufständische Mitglieder, EinfluB des Senats in den Ver. Staaten) könnte dann wiederum auf die Frage der Mitwirkung Sachverständiger bei den gesetzgebenden Körpern eingegangen werden. Von da gelangt man - wobei ich vom Föderalismus ausgehe - auf die Frage eines gemäßigten Staatssystems überhaupt gegenüber der Vorherrschaft eines durch allgemeines Wahlrecht gebildeten Parlaments. Diese Frage deckt sich nicht ohne weiteres mit dem eventuellen Fortbestehen beziehungsweise dem Untergang des Liberalismus.

Schlußwort Leibholz: Auf die Fülle der in der Diskussion gegebenen Anregungen und erhobenen Einwendungen zu replizieren, ist im einzelnen nicht möglich. Nur zum Grundsätzlichen einige Worte.

Ist die von mir versuchte, auf einer immanenten Bewertung beruhende, verfassungstheoretische Analyse der politisch-soziologischen Verhältnisse der Gegenwart eine im wesentlichen zutreffende gewesen, dann ist damit nichts anderes gesagt, wie daß unbeschadet der persönlich politisch wertenden Stellungnahme des Beurteilers eine Auferstehung des repräsentativen Parlamentarismus im Sinne des 19. Jahrhunderts nicht mehr möglich erscheint und damit auch der Einführung des Mehrheits- oder eines in diesem Sinne abgeschwächten Verhältniswahlsystems die ideelle Grundlage entzogen ist. Nur insoweit beruht das Referat auf einer pessimistischen Einstellung, die ich im übrigen - hierin hat Herr Thoma ganz Recht - nicht als dem Referat zugrundeliegend zugeben kann. Denn der an Stelle des repräsentativen Parlamentarismus getretene Parteienstaat ist an sich nicht funktionsunfähig. Ist er doch letzten Endes nichts anderes wie die die unmittelbare Demokratie surrogierende Form des Flächenstaates, die zwar ihre besondere und zwar größere Problematik hat wie die bisher üblicherweise allein sog. unmittelbare Demokratie, aber doch zweifelsohne eine mögliche Form politisch genossenschaftlichen Zusammenlebens der Gemeinschaft darstellt. Ich verweise beispielsweise auf die Erfahrungen des ersten Jahrzehntes unter der Weimarer Verfassung und auf die Verhältnisse in England, deren heutiger parteienstaatlicher Charakter von Herrn Koellreutter soeben herausgestellt worden ist.

In der Konsequenz des massendemokratischen Parteienstaates liegt aber die Möglichkeit einer Wahlreform allein in der 
angedeuteten Richtung einer Demokratisierung des Parteibetriebes. $\mathrm{Ob}$ die erwähnten "primary elections", wie in der Diskussion teilweise bejaht, überwiegend aber verneint wurde, diese Wirkung heute bei uns kaben würden. mag dahingestellt bleiben. Jedenfalls sollte man im Falle einer negativ-politischen Bewertung der Vorwahlen sich hüten - diese Warnung muß nochmals offen und mit Nachdruck ausgesprochen werden -, durch eine Änderung des geltenden Wahlrechtes der politischen Not der Gegenwart begegnen zu wollen, da diese in Wahrheit durch eine Wahlreform, gleichviel welcher Art, zur Zeit nur noch gesteigert werden würde.

GewiB, auch die Lage der liberalistisch unterbauten, parteienstaatlichen Massendemokratie ist heute ebenfalls problematisch geworden, da deren Bestand von den großen, diktaturförmig strukturierten Verbandsparteien bedroht wird, die die die strukturellen Grundlagen der Verfassung bejahenden Parteien ihrerseits zwingen, auf eines ihrer Lebensprinzipien, nämlich das der parteimäBigen Rotation, zu verzichten, und diese damit veranlassen, mittelbar einen Kampf gegen sich selbst zu führen.

Nun wäre, wenn der Parteienstaat auf die Dauer sich nicht als funktionsfähig erweisen sollte, gewiß, wie Herr Triepel meint, auch eine Umbildung der Verfassung durch Stärkung der in ihr vorhandenen, moderierend wirkenden, antiparteienstaatlichen Kräfte wie etwa Ausbau der Stellung der Exekutive, d.h. vor allem der präsidialen Spitze und der Regierung, unter grundsătzlich gleichförmiger Beibehaltung der heute an der willensmäßigen Integration des Staates beteiligten Instanzen möglich und denkbar. Und man könnte sich für die Berechtigung einer solchen Annahme auf gewisse, nicht unbedeutende Ansätze der gegenwärtigen Verfassungspraxis, die in dieser Richtung liegen, berufen. Aber die große und m. E. zu verneinende Frage ist, ob ein solches Bild im Sinne unserer extremistischen Massenparteien liegen und der Entwicklung eines von diesen Parteien erstrebten, zwangsläufig sich radikalisierenden Einparteienstaates entsprechen würde.

Was weiter den von den Herren Triepel und Bilfinger ventilierten Gedanken eines Oberhauses angeht, so kann man unter einem solchen zunächst die typische Erste Kammer des 19. Jahrhunderts verstehen, die aber als politisch mafgeblich entscheidende, repräsentative Instanz heute nicht mehr denkbar ist. Soweit solche Körperschaften heute noch existieren wie etwa in England, Frankreich und Italien haben sie im wesentlichen eine nur dekorative Bedeutung. Versteht man dagegen unter einem Oberhaus eine berufsständische Körperschaft, so vermag auf eine solche die politische Einheit des Staates nicht gegründet $\mathrm{zu}$ werden, weil diese überhaupt nicht berufsständisch 
konstituiert werden kann. Es ist daher kein Zufall, daB in der Staatspraxis die berufsständischen Körperschaften bisher in dieser Richtung einheitsbildend nicht $\mathrm{zu}$ wirken vermochten und in der Regel unter der Hand auch zu etwas anderem umgebildet wurden. Man denke etwa an die Deputiertenkammer des faschistischen stato corporativo, die in Wirklichkeit mehr ein der Form nach plebiszitär fundiertes Oberhaus als eine berufsständische Kammer ist. Schließlich wäre noch denkbar, unter einem Oberhaus eine mäBigend wirkende, föderalistische Staatenrepräsentation zu verstehen etwa im Sinne des amerikanischen Senates, obwohl auch hier bemerkt werden muB, da $B$ es in einem Einparteienstaat keinen Raum für einen wahren, nicht nur ideologisch gefärbten Föderalismus geben kann. Ein solcher Staat ist zwangsläufig zentralistisch und radikal unitarisch.

Herr Triepel hat sich schließlich dagegen verwahrt, gewisse Einrichtungen, wie 2. B. den Rechtsstaat, als liberalistisch und damit politisch in der gegenwärtigen Situation als mit einem negativen Wert behaftet zu bezeichnen. Tatsächlich gehen ideengeschichtlich Grundrechte, Rechtsstaat usw. auf die dem Liberalismus zeitlich vorgelagerten, großen geschichtlichen Bewegungen wie die französische Revolution, die Aufklärung, das Naturrecht, die Reformation und letzten Endes die Renaissance zurück, obwohl nicht $z u$ verkennen ist, daß die gegenwärtige hochwertige Prägung dieser Institutionen entscheidend durch den Liberalismus des letzten Jahrhunderts mitbestimmt worden ist. Insoweit hat der Liberalismus in seinem Kern, nicht in seiner Entartung, dem manchesterlichen Liberalismus, der ihn zumal in der Form eines planlosen Kapitalismus vollends kompromittiert hat, einen im übrigen auch vom Faschismus im Gegensatz zum Bolschewismus jedenfalls ideologisch anerkannten Ewigkeitsgehalt, dessen endgültige Vernichtung auch das kulturelle Ende bedeuten würde. In diesem Sinne umfaBt der Liberalismus auch die in der Staatshaltung konservativ eingestellten Parteien. Aber der wirkliche Kampf ist heute nicht mehr der traditionelle Kampf der liberal, wenn auch stark sozial, um nicht zu sagen, sozialistisch affizierten Kräfte mit den mehr oder minder auch sozial gebundenen konservativen Mächten, sondern der Kampf zwischen den im weitesten Sinne noch irgendwie massendemokratischen, den Eigenwert der Persönlichkeit bejahenden Kräfte mit den mythisch fundierten, die Freiheit des Individuums in einem mehr oder weniger radikalen Kollektivismus aufhebenden Bewegungen. 